\title{
Evaluation and sensitivity analysis of the ecosystem service functions of haze absorption by green space based on its quality in China
}

\author{
Ping Zhang', 2,3, Ning Wang', Lianwei Yang', Xin Zhang', Qi Liu' \\ I School of Environmental and Chemical Engineering, Xi'an Polytechnic University, Xi'an 710048, China \\ 2 Shaanxi Key Laboratory of Land Consolidation, Xian 710075, China 3 Key Laboratory of Water Cycle \\ and Related Land Surface Processes, Institute of Geographic Sciences and Natural Resources Research, Chinese \\ Academy of Sciences, Beijing 100101, China \\ Corresponding author:Xin Zhang (xzh9078@126.com), Qi Liu (qi11709@126.com) \\ Academic editor: Rita Yam | Received 15 December 2017 | Accepted 9 June 2020 | Published 21 July 2020 \\ http://zoobank.org/BC92FA4E-6F51-40E5-8BF7-B1D2CC256F7A \\ Citation: Zhan P, Wang N, Yang L, Zhang X, Liu Q (2020) Evaluation and Sensitivity Analysis of the Ecosystem Service \\ Functions of Haze Absorption by Green Space Based on its Quality in China. Nature Conservation 70: 93-141. https:// \\ doi.org/10.3897/natureconservation.70.23017
}

\begin{abstract}
Evaluation of the ecosystem service functions of haze absorption by green space is important for controlling haze. In this study, the ecosystem service functions of haze absorption by green space in China in 2001, 2004, 2007, 2010, 2013, 2016 and 2018 are analyzed based on green space quality and sensitivity using a geographic information system (GIS) and Moderate Resolution Imaging Spectroradiometer (MODIS) imagery. The results showed that the benchmark ecosystem service functions of haze absorption by green space when considering only the area of green space showed a trend that increases first and then decreases in 2001-2018, with 9000458.55 million $\mathrm{Kg}$, 9145110.75 million $\mathrm{Kg}$ and 7734526.75 million $\mathrm{Kg}$ in 2001, 2013 and 2018, respectively. However, the corrected functions based on green space quality were 7724215.34 million $\mathrm{Kg}, 8320301.79$ million $\mathrm{Kg}$ and 6510132.55 million $\mathrm{Kg}$ in the corresponding years. This indicated large differences between ecosystem service functions of haze absorption based on the quality and area of green space; only considering the area of green space to evaluate ecosystem service functions will result in overestimation. In terms of the spatial distribution of the ecosystem service functions of haze absorption by green space, there were greater differences in the benchmark and corrected functions, and the spatial distributions of the maximum, intermediate and minimum ecosystem service functions were notably different. However, the benchmark and corrected functions all showed a consistent trend in the rank of their contribution rates and ecosystem service functions as well as consistent distribution
\end{abstract}

Copyright Ping Zhang et al. This is an open access article distributed under the terms of the Creative Commons Attribution License (CC BY 4.0), which permits unrestricted use, distribution, and reproduction in any medium, provided the original author and source are credited. 
trends: the spatial distribution of ecosystem service functions of haze absorption by green space was very different in the same year, but there was little difference among different years. The change coefficients for the ecosystem service functions of haze absorption by arable land and grass land remained stable, whereas the coefficient of sensitivity for forest cover was elastic. Patch density (PD) and the ecosystem service functions of $\mathrm{SO}_{2}$ absorption, $\mathrm{NO}_{\mathrm{x}}$ absorption, dust retention and total ecosystem services showed a significant negative correlation, with correlation coefficients of $-0.407,-0.511,-.330$ and -0.332 , respectively. In contrast, the area-weighted mean shape index (SAPE_AM) and ecosystem service functions exhibited significant positive relationships with correlation coefficients of $0.650,0.634,0.568$ and 0.570 , respectively. The results provide an improved method for evaluating the ecosystem service functions of haze absorption by green space as well as a reference for the prevention and control of haze and the coordinated development of regional societies, the economy and the environment.

\section{Keywords}

ecosystem service functions, haze absorption, quality of green space, sensitivity analysis

\section{Introduction}

In recent years, the frequent occurrence of haze in China has seriously threatened human health and environmental safety, becoming a major livelihood and environmental problem that cannot be ignored and needs to be solved. Exploring haze absorption from the perspective of ecosystem services is of great practical significance for scientific formulation of effective haze control policies (Hong et al. 2013; Song et al. 2019).

Haze, a kind of disastrous weather occurring in the near-ground atmospheric layer, is the result of interaction between specific climatic conditions and human activities (Chuai et al. 2019). Haze is composed of dust, sulfuric acid $\left(\mathrm{H}_{2} \mathrm{SO}_{4}\right)$, nitric acid $\left(\mathrm{HNO}_{3}\right)$, organic hydrocarbons and other particles in the air, and of these materials, $\mathrm{SO}_{2}, \mathrm{NO}_{\mathrm{X}}$ and respirable particulate matter are the main components; the first two are gaseous pollutants, while particulate matter is the main hazardous component (Yu et al. 2018). Sulfur dioxide and $\mathrm{NO}_{\mathrm{X}}$ are the main gaseous components of haze. Atmospheric $\mathrm{SO}_{2}$ is mainly derived from the combustion of sulfur-containing fuel, which is harmful to the human respiratory tract, and high levels of $\mathrm{SO}_{2}$ can damage leaf tissue. Furthermore, $\mathrm{SO}_{2}$ is involved in the formation of $\mathrm{H}_{2} \mathrm{SO}_{4}$ fumes and acid rain, which is very harmful to human health. Nitrogen oxides are mainly derived from emissions from automotive exhaust and stationary combustion sources, and they can weaken the ability of blood to transport oxygen, seriously endanger human health, and contribute to atmospheric photochemical pollution (Sun et al. 2018). Areas with high densities of economic and social activities will inevitably discharge a large amount of fine particles $\left(\mathrm{PM}_{2.5}\right)$, and once the discharge exceeds the atmospheric circulation capacity and bearing capacity, fine particulates will accumulate, contributing to a wide range of haze events (Green and Xu 2007; Waters et al. 1998). There are two main aspects of haze production. The first includes human factors such as automobile exhaust, coal waste 
gas, industrial emissions, construction and road traffic dust, climate change, waste incineration, and even volcanic eruptions (Hansen et al. 2019). The role of different sources of pollution varies in different haze regions. In addition, haze is affected by meteorological factors such as weather that is not conducive to the spread of pollutants, and when pollutants accumulate under static weather conditions, haze is readily formed. Secondly, meteorological factors, the static wind in the horizontal direction and the inverse temperature in the vertical direction cause pollutants to gather and lead to the formation of haze weather (Li et al. 2019; Wu et al. 2016).

The hazards of haze include the following aspects: on the one hand, haze reduces visibility, increases the frequency of traffic accidents, and has an important impact on highways, railways, aviation, shipping, and power supply systems (Xue et al. 2018). On the other hand, haze also causes a decline in air quality, threatens human health, and increases the incidence and mortality of diseases in the respiratory tract, cardiovascular and reproductive systems (Ramakreshnan et al. 2018). Furthermore, haze can result in a weakening of near-surface ultraviolet light, resulting in an increase in the infectious bacteria in the air. Due to the reduced sunshine during haze weather, the ultraviolet radiation received by children is insufficient and not conducive to growth. Additionally, haze weather will reduce crop yields and quality but can also impact the atmospheric radiation budget, thereby impacting the climate system of the earth (Thach et al. 2010). In 2017, China implemented new air quality standards and monitored 338 cities, of which only 99 meet the annual average air quality standards and 239 exceed them. The frequent occurrence of haze weather affects the physical and mental health of the public and the sustainable development of the ecological environment (Zhang et al. 2016).

Haze is affected by pollution sources (Wang et al. 2015), meteorological conditions (Bei et al. 2016) and vegetation coverage (Ye et al. 2016; Zhang 2019). Reducing pollutant emissions is accomplished by actions such as reducing vehicle pollution and dust, controlling industrial pollution and the emission of $\mathrm{NH}_{3}$ in agricultural areas, reducing the unorganized combustion of biomass and concentration of air pollutants, and coping with haze pollution (An et al. 2019; Yang et al. 2016). Some researchers have also explored the response mechanism of haze weather to meteorological conditions; rainfall through wet sedimentation and wind speed can accelerate the diffusion of pollutants to alleviate haze (Gao et al. 2015; Zhang et al. 2015a). However, meteorological conditions are external causes and are uncontrollable, while pollution sources are internal causes and are closely related to human activities, although pollution source treatment methods are not yet complete and immature. Previous studies have shown that vegetation leaf area (Gómez-Moreno et al. 2019; Setälä et al. 2013), vegetation coverage (De Carvalho and Szlafsztein 2019; Zhang 2019) and plant community structure (Pandey et al. 2014; Selmi et al. 2016) can absorb and block air pollutants, and vegetation coverage is relatively stable, which can effectively alleviate haze pollution. Therefore, there is still important significance for research on haze absorption by green space. Green space can effectively reduce haze, and it not only has a very important dust retention function but can absorb and convert toxic substances, 
be used to reduce the concentration of atmospheric particulate matter, and keep the air fresh through photosynthesis (Freer-Smith et al. 2004; Liu and Shen 2014).

Green space is an important part of social, economic and natural systems (Rysgaard et al. 1999). These spaces are completely undeveloped or basically undeveloped natural areas where the natural landscape is restored or where the land is reserved to offset urban construction. They primarily include arable land, forest cover and grass land and provide important ecological service functions such as air purification, water source conservation, climate regulation and biodiversity maintenance (Green et al. 2016). With rapid urbanization to meet the needs of the expanding population on limited land, vegetation is gradually being replaced by buildings (Cuffney et al. 2010). Therefore, green space is constantly being reduced and destroyed, and ecosystem service functioning is being severely diminished or is disappearing, thus weakening the maintenance and regulation of the urban environment. Thus, increasing the footprint of the urban environment results in more serious air pollution and increased haze in cities, and many countries are seeking sustainable social, economic and environmental development to maintain the various types of natural resources and simultaneously achieve both economic and ecological benefits. Urban green space (UGS) can, to a certain extent, alleviate the adverse effects of urbanization, produce urban cooling effects and increase moisture availability, and ease urban heat island effects as well as reduce surface runoff and maintain high evaporation rates and surface permeability. A reasonable amount of green space can control the unlimited expansion of a city and improve the urban environment. Therefore, green space is the core of the healthy development of urban ecosystems (Margaritis and Kang 2016; Park et al. 2017). Green vegetation plays a key role in UGS ecosystems and air purification. First, green vegetation has the unique physiological function of performing photosynthesis, relying on leaf pores to convert gas pollutants, such as sulfur dioxide $\left(\mathrm{SO}_{2}\right)$ and nitrogen oxides $\left(\mathrm{NO}_{\mathrm{x}}\right)$, into non-toxic substances through redox processes; these products are then accumulated in plant organs or excreted by the root system. Second, foliage secretes bactericides and mucus that can absorb particles and retain dust. Third, vegetation can reduce wind speeds, reducing sedimentation. Finally, vegetation blocks and inhibits dust, thereby reducing particulate levels. Haze is mainly composed of $\mathrm{SO}_{2}, \mathrm{NO}_{\mathrm{x}}$, and respirable particulate matter, and green space can purify the air of these materials (Han and Zhou 2015).

Previous studies on green space have focused on the impacts of heat island mitigation (Alavipanah et al. 2015; Heusinkveld et al. 2014), climate regulation (Maimaitiyiming et al. 2014), and ecosystem services monitoring and evaluation (Kopperoinen et al. 2014). Kuttler and Strassburger (Kuttler and Strassburger 1999) investigated the influence of traffic-induced pollutants (e.g., carbon monoxide (CO), nitrogen oxide (NO), nitrogen dioxide $\left(\mathrm{NO}_{2}\right)$ and ozone $\left(\mathrm{O}_{3}\right)$ ) on the air quality of urban green areas in the city of Essen, North Rhine-Westphalia (NRW), Germany. Zoulia et al. (Zoulia et al. 2009) monitored the effect of urban green areas on the heat island in Athens, Greece. Hamada and Ohta (Hamada and Ohta 2010) measured air temperatures in an urban green area that includes forest and grass land as well as the surrounding urban area for a 
full year in Nagoya, central Japan to elucidate seasonal variations in the differences in air temperature between urban and green areas. Mahmoud and El-Sayed (Mahmoud and El-Sayed 2011) studied sustainable urban green areas in Egypt, and the results revealed that greenways could play a more significant role in bringing nature into the city. Saphores and Li (Saphores and Li 2012) used a hedonic pricing analysis of the single-family housing market to estimate the functions of urban green areas in Los Angeles, California, USA. Larondelle and Haase (Larondelle and Haase 2013) evaluated the climate regulation, cooling and entertainment features of urban ecosystems in Europe, and the results showed that the core of the city does not necessarily provide fewer ecosystem services. Chen et al. (Chen et al. 2015) investigated the impact of reclaimed water irrigation on soil health in urban green areas. Ozimec et al. (Ozimec et al. 2016) monitored air pollution by using lichens in the green space of the university campus in Osijek, Croatia, and the results showed that the air is moderately polluted. Selmi et al. (Selmi et al. 2016) employed the i-Tree Eco model to estimate air pollution removal by urban trees in Strasbourg, France, and the model showed that public trees managed by the city removed approximately $88 \mathrm{t}$ of pollutants during a one-year period (from July 2012 to June 2013).

The dust retention and atmospheric pollutant absorption effects of green space have mostly explored the functional effects of different plant species based on individual differences in the levels of green space and have been limited to small scales (Devuyst et al. 2001). Beckett et al. demonstrated that trees can act as biological filters, removing large amounts of airborne particles, thus improving the air quality in polluted environments due to their large leaf areas relative to the ground on which they stand and the physical properties of their surfaces (Beckett et al. 1998). Davies and Unam monitored and analyzed the relationship between smoke-haze from the 1997 Indonesian forest fires and three tree species (Davies and Unam 1999). McDonald et al. estimated the potential of urban tree planting to mitigate urban $\mathrm{PM}_{10}$ using an atmospheric transport model to simulate particulate transport and deposition across two UK conurbations, and the results indicated that increasing the total tree cover in West Midlands from $3.7 \%$ to $16.5 \%$ removed 110 t of primary PM $_{10}$ from the atmosphere per year (McDonald et al. 2007). However, few studies have been carried out on the national scale, and the ecosystem service functions of haze absorption by green space based on its quality have not been explored. On this basis, the correlation between absorbing haze and the landscape pattern of green space and its sensitivity to the change of ecosystem service functions have been analyzed.

The objectives of this study were: 1) comparison and analysis of the spatial and temporal patterns of the benchmark and corrected values of ecosystem service functions of haze absorption based on the quality of green space; 2) sensitivity analysis of changes in ecosystem service functions; 3) determination of the relationship between the landscape pattern and the ecosystem service functions of haze absorption by green space, providing a scientific basis for the quantitative evaluation of air pollution regulation using service functions, green space planning and urban ecological construction of green space in China. 


\section{Materials and methods}

Ecosystem service functions of haze absorption by green space per unit area

The main components of haze are $\mathrm{SO}_{2}, \mathrm{NO}_{\mathrm{x}}$ and particulate matter. The uptake of haze material by types of green space per unit area (Jin et al. 2005; Ye et al. 1998) (Table 1) and green space area were used to calculate the ecosystem service functions of haze absorption by green space (Han and Zhou 2015; Kuttler and Strassburger 1999).

\section{Calculation of the ecosystem service functions of haze absorption by green space}

The ecosystem service functions of haze absorption by green space include the absorption of $\mathrm{SO}_{2}, \mathrm{NO}_{\mathrm{x}}$ and respirable particulate matter. According to the various types of green space and the ecosystem service functions of haze absorption by each type of green space per unit area, the total ecosystem service functions of haze absorption by green space in China can be calculated from formula (1) (Han and Zhou 2015; Kuttler and Strassburger 1999).

$$
E S F=\sum_{i=1}^{3} \sum_{j=1}^{3} A_{i} F_{i j}
$$

where $E S F$ is the total ecosystem service functions of haze absorption by green space; $A_{i}$ is the area of green space type $i ; F_{i j}$ is the ecosystem service of absorbing haze component $j$ by green space $i$ per unit area; $i$ is the green space type including forest cover, grass land and arable land; and $j$ is the haze component including $\mathrm{SO}_{2}, \mathrm{NO}_{\mathrm{x}}$ and particulate matter.

\section{Ecosystem service functions correction based on green space quality}

Both the ecosystem itself and its spatial heterogeneity affect ecosystem service functions. Considering the ecological system, the quality of green space plays an important role in its function, and the vegetation coverage (normalized difference vegetation

Table I. The uptake of haze components by green space per unit area $\left(\mathrm{kg} \cdot \mathrm{ha}^{-1} \cdot \mathrm{yr}^{-1}\right)$.

\begin{tabular}{l|c|c|c|c}
\hline \multirow{2}{*}{ Ecosystem service } & \multicolumn{4}{c}{ Green space types } \\
\cline { 2 - 5 } & Arable land & Forest cover & Grass land & Total \\
\hline Absorption of sulfur dioxide & 45.00 & 152.13 & 279.03 & 476.16 \\
\hline Absorption of nitrogen oxides & 33.50 & 6.00 & 6.00 & 45.50 \\
\hline Dust retention & 0.95 & 21655.00 & 1.20 & 21657.15 \\
\hline Total & 79.45 & 21813.13 & 286.23 & 22178.81 \\
\hline
\end{tabular}

Note: "yr" refers to annum. 
index (NDVI) ) and net primary productivity (NPP) affect the corresponding service functions. The above ecosystem service functions calculation is only based on the land use area, without considering the impact of green space quality, so the results cannot reflect the true ecosystem service functions of haze absorption by green space. Using NDVI and NPP as evaluation indicators of green space quality and the correction coefficient to adjust the ecosystem service functions, the formula for the calculation is as follows (Gao et al. 2012):

$$
\begin{gathered}
f_{i}=\frac{N D V_{i}-N D V I_{\text {min }}}{N D V I_{\text {max }}-N D V I_{\text {min }}} \\
Q_{i}=\left[\frac{N P P_{i}}{N P P_{\text {mean }}}+\frac{f_{i}}{f_{\text {mean }}}\right] / 2 \\
E S F^{\prime}=E S F \times Q_{i}
\end{gathered}
$$

where $f_{i}$ and $N P P_{i}$ are the NDVI and NPP of grid $I$, respectively; $N P P_{\text {mean }}$ and $f_{\text {mean }}$ are the mean NPP and NDVI values of various ecosystems in the study region, respectively; $N D V I_{\max }$ and $N D V I_{\text {min }}$ are the maximum and minimum NDVI values for the entire growing season; $Q_{i}$ is the green space quality coefficient; $E S F$ is the ecosystem service functions before the green space quality correction; and $E S F^{\prime}$ is the ecosystem service functions after the green space quality correction.

\section{Sensitivity analysis}

To reflect the dependence of ecosystem service functions on the ecological functions index over time, the economic elasticity coefficient is selected to calculate the coefficient of sensitivity (formula (6)) (Kreuter et al. 2001).

$$
C S=\left|\frac{\left(E S F_{j}-E S F_{i}\right) / E S F_{i}}{\left(F_{j k}-F_{i k}\right) / F_{i k}}\right|
$$

where $E S F$ is the total ecosystem service functions; $F$ is the functions coefficient; $i$ and $j$ are the initial and adjusted functions coefficients, respectively; $k$ is the green space type; and $C S$ is the coefficient of sensitivity. If $C S>1$, the $E S F$ for $F$ is flexible, indicating that the total ecosystem service functions increase faster than the functions coefficient and that the proportion of the total ecosystem service functions and the functions coefficient are increasing. However, if $C S<1$, the $E S F$ for $F$ is inelastic. $C S=1$ represents complete elasticity; $C S=0$ represents complete inelasticity. A higher ratio indicates that the elasticity of the ecosystem service functions index is more important. 


\section{Landscape pattern indices}

Landscape pattern indices are used to describe the spatial organization of a landscape and provide a quantitative measure of the composition and spatial configuration of landscape structure. The interaction between landscape patterns and ecological processes as well as green space impacts haze absorption to different degrees. Based on previous research (Fang et al. 2014), we selected the landscape-level indices of patch density (PD), the interspersion and juxtaposition index (IJI), the area-weighted mean shape index (SHAPE_ $\mathrm{AM}$ ), and Shannon's diversity index (SHDI) to study the relationship between landscape patterns and the ecosystem service functions of haze absorption by green space in China. Among these indices, SHAPE_AM was calculated by the formula from reference (Fang et al. 2014), and PD, IJI and SHDI were calculated by the following formulas.

$$
P D=\frac{1}{A} \sum_{i=1}^{n} N_{i}
$$

where $P D$ is patch density; $A$ is the total area of the landscape; $N_{i}$ is the number of patches in landscape $i$; $i$ is the landscape element; and $n$ is the total number of patches in the landscape.

$$
\begin{gathered}
I J I=\frac{-\sum_{i=1}^{m} \sum_{k=1+1}^{m}\left[\left(\frac{e_{i k}}{E}\right) \ln \left(\frac{e_{i k}}{E}\right)\right]}{\ln (0.5[m-(m-1)])} \times 100 \\
S H D I=-\sum_{i=1}^{m}\left(P_{i} \cdot \ln P_{i}\right)
\end{gathered}
$$

where $m$ is the total number of landscape types; $i$ and $k$ are the numbers of patches of types $i$ and $k$, respectively; $e_{i k}$ is the total boundary length of the patch types between patch types $i$ and $k$; $E$ is the total boundary length of the landscape, including the background; and $p_{i}$ is the perimeter of patch type $i$.

\section{Correlation analysis}

The ecosystem service functions of haze absorption by green space, including measures of the absorption of $\mathrm{SO}_{2}$ and $\mathrm{NO}_{\mathrm{x}}$, dust retention and the total ecosystem service functions, were calculated for different provinces in China using a geographic information system (GIS). The calculations of landscape pattern indexes including PD, IJI, SHAPE_AM, and SHDI for provinces of China were performed in FRAGSTATS. Correlations between landscape patterns and the absorption of $\mathrm{SO}_{2}$ and $\mathrm{NO}_{\mathrm{X}}$, dust retention and total ecosystem service functions were calculated as Pearson correlation coefficients as follows: 


$$
\rho_{x, y}=\frac{\operatorname{cov}(X, Y)}{\sigma_{X} \sigma_{Y}}
$$

where $\operatorname{cov}(X, Y)$ represents the covariance between two variables, and $\sigma_{X}$ and $\sigma_{Y}$ refer to the variance of the two variables. The Pearson correlation coefficient is used to measure the correlation between two variables. The value of this coefficient falls between 1 and $-1: 1$ represents a full positive correlation of the variables; 0 indicates that the variables are independent; and -1 indicates a completely negative correlation.

\section{Research data}

A MODIS land cover classification product $(\bmod 12 \mathrm{q} 1)$ was used for the land use data for China in 2001, 2004, 2007, 2010, 2013, 2016 and 2018. The spatial resolution of this product is $500 \mathrm{~m}$, and land use is divided into arable land, forest cover, grass land, construction land, unused land and water bodies. Because the ecosystem service functions of haze absorption by water bodies are relatively small (Han and Zhou 2015), and few studies have been conducted on haze absorption by water bodies, it is difficult to obtain ecosystem service functions for the absorption of $\mathrm{SO}_{2}$ and $\mathrm{NO}_{\mathrm{x}}$ and dust retention by this land use type per unit area (Liu and Yu 2016), so the functions were not included as green space in this study. Therefore, green space in this study includes arable land, forest cover and grass land (Han and Zhou 2015; Kuttler and Strassburger 1999). Both NDVI and NPP are MODIS data products for China in 2001, 2004, 2007, 2010, 2013, 2016 and 2018 with a spatial resolution of $500 \mathrm{~m}$, and in addition, the NPP data of NTSG (Numerical Terra-dynamic Simulation Group) was used as a supplement; the resolution of the data was $1 \mathrm{~km} \times 1 \mathrm{~km}$, and the annual NPP of the terrestrial ecosystem was obtained by using the NPP estimation model established by Biome-BGC and light energy utilization model. A dataset of the boundaries of the provinces in China was also included in this study.

\section{Results and analysis}

\section{Analysis of the ecosystem service functions of haze absorption by green space in China}

As shown in Table 2, the total ecosystem service functions (benchmark values) of haze absorption by green space in China were 9000458.55 million $\mathrm{Kg}$ in 2001, 8784710.32 million $\mathrm{Kg}$ in 2004, 8900539.79 million $\mathrm{Kg}$ in 2007, 9179977.89 million $\mathrm{Kg}$ in 2010, 9145110.75 million $\mathrm{Kg}$ in 2013, 7761608.74 million $\mathrm{Kg}$ in 2016 and 7734526.75 million $\mathrm{Kg}$ in 2018. The ecosystem service functions of haze absorption by green space in China showed a trend of first increasing and then decreasing in 2001-2018, exhibiting an upward trend from 2001-2013 and increasing by 144652.20 million $\mathrm{Kg}$ (1.61\%), primarily because the Chinese government invested 179 billion Yuan in a series of ecological restoration programs (Wang et al. 2007), including the Three North Shel- 
terbelt Development Program, the Conversion from Cropland to Forest Program and the Natural Forest Protection Program, to restore degraded ecological environments and to foster stable and sustainable development. The area of forest cover increased by 6886085.77 ha (1.69\%) between 2001 and 2013, but the ecosystem service functions fell by 1410584.00 million $\mathrm{Kg}$ from $2013-2018$, a decrease of $15.42 \%$, primarily because of adjustment of ecological land structure, the reduction of forest cover with high haze absorption ecological service function, the increase of grass land with low haze absorption function, and the reduction of arable land caused by the expansion of construction land. The ecosystem service functions decreased by 215748.23 million $\mathrm{Kg}$ from 2001-2004, a decrease of $2.40 \%$, and the main reasons are a reduction in the area of forest cover and grass land. In contrast, the ecosystem service functions increased by $115,829.48$ million $\mathrm{Kg}$ from $2004-2007$, an increase of $1.32 \%$, mainly due to the increase in forest cover and grass land and the decrease in arable land that is largely attributed to the Program for Conversion from Cropland to Forest and Grass Land in China. Additionally, the ecosystem service functions increased by 279438.10 million $\mathrm{Kg}$ from 2007-2010, an increase of 3.14\%, primarily due to an increase in forest cover and a reduction in arable land and grass land. From 2010-2013, the ecosystem service functions decreased by $34,867.15$ million $\mathrm{Kg}$, a reduction of $0.38 \%$, mainly due to the decrease in forest cover and grass land and the increase in arable land. In comparison, the ecosystem service functions fell by 1,383,502.01 million Kg from 2013-2016, a decrease of $15.13 \%$, primarily because of the increase in grass land and decrease in arable land and forest cover. The ecosystem service functions decreased by 27081.99 million $\mathrm{Kg}$ from 2016-2018, a decrease of $0.35 \%$, mainly attributable to a reduction in the area of forest cover and arable land.

The contributions to haze absorption by green spaces indicated that the types are very different (Table 2). The overall contribution of forest cover was the largest, and these proportions were 98.68\%, 98.67\%, 98.68\%, 98.75\%, 98.77\%, 98.17\% and $98.16 \%$ in 2001, 2004, 2007, 2010, 2013, 2016 and 2018, respectively. Grass land had the next largest contribution, accounting for $1.15 \%, 1.13 \%, 1.14 \%, 1.08 \%$, $1.05 \%, 1.67 \%$ and $1.67 \%$ in 2001, 2004, 2007, 2010, 2013, 2016 and 2018, respectively. The total contribution of arable land was less than $1 \%$ from 2001-2018, mainly due to the large area of forest cover combined with the higher per-unit functions of respirable particulate matter and $\mathrm{SO}_{2}$ in the haze, both of which resulted in a higher contribution to ecosystem service functions from the other types. In contrast, the relatively lower contributions from grass land and arable land were primarily due to the smaller per-unit functions of haze absorption.

The primary haze absorption ecological function by green space was primarily dust retention (Table 2), the functions of which accounted for 97.98\%, 97.97\%, 97.97\%, $98.04 \%, 98.06 \%, 97.47 \%$ and $97.46 \%$ of the total functions in 2001, 2004, 2007, 2010, 2013, 2016 and 2018, respectively. Sulfur dioxide followed, accounting for $1.90 \%, 1.89 \%, 1.90 \%, 1.83 \%, 1.82 \%, 2.40 \%$ and $2.41 \%$ of the total functions in 2001, 2004, 2007, 2010, 2013, 2016 and 2018, respectively. The functions of $\mathrm{NO}_{\mathrm{x}}$ absorption from 2001-2018 were less than 1\% of the total, primarily due to the lower 
Table 2. Ecosystem service functions (benchmark values) of haze absorption by green space in China in 2001, 2004, 2007, 2010, 2013, 2016 and 2018 (106 Kg).

\begin{tabular}{|c|c|c|c|c|c|c|c|c|}
\hline $\begin{array}{c}\text { Green space } \\
\text { types }\end{array}$ & $\begin{array}{c}\text { Ecosystem } \\
\text { service }\end{array}$ & 2001 & 2004 & 2007 & 2010 & 2013 & 2016 & 2018 \\
\hline \multirow[t]{5}{*}{ Arable land } & \begin{tabular}{|l|} 
Absorption of \\
sulfur dioxide
\end{tabular} & 8591.57 & 9622.49 & 9006.41 & 8835.75 & 9329.70 & 6805.30 & 6864.45 \\
\hline & $\begin{array}{c}\text { Absorption } \\
\text { of nitrogen } \\
\text { oxides }\end{array}$ & 6395.95 & 7163.41 & 6704.77 & 6577.72 & 6945.45 & 5066.17 & 5110.20 \\
\hline & Dust retention & 181.38 & 203.14 & 190.14 & 186.53 & 196.96 & 143.67 & 144.92 \\
\hline & Total & 15168.90 & 16989.04 & 15901.31 & 15600.00 & 16472.11 & 12015.14 & 12119.58 \\
\hline & Percentage (\%) & 0.17 & 0.19 & 0.18 & 0.17 & 0.18 & 0.15 & 0.16 \\
\hline \multirow[t]{5}{*}{ Forest cover } & \begin{tabular}{|l|} 
Absorption of \\
sulfur dioxide
\end{tabular} & 61945.79 & 60457.74 & 61255.74 & 63225.21 & 62993.37 & 53141.91 & 52954.45 \\
\hline & $\begin{array}{c}\text { Absorption } \\
\text { of nitrogen } \\
\text { oxides }\end{array}$ & 2443.14 & 2384.45 & 2415.92 & 2493.60 & 2484.46 & 2095.91 & 2088.52 \\
\hline & Dust retention & 8817696.60 & 8605879.12 & 8719471.22 & 8999815.52 & 8966814.78 & 7564504.47 & 7537820.05 \\
\hline & Total & 8882085.53 & 8668721.31 & 8783142.89 & 9065534.33 & 9032292.61 & 7619742.29 & 7592863.02 \\
\hline & Percentage (\%) & 98.68 & 98.67 & 98.68 & 98.75 & 98.77 & 98.17 & 98.16 \\
\hline \multirow[t]{5}{*}{ Grass land } & $\begin{array}{l}\text { Absorption of } \\
\text { sulfur dioxide }\end{array}$ & 100608.06 & 96509.66 & 98942.51 & 96357.20 & 93922.48 & 126584.95 & 126285.53 \\
\hline & $\begin{array}{c}\text { Absorption } \\
\text { of nitrogen } \\
\text { oxides }\end{array}$ & 2163.38 & 2075.25 & 2127.57 & 2071.97 & 2019.62 & 2721.96 & 2715.53 \\
\hline & Dust retention & 432.68 & 415.05 & 425.51 & 414.39 & 403.92 & 544.39 & 543.11 \\
\hline & Total & 103204.12 & 98999.97 & 101495.59 & 98843.57 & 96346.03 & 129851.31 & 129544.16 \\
\hline & Percentage (\%) & 1.15 & 1.13 & 1.14 & 1.08 & 1.05 & 1.67 & 1.67 \\
\hline \multirow[t]{5}{*}{ Total } & \begin{tabular}{|l|}
$\begin{array}{l}\text { Absorption of } \\
\text { sulfur dioxide }\end{array}$ \\
\end{tabular} & 171145.43 & 166589.89 & 169204.66 & 168418.15 & 166245.56 & 186532.16 & 186104.43 \\
\hline & $\begin{array}{c}\text { Absorption } \\
\text { of nitrogen } \\
\text { oxides }\end{array}$ & 11002.47 & 11623.11 & 11248.26 & 11143.30 & 11449.52 & 9884.05 & 9914.25 \\
\hline & Dust retention & 8818310.65 & 8606497.31 & 8720086.87 & 9000416.45 & 8967415.67 & 7565192.53 & 7538508.07 \\
\hline & Total & 9000458.55 & 8784710.32 & 8900539.79 & 9179977.89 & 9145110.75 & 7761608.74 & 7734526.75 \\
\hline & Percentage (\%) & 100.00 & 100.00 & 100.00 & 100.00 & 100.00 & 100.00 & 100 \\
\hline \multirow[t]{5}{*}{$\begin{array}{l}\text { Percentage } \\
(\%)\end{array}$} & $\begin{array}{l}\text { Absorption of } \\
\text { sulfur dioxide }\end{array}$ & 1.90 & 1.89 & 1.90 & 1.83 & 1.82 & 2.40 & 2.41 \\
\hline & $\begin{array}{c}\text { Absorption } \\
\text { of nitrogen } \\
\text { oxides }\end{array}$ & 0.12 & 0.13 & 0.13 & 0.12 & 0.13 & 0.13 & 0.13 \\
\hline & Dust retention & 97.98 & 97.97 & 97.97 & 98.04 & 98.06 & 97.47 & 97.46 \\
\hline & Total & 100.00 & 100.00 & 100.00 & 100.00 & 100.00 & 100.00 & 100 \\
\hline & Percentage (\%) & 100.00 & 100.00 & 100.00 & 100.00 & 100.00 & 100.00 & 100 \\
\hline
\end{tabular}

per-unit area function of the absorption of $\mathrm{SO}_{2}$ and $\mathrm{NO}_{\mathrm{x}}$ by various types of green space. However, the effect of dust retention was clear: the function of respirable particulate matter absorption by forest cover was especially high, indicating that green space plays an important role in dust removal and retention. Respirable particulate matter is the most important component of haze, so planning a reasonable amount of green space is conducive to reducing haze.

The ecosystem service functions (corrected value) of haze absorption by green space in China increased by 596086.46 million $\mathrm{Kg}(7.72 \%)$ from 2001-2013 (Table 3), while decreasing by 1810169.25 million $\mathrm{Kg}(21.76 \%)$ from 2013-2018: 7724215.34 million $\mathrm{Kg}$ 
Table 3. Ecosystem service functions (corrected values) of haze absorption by green space in China in 2001, 2004, 2007, 2010, 2013, 2016 and $2018\left(10^{6} \mathrm{Kg}\right)$.

\begin{tabular}{|c|c|c|c|c|c|c|c|c|}
\hline $\begin{array}{c}\text { Green space } \\
\text { types }\end{array}$ & Ecosystem service & 2001 & 2004 & 2007 & 2010 & 2013 & 2016 & 2018 \\
\hline \multirow[t]{5}{*}{ Arable land } & $\begin{array}{l}\text { Absorption of sulfur } \\
\text { dioxide }\end{array}$ & 10623.08 & 12214.32 & 11709.68 & 11281.32 & 11648.15 & 3912.29 & 3921.82 \\
\hline & $\begin{array}{l}\text { Absorption of } \\
\text { nitrogen oxides }\end{array}$ & 7908.29 & 9092.88 & 8717.21 & 8398.32 & 8671.40 & 2699.42 & 2691.12 \\
\hline & Dust retention & 224.27 & 257.86 & 247.20 & 238.16 & 245.91 & 1672.12 & 1884.59 \\
\hline & Total & 18755.64 & 21565.06 & 20674.09 & 19917.80 & 20565.45 & 8283.83 & 8497.53 \\
\hline & Percentage (\%) & 0.24 & 0.29 & 0.27 & 0.24 & 0.25 & 0.13 & 0.13 \\
\hline \multirow[t]{5}{*}{ Forest cover } & $\begin{array}{l}\text { Absorption of sulfur } \\
\text { dioxide }\end{array}$ & 53221.67 & 52114.40 & 53757.20 & 56257.75 & 57464.17 & 45259.90 & 45242.86 \\
\hline & $\begin{array}{c}\text { Absorption of } \\
\text { nitrogen oxides }\end{array}$ & 2099.06 & 2055.39 & 2120.18 & 2218.80 & 2266.38 & 1776.64 & 1775.52 \\
\hline & Dust retention & 7575858.33 & 7418243.69 & 7652088.58 & 8008029.84 & 8179758.25 & 6357175.05 & 6347113.37 \\
\hline & Total & 7631179.06 & 7472413.48 & 7707965.96 & 8066506.39 & 8239488.80 & 6404211.47 & 6394131.50 \\
\hline & Percentage (\%) & 98.80 & 98.86 & 98.89 & 98.97 & 99.03 & 98.29 & 98.22 \\
\hline \multirow[t]{5}{*}{ Grass land } & $\begin{array}{l}\text { Absorption of sulfur } \\
\text { dioxide }\end{array}$ & 72412.13 & 63058.21 & 63850.41 & 62667.81 & 58732.04 & 56177.81 & 56741.54 \\
\hline & $\begin{array}{l}\text { Absorption of } \\
\text { nitrogen oxides }\end{array}$ & 1557.08 & 1355.94 & 1372.98 & 1347.55 & 1262.92 & 1246.38 & 1260.91 \\
\hline & Dust retention & 311.42 & 271.19 & 274.60 & 269.51 & 252.58 & 45770.85 & 49501.07 \\
\hline & Total & 74280.63 & 64685.34 & 65497.99 & 64284.87 & 60247.54 & 103195.05 & 107503.52 \\
\hline & Percentage (\%) & 0.96 & 0.86 & 0.84 & 0.79 & 0.72 & 1.58 & 1.65 \\
\hline \multirow[t]{5}{*}{ Total } & $\begin{array}{l}\text { Absorption of sulfur } \\
\text { dioxide }\end{array}$ & 136256.89 & 127386.94 & 129317.30 & 130206.88 & 127844.36 & 105350.00 & 105906.22 \\
\hline & $\begin{array}{l}\text { Absorption of } \\
\text { nitrogen oxides }\end{array}$ & 11564.44 & 12504.22 & 12210.37 & 11964.67 & 12200.70 & 5722.45 & 5727.55 \\
\hline & Dust retention & 7576394.02 & 7418772.74 & 7652610.38 & 8008537.51 & 8180256.73 & 6404618.02 & 6398499.03 \\
\hline & Total & 7724215.34 & 7558663.89 & 7794138.04 & 8150709.06 & 8320301.79 & 6515690.35 & 6510132.55 \\
\hline & Percentage (\%) & 100.00 & 100.00 & 100.00 & 100.00 & 100.00 & 100.00 & 100.00 \\
\hline \multirow[t]{5}{*}{$\begin{array}{l}\text { Percentage } \\
(\%)\end{array}$} & $\begin{array}{l}\text { Absorption of sulfur } \\
\text { dioxide }\end{array}$ & 1.76 & 1.69 & 1.66 & 1.60 & 1.54 & 1.62 & 1.63 \\
\hline & $\begin{array}{l}\text { Absorption of } \\
\text { nitrogen oxides }\end{array}$ & 0.15 & 0.17 & 0.16 & 0.15 & 0.15 & 0.09 & 0.09 \\
\hline & Dust retention & 98.09 & 98.15 & 98.18 & 98.26 & 98.32 & 98.30 & 98.29 \\
\hline & Total & 100.00 & 100.00 & 100.00 & 100.00 & 100.00 & 100.00 & 100.00 \\
\hline & Percentage (\%) & 100.00 & 100.00 & 100.00 & 100.00 & 100.00 & 100.00 & 100.00 \\
\hline
\end{tabular}

in 2001, 7558663.89 million $\mathrm{Kg}$ in 2004, 7794138.04 million $\mathrm{Kg}$ in 2007, 8150709.06 million $\mathrm{Kg}$ in 2010, 8320301.79 million $\mathrm{Kg}$ in 2013, 6515690.35 million $\mathrm{Kg}$ in 2016 and 6510132.55 million $\mathrm{Kg}$ in 2018. In addition to the decrease of 165551.45 million $\mathrm{Kg}(2.14 \%)$ in $2001-2004$, decrease of 1804611.45 million $\mathrm{Kg}(21.69 \%)$ in 2013 2016 and decrease of 5557.80 million $\mathrm{Kg}(0.09 \%)$ in 2016-2018, the functions from 2004-2007, 2007-2010 and 2010-2013 increased by 235474.15 million $\mathrm{Kg}$ (3.12\%), 356571.02 million $\mathrm{Kg}$ (4.57\%) and 169592.74 million $\mathrm{Kg}$ (2.08\%), respectively.

The contribution rate of the various types of green space to haze absorption varied greatly. The contribution rate of forest cover was the largest, accounting for $98.80 \%$, $98.86 \%, 98.89 \%, 98.97 \%, 99.03 \%, 98.29 \%$ and $98.22 \%$ of the total in 2001, 2004, 2007, 2010, 2013, 2016 and 2018, respectively. The second was grass land, which accounted for $0.96 \%, 0.86 \%, 0.84 \%, 0.79 \%, 0.72 \%, 1.58 \%$ and $1.65 \%$ of the total in 2001, 2004, 2007, 2010, 2013, 2016 and 2018, respectively. Arable land made the 
smallest contribution, accounting for $0.24 \%, 0.29 \%, 0.27 \%, 0.24 \%, 0.25 \%, 0.13 \%$ and $0.13 \%$ of the total in 2001, 2004, 2007, 2010, 2013, 2016 and 2018, respectively.

The haze absorption by green space was dominated by dust retention, the functions of which accounted for $98.09 \%, 98.15 \%, 98.18 \%, 98.26 \%, 98.32 \%, 98.30 \%$ and $98.29 \%$ of the total in 2001, 2004, 2007, 2010, 2013, 2016 and 2018, respectively. The function of $\mathrm{SO}_{2}$ absorption accounted for $1.76 \%, 1.69 \%, 1.66 \%, 1.60 \%$, $1.54 \%, 1.62 \%$ and $1.63 \%$ of the total, and the function of $\mathrm{NO}_{\mathrm{x}}$ absorption accounted for $0.15 \%, 0.17 \%, 0.16 \%, 0.15 \%, 0.15 \%, 0.09 \%$ and $0.09 \%$ in $2001,2004,2007$, 2010, 2013, 2016 and 2018, respectively.

As can be seen from Figure 1, the correction based on green space quality reduced the functions by 1276243.21 million $\mathrm{Kg}(14.18 \%), 1226046.43$ million $\mathrm{Kg}(13.96 \%)$, 1106401.75 million $\mathrm{Kg}(12.43 \%), 1029268.84$ million $\mathrm{Kg}(11.21 \%), 824808.96$ million $\mathrm{Kg}$ (9.02\%), 1245918.40 million $\mathrm{Kg}(16.05 \%)$ and 1224394.20 million $\mathrm{Kg}$ (15.83\%) in 2001, 2004, 2007, 2010, 2013, 2016 and 2018, respectively, compared with the benchmark values of the ecosystem service of haze absorption by green space. However, in terms of general trends, the benchmark and corrected values of ecosystem services of haze absorption by green space in China increased by 144652.20 million $\mathrm{Kg}$

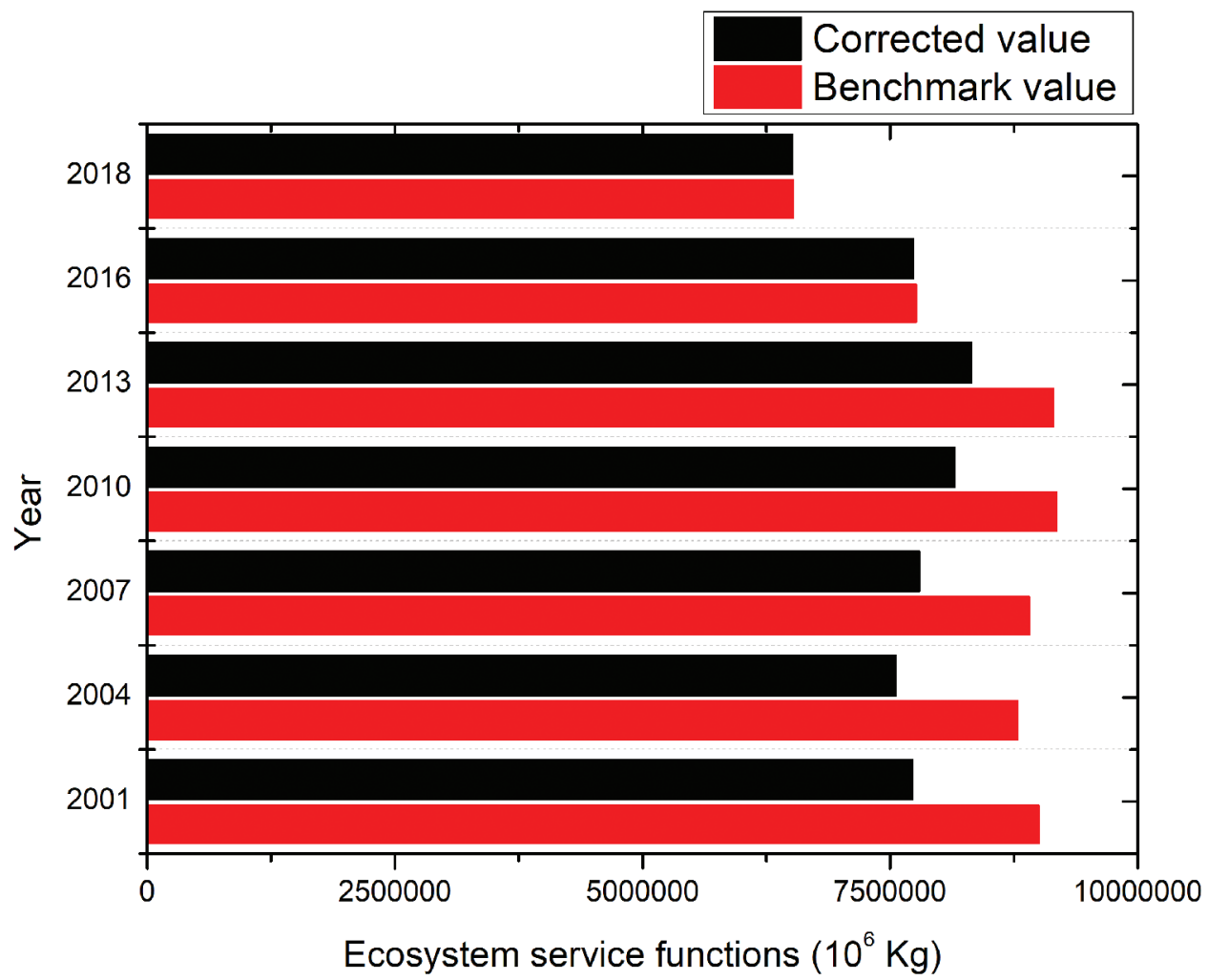

Figure I. Comparison of benchmark and corrected ecosystem service functions of haze absorption by green space in China in 2001, 2004, 2007, 2010, 2013, 2016 and 2018 based on the quality of green space $\left(10^{6} \mathrm{Kg}\right)$. 
(1.61\%) and 596086.46 million $\mathrm{Kg}$ (7.72\%), respectively, from 2001-2013, while decreasing by 1410584.00 million $\mathrm{Kg}(15.42 \%)$ and 1810169.25 million $\mathrm{Kg}(21.76 \%)$, respectively, from 2013-2018, indicating that the ecosystem service functions based on green space quality differ greatly from the functions considering only the area green space. If only the green space area, and not the quality, is considered when evaluating the ecosystem service functions, the evaluation results will be too high. Nonetheless, the overall trends in the benchmark and corrected ecosystem service functions of haze absorption by green space in China are consistent during 2001-2013 and 2013-2018, showing first an increase and then a decreasing trend, indicating that the ecological restoration and conservation projects of the Chinese government have enhanced the ecosystem service functions of haze absorption by green space in 2001-2013, but the adjustment of ecological land structure and the expansion of construction land have led to a reduction in the ecosystem service functions of haze absorption in 2013-2018. The government should strengthen the restoration of forest vegetation with high haze absorption capacity and regulate the speed of urban expansion to improve the ability of haze absorption by ecological land.

Compared with the benchmark values, the contribution rates of the corrected value of haze absorption by forest cover increased by $0.11 \%, 0.19 \%, 0.21 \%, 0.21 \%, 0.26 \%$, $0.12 \%$ and $0.06 \%$ in $2001,2004,2007,2010,2013,2016$ and 2018 , respectively, while the contribution rates of the corrected value of haze absorption by grass land decreased by $0.18 \%, 0.27 \%, 0.30 \%, 0.29 \%, 0.33 \%, 0.09 \%$ and $0.02 \%$, whereas those of arable land increased by $0.07 \%, 0.09 \%, 0.09 \%, 0.07 \%$ and $0.07 \%$ in $2001,2004,2007,2010$ and 2013 but decreased by $0.03 \%$ and $0.03 \%$ in 2016 and 2018 , respectively.

The analysis of the ecosystem services functions of haze absorption by green space revealed that the corrected value of dust retention increased by $0.11 \%, 0.18 \%, 0.21 \%$, $0.21 \%, 0.26 \%, 0.83 \%$ and $0.83 \%$ compared with the benchmark value in 2001, 2004, 2007, 2010, 2013, 2016 and 2018, respectively. The corrected value of $\mathrm{SO}_{2}$ absorption decreased by $0.14 \%, 0.20 \%, 0.24 \%, 0.24 \%, 0.28 \%, 0.79 \%$ and $0.78 \%$ in 2001, 2004, 2007, 2010, 2013, 2016 and 2018, respectively. The corrected value of $\mathrm{NO}_{\mathrm{X}}$ absorption in 2001, 2004, 2007, 2010 and 2013 increased by $0.03 \%, 0.03 \%$, $0.03 \%, 0.03 \%$ and $0.02 \%$, respectively, although the value decreased by $0.04 \%$ and $0.04 \%$ in 2016 and 2018, respectively. These results indicated that the benchmark and corrected values of the contribution rates of haze absorption by different types of green space and thus the ecosystem service functions are different, but all the functions exhibited a consistent trend. The contribution rates were ranked as forest cover, grass land and arable land, and the order of ecosystem service function was dust retention, $\mathrm{SO}_{2}$ absorption, and $\mathrm{NO}_{\mathrm{X}}$ absorption.

\section{Spatial distribution of the ecosystem service functions of haze absorption by green space in China}

Figures 2-8 (benchmark values) show that the ecosystem service functions of haze absorption by green space had different spatial distributions in China from 2001-2018. 
In general, different ecosystem service functions had very different spatial distributions within the same year, while the spatial distribution of ecosystem service functions exhibited little difference between different years.

The maximum ecosystem service functions for the absorption of $\mathrm{SO}_{2}$ (Fig. 2a), dust retention (Fig. 2c) and the total ecosystem services (Fig. 2d) for green space were 80459.35-100608.06 million $\mathrm{Kg}$, 440884.21-8817697.00 million $\mathrm{Kg}$ and 69663.42-8882085.53 million $\mathrm{Kg}$, respectively, in 2001. These services were primarily distributed in the northwestern, central-southern and northeastern regions, which is consistent with the spatial distributions of the different ecosystem service functions presented in Figures 3-8 (a, c, d) for 2004, 2007, 2010, 2013, 2016 and 2018, respectively. In contrast, the minimum ecosystem service functions for the absorption of $\mathrm{NO}_{\mathrm{x}}$ (Fig. 2b) by green space were 0-964.80 million $\mathrm{Kg}$ in 2001, and high values for this service occurred mainly in the eastern and northeastern zones, which is inconsistent with the spatial distribution of $\mathrm{NO}_{\mathrm{x}}$ absorption in Figures 3-8b for 2004, 2007, 2010, 2013, 2016 and 2018, respectively.

However, compared with the maximum and minimum values, intermediate ecosystem service functions for the absorption of $\mathrm{SO}_{2}$ (Fig. 2a) by green space were 7719.3527868.06 million $\mathrm{Kg}$ and 27868.06-80459.35 million $\mathrm{Kg}$ in 2001, and these functions were mainly distributed in the northwestern, southwestern, central, northeastern and eastern regions, which is consistent with the spatial distribution of the absorption of
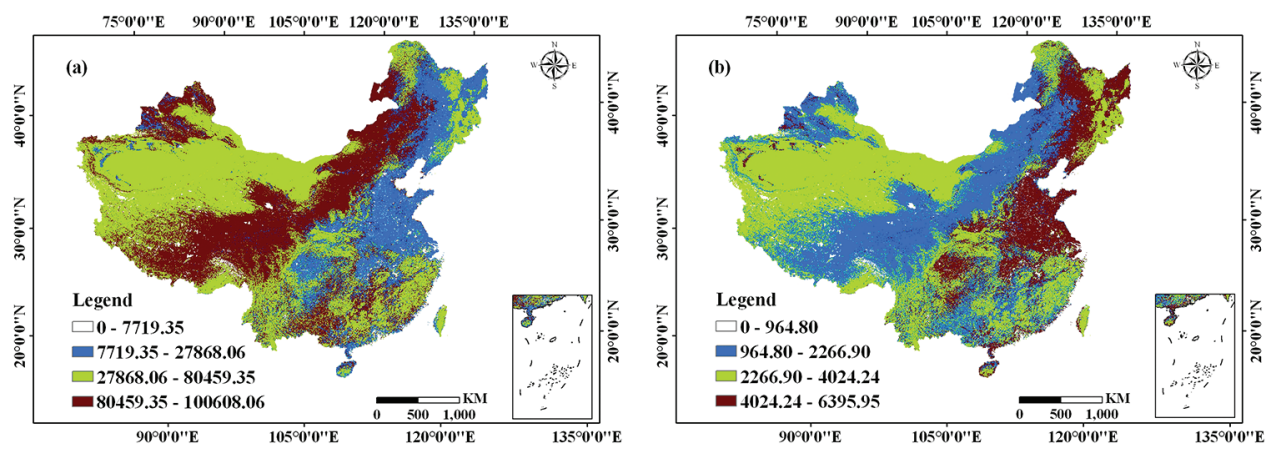

$75^{\circ} 0^{\prime} 0^{\prime \prime} \mathrm{E} \quad 90^{\circ} 0^{\prime} 0^{\prime \prime} \mathrm{E} \quad 10^{\circ} 0^{\prime} 0^{\prime \prime} \mathrm{E} \quad 120^{\circ} 0^{\prime} \mathrm{O}^{\prime \prime} \mathrm{E} \quad 135^{\circ} 0^{\prime} 0^{\prime \prime} \mathrm{E}$

$7^{\circ} 0^{\prime} 0^{\prime \prime} \mathrm{E} \quad 90^{\circ} 0^{\prime} 0^{\prime \prime} \mathrm{E} \quad 105^{\circ} 0^{\prime} 0^{\prime \prime} \mathrm{E} \quad 120^{\circ} 0^{\prime} 0^{\prime \prime} \mathrm{E} \quad 135^{\circ} 0^{\prime} 0^{\prime \prime} \mathrm{E}$
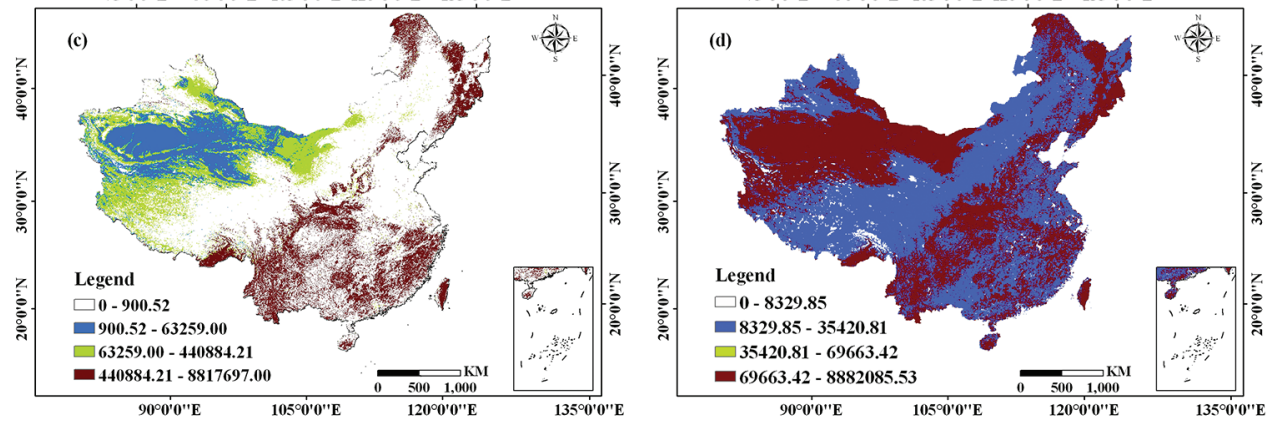

Figure 2. Spatial distribution of the ecosystem service functions of haze absorption by green space in China in $2001\left(10^{6} \mathrm{Kg}\right)(\mathbf{a}, \mathbf{b}, \mathbf{c}$ and $\mathbf{d}$ are the absorption of sulfur dioxide and nitrogen oxides, dust retention, and the total ecosystem service functions, respectively). 
$75^{\circ} 0^{\prime} 0^{\prime \prime} \mathrm{E} \quad 90^{\circ} 0^{\prime} 0^{\prime \prime} \mathrm{E} \quad 105^{\circ} 0^{\prime} 0^{\prime \prime} \mathrm{E} \quad 120^{\circ} 0^{\prime} 0^{\prime \prime} \mathrm{E} \quad 135^{\circ} 0^{\prime} 0^{\prime \prime} \mathrm{E}$

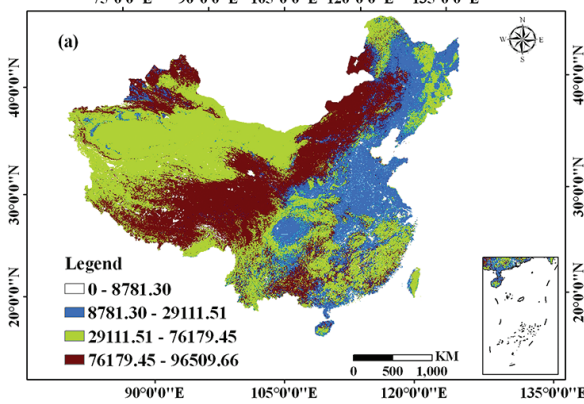

$75^{\circ} 0^{\circ} 0^{\prime \prime E} \quad 90^{\circ} 0^{\prime} 0^{\prime \prime} \mathrm{E} \quad 105^{\circ} 0^{\prime} 0^{\prime \prime} \mathrm{E} \quad 120^{\circ} 0^{\prime} 0^{\prime \prime} \mathrm{E} \quad 135^{\circ} 0^{\prime} 0^{\prime \prime E}$

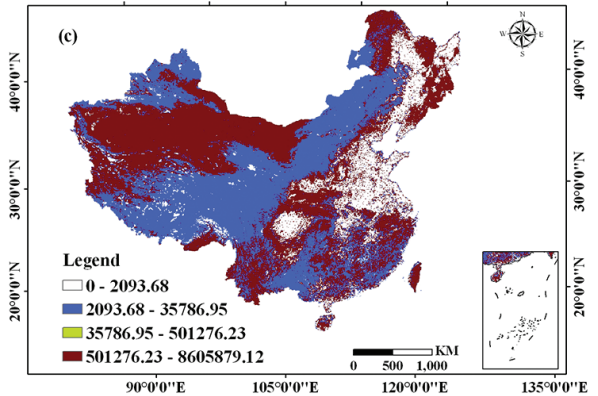

$75^{\circ} 0^{\prime} 0^{\prime \prime} \mathrm{E} \quad 90^{\circ} 0^{\prime} 0^{\prime \prime} \mathrm{E} \quad 105^{\circ} 0^{\prime} 0^{\prime \prime} \mathrm{E} \quad 120^{\circ} 0^{\prime} 0^{\prime \prime} \mathrm{E} \quad 135^{\circ} 0^{\prime} 0^{\prime \prime} \mathrm{E}$

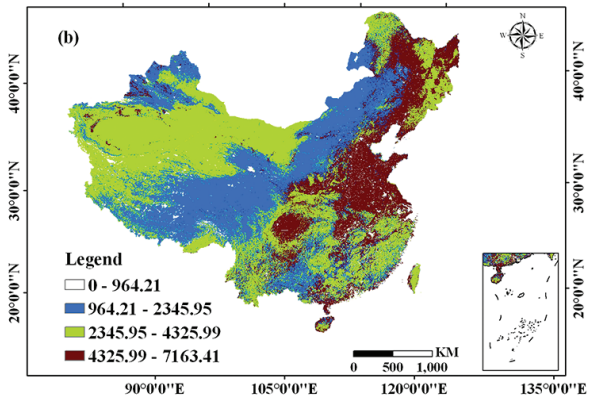

$75^{\circ} 0^{\prime} 0^{\prime \prime} \mathrm{E} \quad 90^{\circ} 0^{\prime} 0^{\prime \prime} \mathrm{E} \quad 105^{\circ} 0^{\prime} 0^{\prime \prime} \mathrm{E} \quad 120^{\circ} 0^{\prime} 0^{\prime \prime} \mathrm{E} \quad 135^{\circ} 0^{\prime} 0^{\prime \prime} \mathrm{E}$

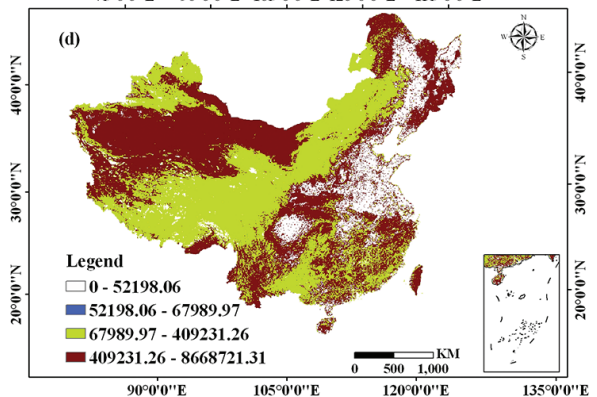

Figure 3. Spatial distribution of the ecosystem service functions of haze absorption by green space in China in $2004\left(10^{6} \mathrm{Kg}\right)(\mathbf{a}, \mathbf{b}, \mathbf{c}$ and $\mathbf{d}$ are the absorption of sulfur dioxide and nitrogen oxides, dust retention, and the total ecosystem service functions, respectively).
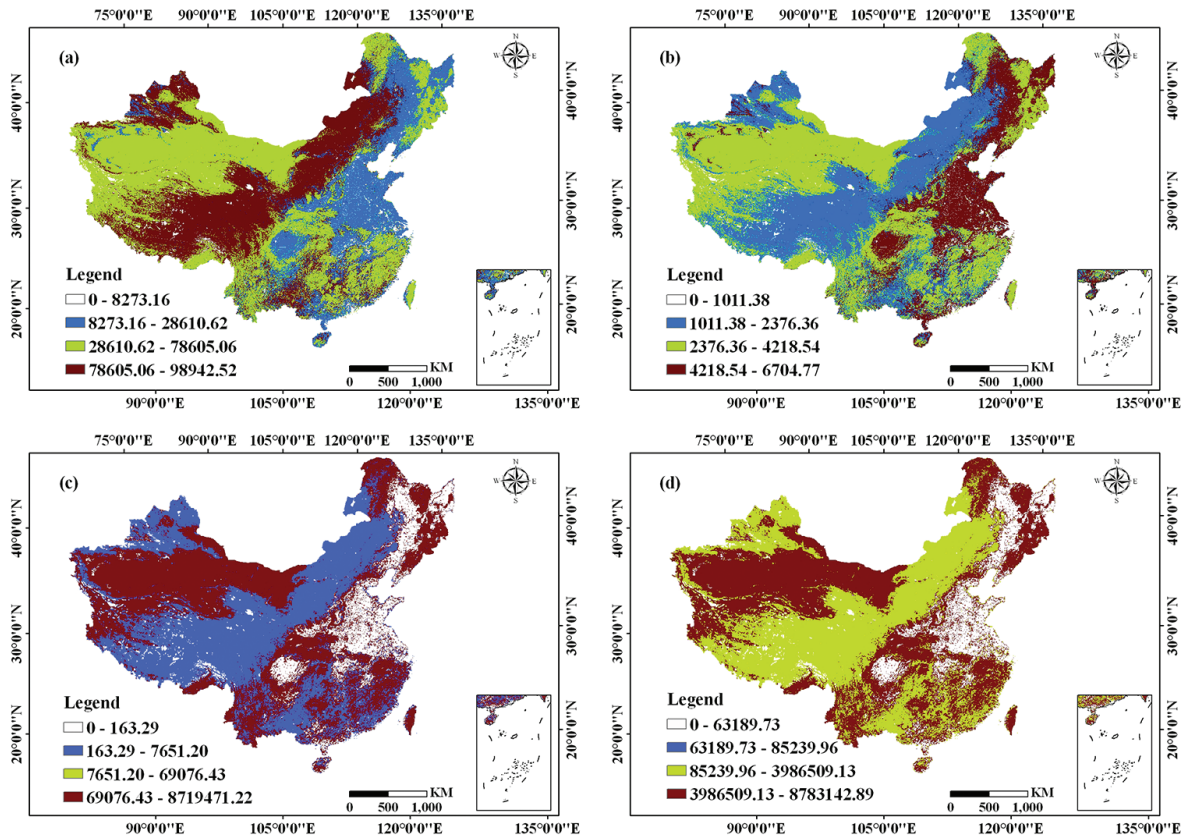

Figure 4. Spatial distribution of the ecosystem service functions of haze absorption by green space in China in $2007\left(10^{6} \mathrm{Kg}\right)(\mathbf{a}, \mathbf{b}, \mathbf{c}$ and $\mathbf{~ d}$ are the absorption of sulfur dioxide and nitrogen oxides, dust retention, and the total ecosystem service functions, respectively). 

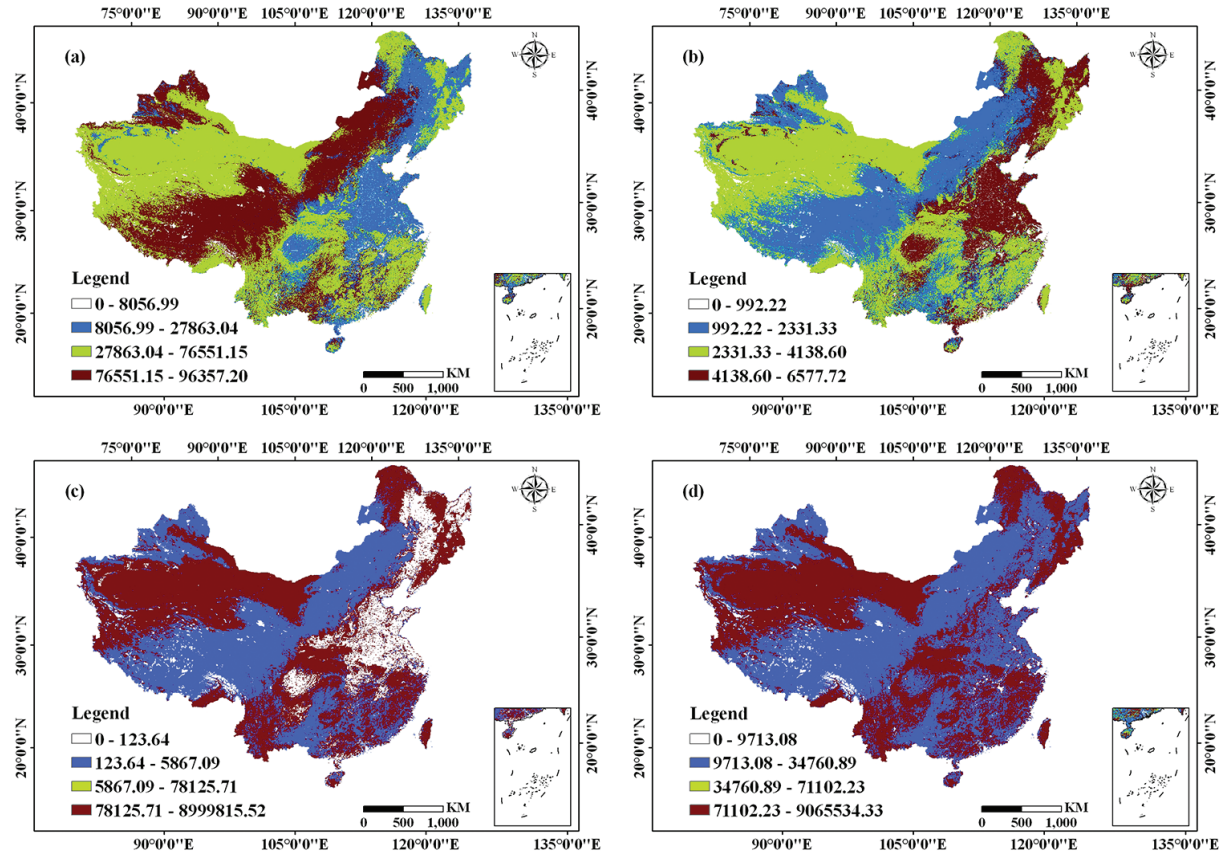

Figure 5. Spatial distribution of the ecosystem service functions of haze absorption by green space in China in $2010\left(10^{6} \mathrm{Kg}\right)(\mathbf{a}, \mathbf{b}, \mathbf{c}$ and $\mathbf{d}$ are the absorption of sulfur dioxide and nitrogen oxides, dust retention, and the total ecosystem service functions, respectively).
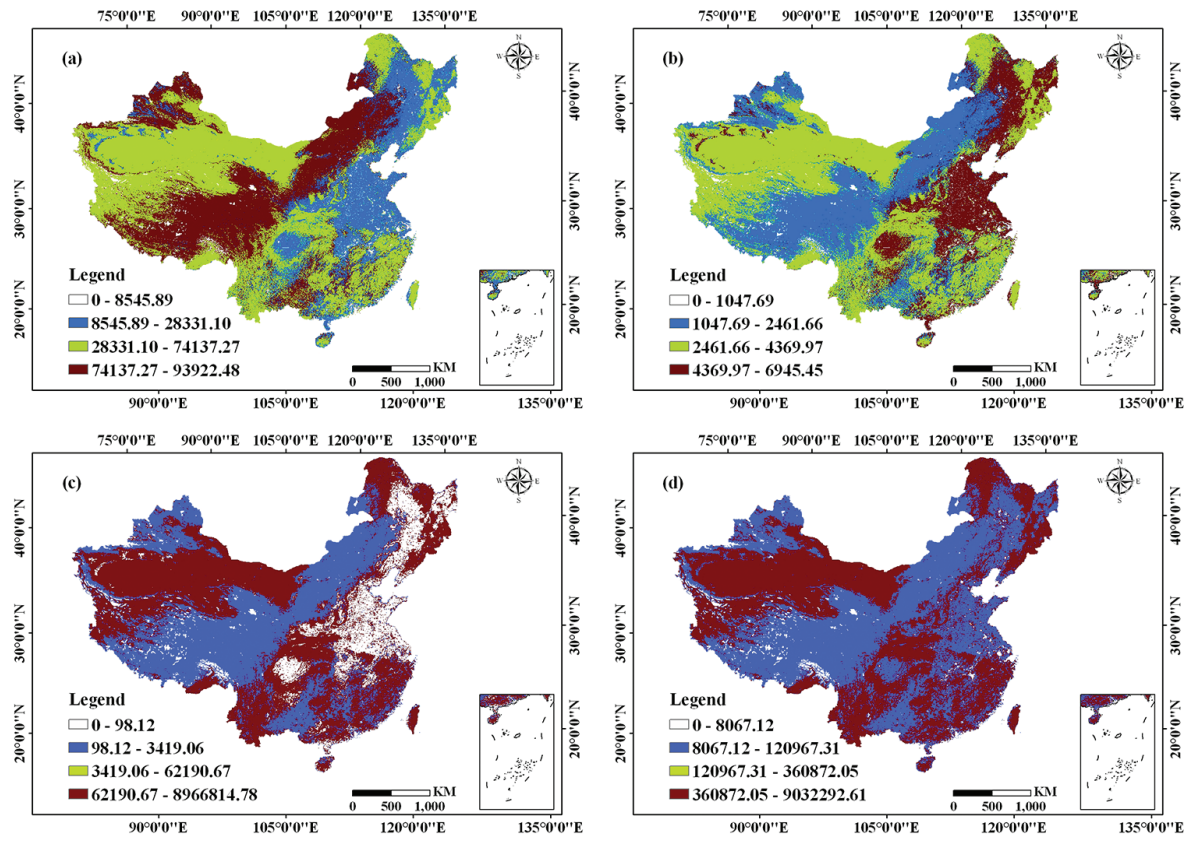

Figure 6. Spatial distribution of the ecosystem service functions of haze absorption by green space in China in $2013\left(10^{6} \mathrm{Kg}\right)(\mathbf{a}, \mathbf{b}, \mathbf{c}$ and $\mathbf{~ d}$ are the absorption of sulfur dioxide and nitrogen oxides, dust retention, and the total ecosystem service functions, respectively). 

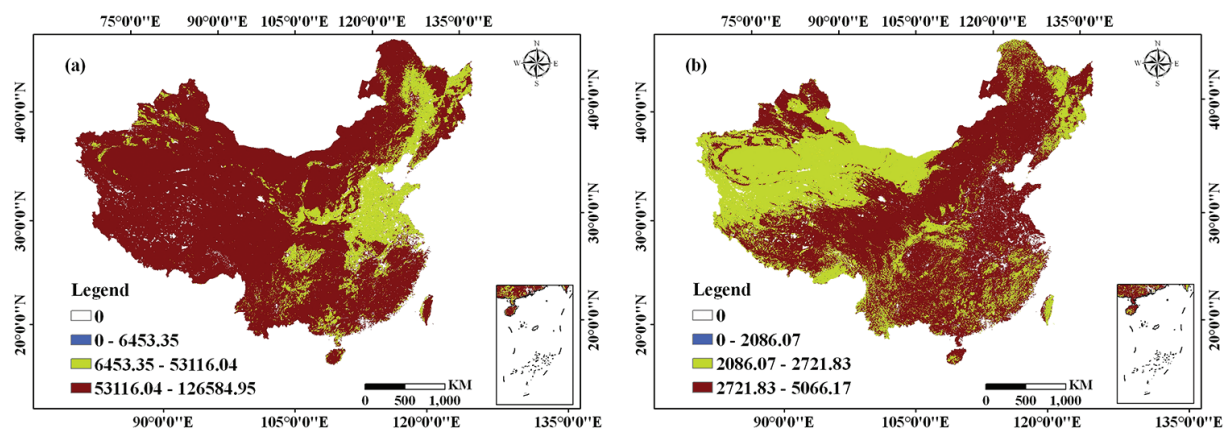

$7^{\circ} 5^{\circ} 0$ "E $\quad 90^{\circ} 0^{\prime} 0^{\prime \prime}$ E $105^{\circ} 0^{\prime} 0^{\prime \prime}$ E $120^{\circ} 0^{\prime} 0^{\prime \prime}$ E $135^{\circ} 0^{\prime} 0^{\prime \prime}$ E

$75^{\circ} 0^{\prime} 0^{\prime \prime}$ E $\quad 90^{\circ} 0^{\prime} 0^{\prime \prime E} \quad 105^{\circ} 0^{\prime} 0^{\prime \prime} \mathrm{E} \quad 120^{\circ} 0^{\prime} 0^{\prime \prime} \mathrm{E} \quad 135^{\circ} 0^{\prime} \mathrm{O}^{\prime \prime} \mathrm{E}$
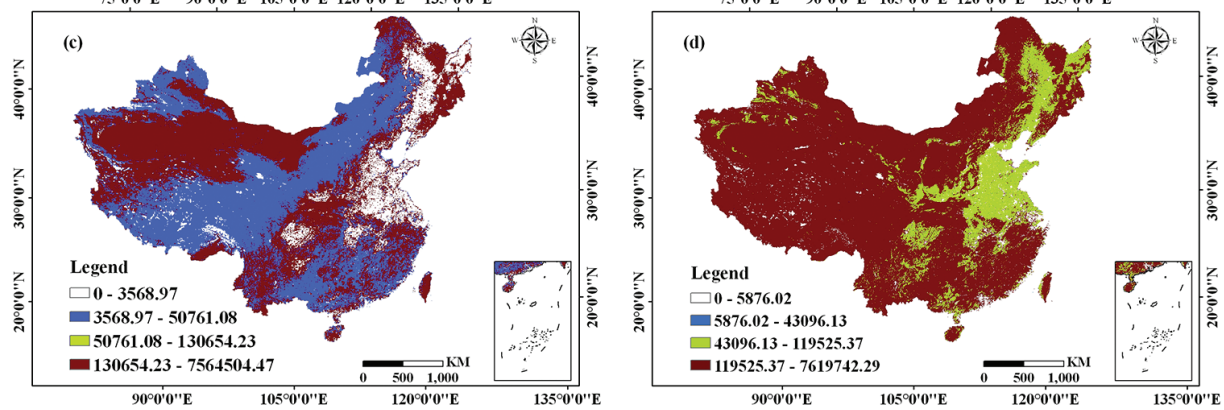

Figure 7. Spatial distribution of the ecosystem service functions of haze absorption by green space in China in $2016\left(10^{6} \mathrm{Kg}\right)(\mathbf{a}, \mathbf{b}, \mathbf{c}$ and $\mathbf{d}$ are the absorption of sulfur dioxide and nitrogen oxides, dust retention, and the total ecosystem service functions, respectively).
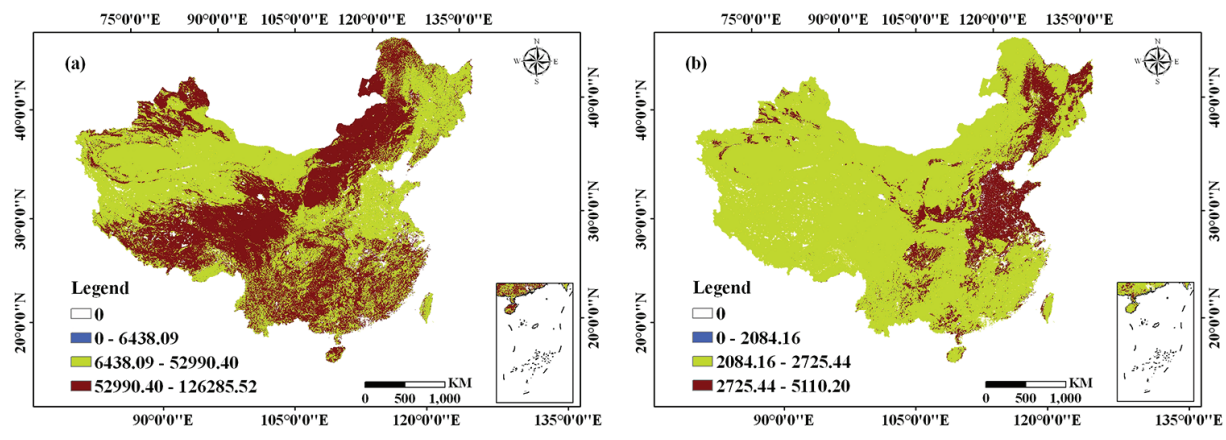

$75^{\circ} 0^{\prime} 0^{\prime \prime} \mathrm{E} \quad 90^{\circ} 0^{\prime} 0^{\prime \prime} \mathrm{E} \quad 15^{\circ} 0^{\prime} 0^{\prime \prime} \mathrm{E} \quad 120^{\circ} 0^{\prime} 0^{\prime \prime} \mathrm{E} \quad 135^{\circ} 0^{\prime} 0^{\prime \prime} \mathrm{E}$

$75^{\circ} 0^{\prime} 0^{\prime \prime} \mathrm{E} \quad 90^{\circ} 0^{\prime} 0^{\prime \prime} \mathrm{E} \quad 105^{\circ} 0^{\prime} 0^{\prime \prime} \mathrm{E} \quad 120^{\circ} 0^{\prime} 0^{\prime \prime} \mathrm{E} \quad 135^{\circ} 0^{\prime} 0^{\prime \prime} \mathrm{E}$
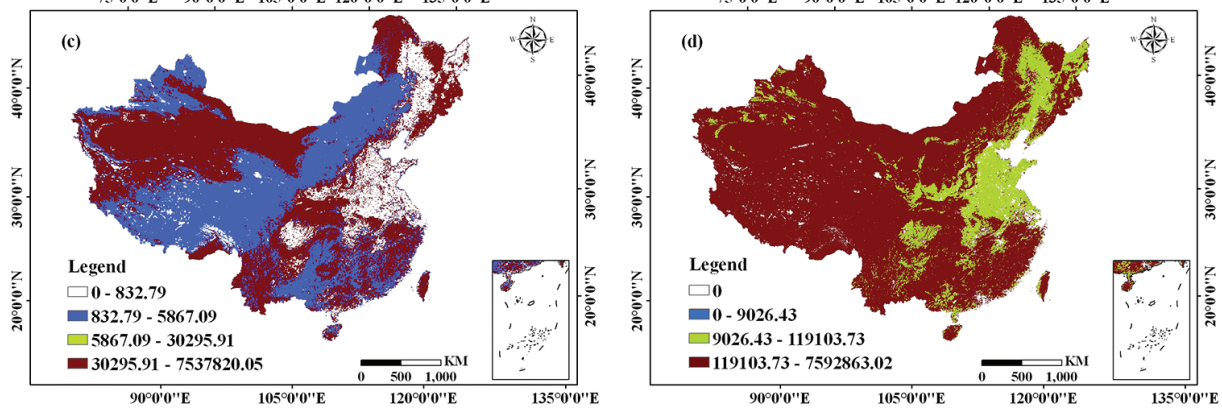

Figure 8. Spatial distribution of the ecosystem service functions of haze absorption by green space in China in $2018\left(10^{6} \mathrm{Kg}\right)(\mathbf{a}, \mathbf{b}, \mathbf{c}$ and $\mathbf{d}$ are the absorption of sulfur dioxide and nitrogen oxides, dust retention, and the total ecosystem service functions, respectively). 
$\mathrm{SO}_{2}$ in Figures 3-8a for 2004, 2007, 2010, 2013, 2016 and 2018, respectively. In addition, intermediate values for $\mathrm{NO}_{\mathrm{x}}$ absorption (Fig. 2b) were 964.80-2266.90 million $\mathrm{Kg}$ and 2266.90-4024.24 million $\mathrm{Kg}$ in 2001, and these functions were mainly in the western, central-northern, central-southern, southern and southeastern regions, which is in accordance with the spatial distribution of the absorption of $\mathrm{NO}_{\mathrm{X}}$ in Figures 3-8b for 2004, 2007, 2010, 2013, 2016 and 2018, respectively.

Intermediate ecosystem service functions for dust retention (Fig. 2c) by green space were 900.52-63259.00 million $\mathrm{Kg}$ and 63259.00-440884.21 million Kg in 2001, and these functions were mainly distributed in the northwestern, southwestern, centralnorthern and northeastern regions, which is consistent with the spatial distribution of dust retention in Figures 3-8 (c) for 2004, 2007, 2010, 2013, 2016 and 2018, respectively. Furthermore, intermediate values for total ecosystem services (Fig. 2d) were 8329.85-35420.81 million $\mathrm{Kg}$ and 35420.81-69663.42 million $\mathrm{Kg}$ in 2001, and these values were mainly in the northwestern, southwestern, southern, eastern and northeastern regions, which is in accordance with the spatial distribution of total ecosystem services in Figures 5-7d for 2010, 2013 and 2016, respectively, but is inconsistent with Figures 3-4 and 8d for 2004, 2007 and 2018, during which these functions were mainly distributed in the northwestern, southwestern, and central regions.

As shown in Figures 9-15 (corrected values), the maximum ecosystem service functions of $\mathrm{SO}_{2}$ absorption (Fig. 9a), dust retention (Fig. 9c) and total ecosystem services (Fig. 9d) by green space were 53386.20-72412.13 million Kg, 5681893.887575858.50 million $\mathrm{Kg}$ and 5723384.25-7631179.00 million $\mathrm{Kg}$ in 2001, respectively, and were mainly in the southeastern, central-southern and southwestern areas, which is in accordance with the spatial distributions of the different ecosystem service functions presented in Figures 10-15 (a, c, d) for 2004, 2007, 2010, 2013, 2016 and 2018, respectively.

In contrast, the intermediate ecosystem service functions of $\mathrm{SO}_{2}$ absorption (Fig. 9a) by green space were $0-10506.86$ million $\mathrm{Kg}$ and $10506.86-53386.20$ million $\mathrm{Kg}$ in 2001 and were mainly distributed in the southwestern, central-northern and northeastern regions, which is consistent with the spatial distribution of $\mathrm{SO}_{2}$ absorption in Figures 10-15a for 2004, 2007, 2010, 2013, 2016 and 2018, respectively. Moreover, the intermediate ecosystem service functions of dust retention (Fig. 9c) by green space were 1893964.63-3787929.25 million $\mathrm{Kg}$ and 5681893.88-7575858.50 million $\mathrm{Kg}$ in 2001 and occurred mainly in the northeastern, central and southeastern areas, which is in accordance with the spatial distribution of dust retention in Figures 9-15c for 2004, 2007, 2010, 2013, 2016 and 2018, respectively. Furthermore, the minimum values of the total ecosystem service functions (Fig. 9d) by green space were $0-1907794.75$ million $\mathrm{Kg}$ in 2001 and occurred mainly in the western, centralnorthern and southwestern zones, respectively, which is in accordance with the spatial distribution of the total ecosystem service functions (Figures 10-15d) in 2004, 2007, 2010, 2013, 2016 and 2018.

The results show that there was a great difference in the spatial distributions of the benchmark and corrected values of haze absorption by green space, and the spatial distributions of the maximum, intermediate and minimum ecosystem 

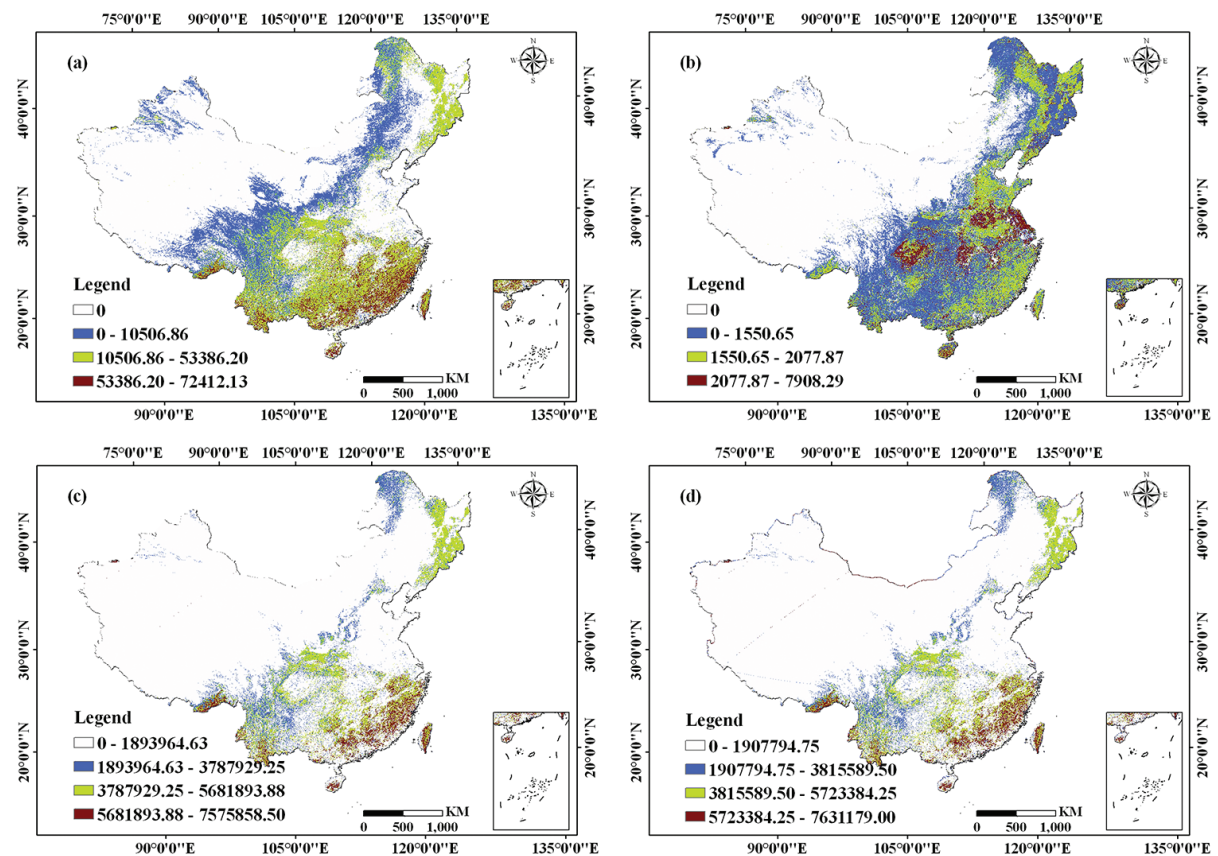

Figure 9. Spatial distribution of the ecosystem service functions of haze absorption by green space in China in $2001\left(10^{6} \mathrm{Kg}\right)(\mathbf{a}, \mathbf{b}, \mathbf{c}$ and $\mathbf{d}$ are the absorption of sulfur dioxide and nitrogen oxides, dust retention, and the total ecosystem service functions, respectively).
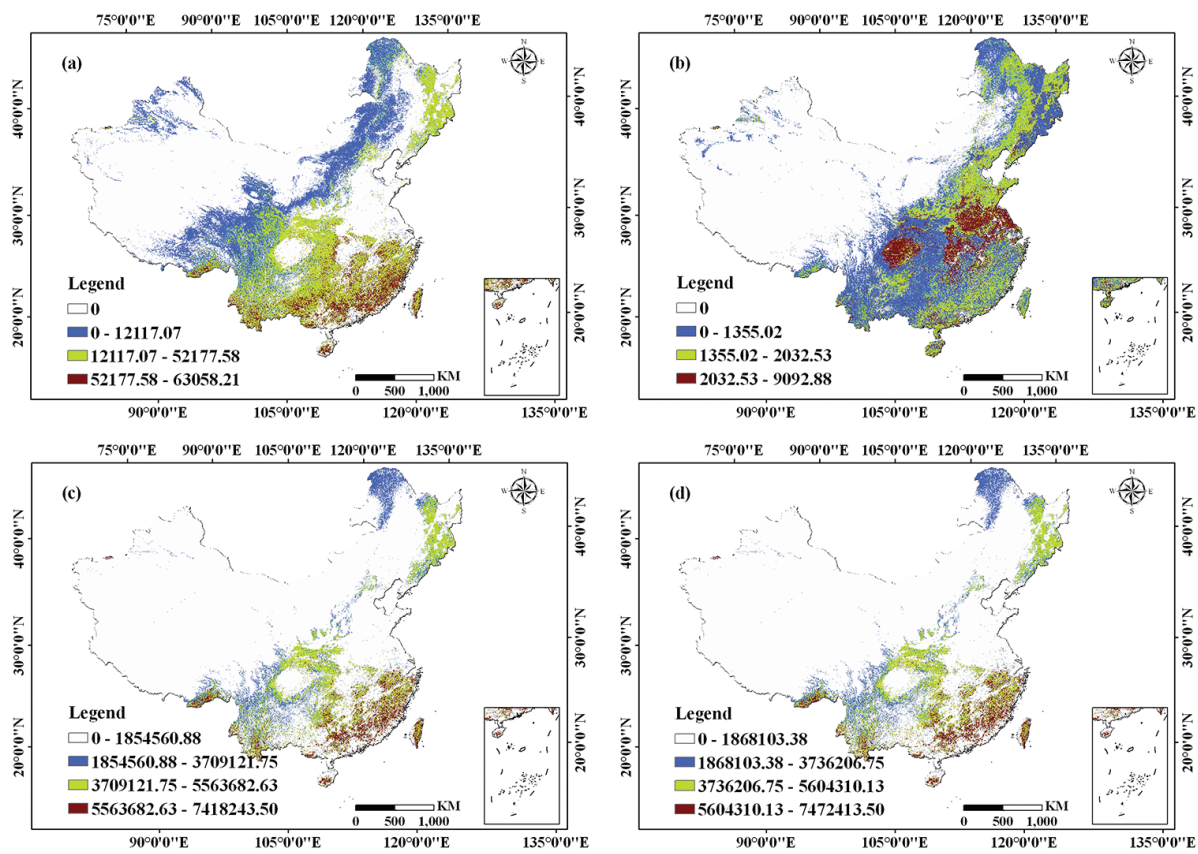

Figure 10. Spatial distribution of the ecosystem service functions of haze absorption by green space in China in $2004\left(10^{6} \mathrm{Kg}\right)(\mathbf{a}, \mathbf{b}, \mathbf{c}$ and $\mathbf{d}$ are the absorption of sulfur dioxide and nitrogen oxides, dust retention, and the total ecosystem service functions, respectively). 

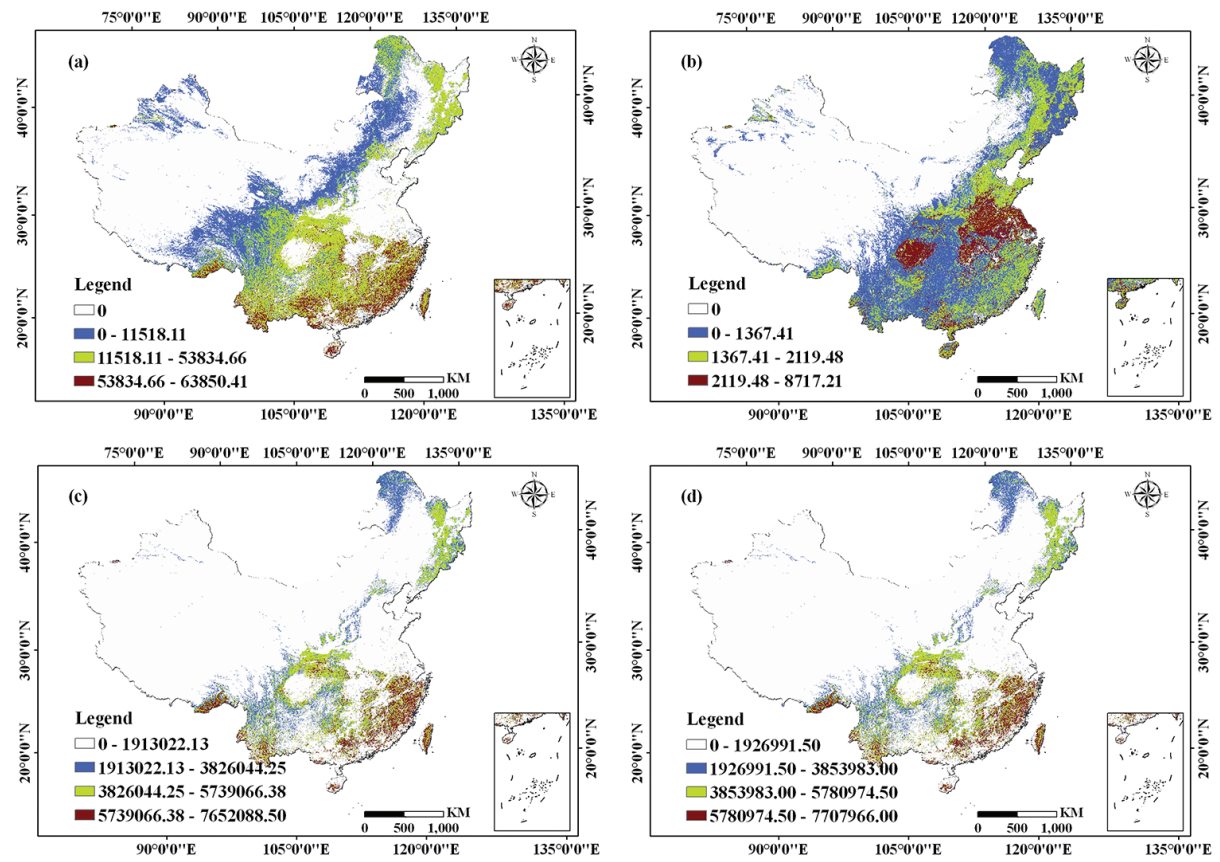

Figure I I. Spatial distribution of the ecosystem service functions of haze absorption by green space in China in $2007\left(10^{6} \mathrm{Kg}\right)(\mathbf{a}, \mathbf{b}, \mathbf{c}$ and $\mathbf{d}$ are the absorption of sulfur dioxide and nitrogen oxides, dust retention, and the total ecosystem service functions, respectively).
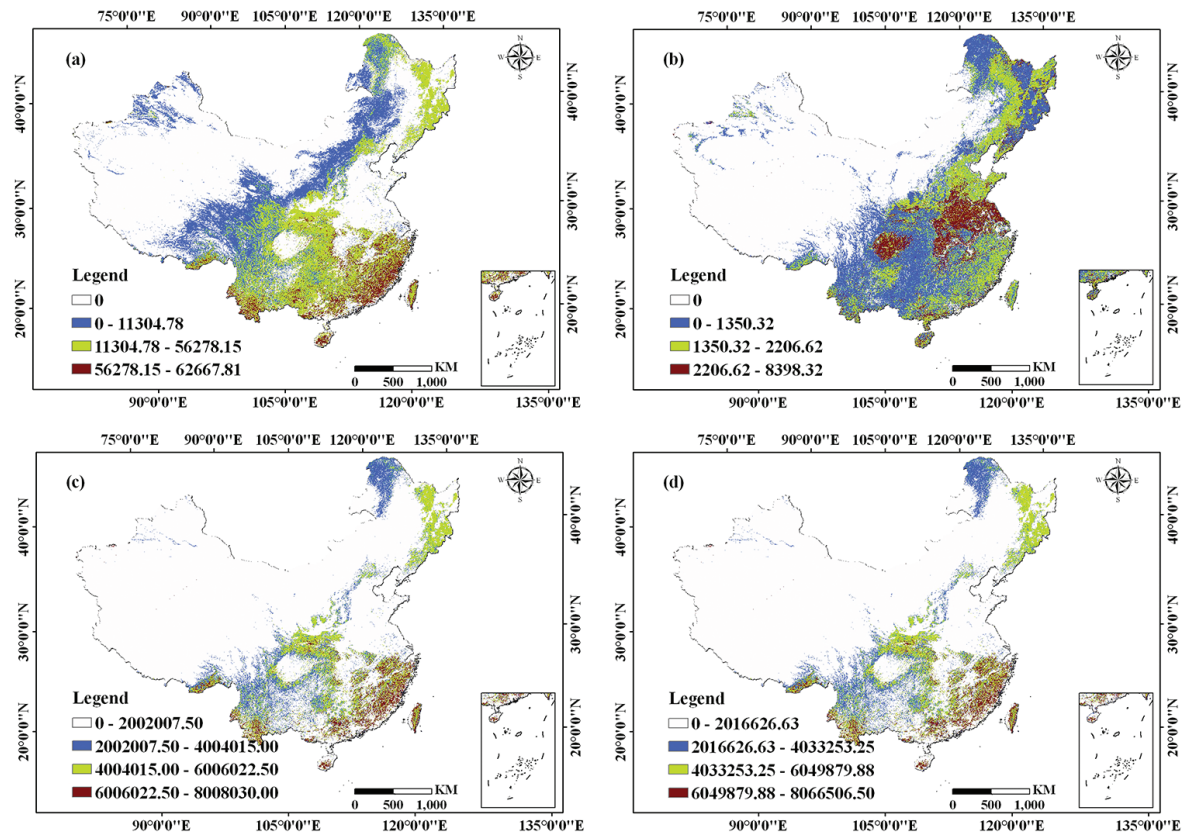

Figure I2. Spatial distribution of the ecosystem service functions of haze absorption by green space in China in $2010\left(10^{6} \mathrm{Kg}\right)(\mathbf{a}, \mathbf{b}, \mathbf{c}$ and $\mathbf{~ d}$ are the absorption of sulfur dioxide and nitrogen oxides, dust retention, and the total ecosystem service functions, respectively). 

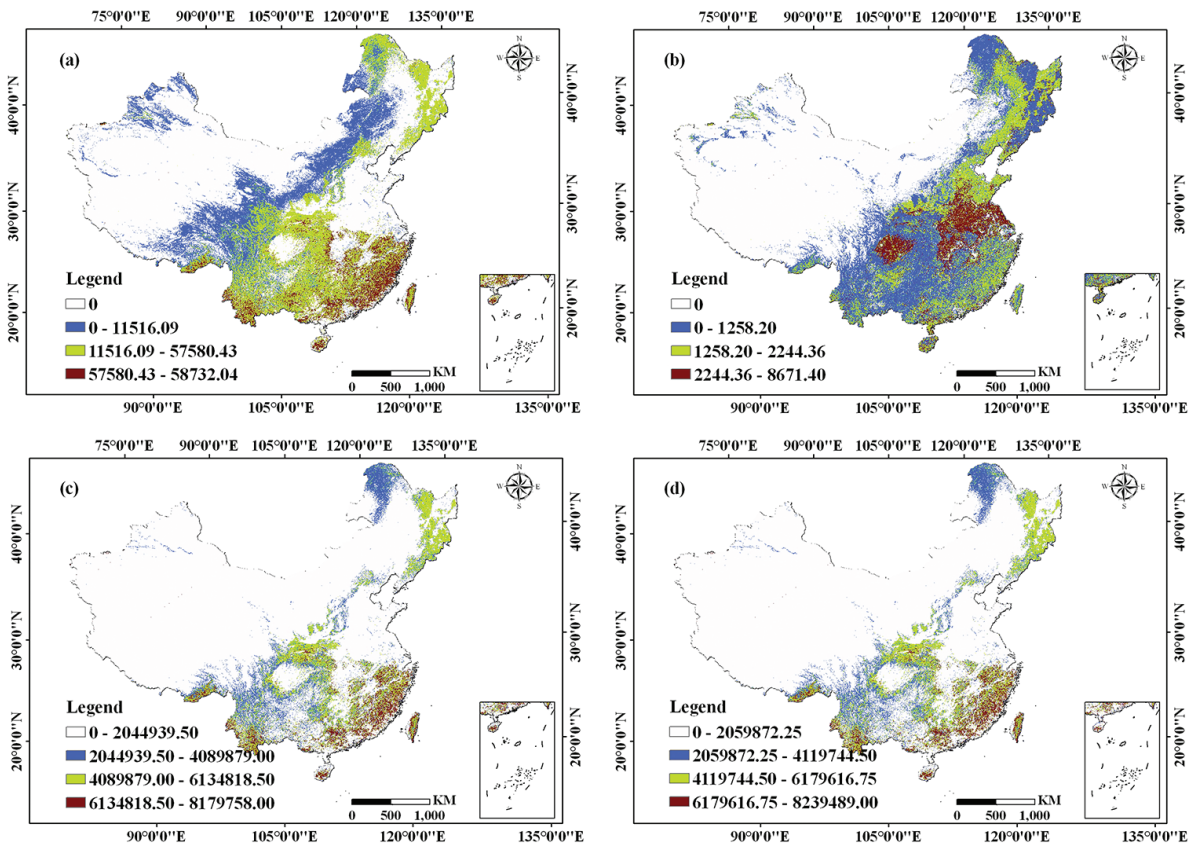

Figure 13. Spatial distribution of the ecosystem service functions of haze absorption by green space in China in $2013\left(10^{6} \mathrm{Kg}\right)$ (a, b, $\mathbf{c}$ and $\mathbf{d}$ are the absorption of sulfur dioxide and nitrogen oxides, dust retention, and the total ecosystem service functions, respectively).
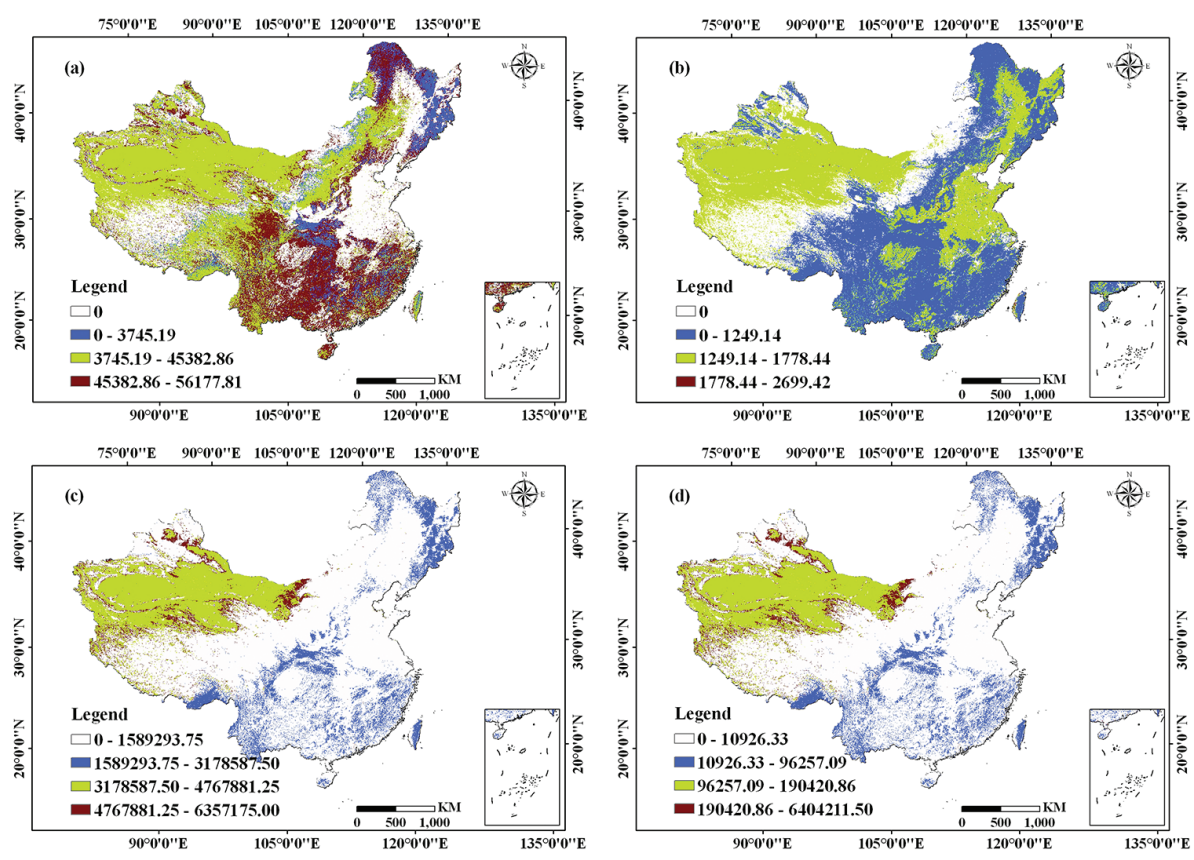

Figure 14. Spatial distribution of the ecosystem service functions of haze absorption by green space in China in $2016\left(10^{6} \mathrm{Kg}\right)(\mathbf{a}, \mathbf{b}, \mathbf{c}$ and $\mathbf{d}$ are the absorption of sulfur dioxide and nitrogen oxides, dust retention, and the total ecosystem service functions, respectively). 

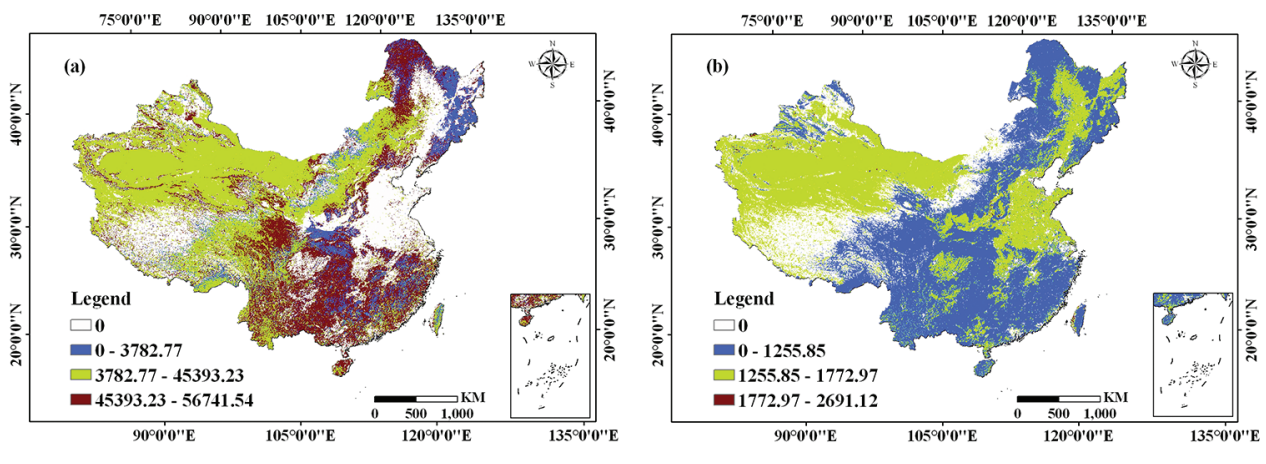

$75^{\circ} 0^{\prime} 0^{\prime \prime} \mathrm{E} \quad 90^{\circ} 0^{\prime} 0^{\prime \prime} \mathrm{E} \quad 105^{\circ} 0^{\prime} 0^{\prime \prime} \mathrm{E} \quad 120^{\circ} 0^{\prime} 0^{\prime \prime} \mathrm{E} \quad 135^{\circ} 0^{\prime} 0^{\prime \prime} \mathrm{E}$

$75^{\circ} 0^{\prime} 0^{\prime \prime} \mathrm{E} \quad 90^{\circ} 0^{\prime} 0^{\prime \prime} \mathrm{E} \quad 105^{\circ} 0^{\prime} 0^{\prime \prime E} \quad 120^{\circ} 0^{\prime} 0^{\prime \prime} \mathrm{E} \quad 135^{\circ} 0^{\prime} 0^{\prime \prime} \mathrm{E}$
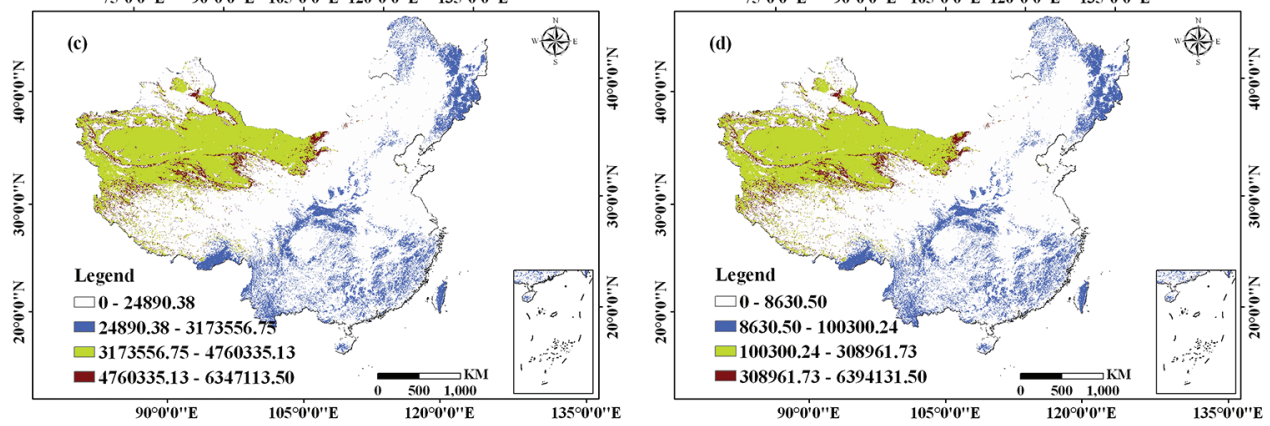

Figure 15. Spatial distribution of the ecosystem service functions of haze absorption by green space in China in $2018\left(10^{6} \mathrm{Kg}\right)(\mathbf{a}, \mathbf{b}, \mathbf{c}$ and $\mathbf{d}$ are the absorption of sulfur dioxide and nitrogen oxides, dust retention, and the total ecosystem service functions, respectively).

service function values were obviously different. However, the spatial distributions of the benchmark and corrected values also exhibited the same trend. In the same year, the spatial distribution of the ecosystem service functions of haze absorption by green space was very different, but in different years, the difference in the spatial distribution of the ecosystem service functions of haze absorption by green space exhibited little difference.

\section{Comparison of the ecosystem service functions of haze absorption by green space in different zones}

Figures 16-22 (benchmark values) show that the spatial distribution of ecosystem service functions and the proportion of haze absorption by green space differed in different provinces in China. Overall, different ecosystem service functions exhibited different spatial distributions in the same year or between different years. Some spatial distributions were quite different; others were more similar.

The ecosystem service functions of the absorption of $\mathrm{SO}_{2}$ (Fig. 16a) and $\mathrm{NO}_{\mathrm{x}}$ (Fig. 16b) by green space were 2.74-30586.00 million $\mathrm{Kg}$ and 0.16-1207.44 million $\mathrm{Kg}$ in 2001, respectively. The maximum and minimum values were primarily distributed in Xinjiang and in Shanghai, accounting for 17.88\%, 0.02\%, 10.98\% and 

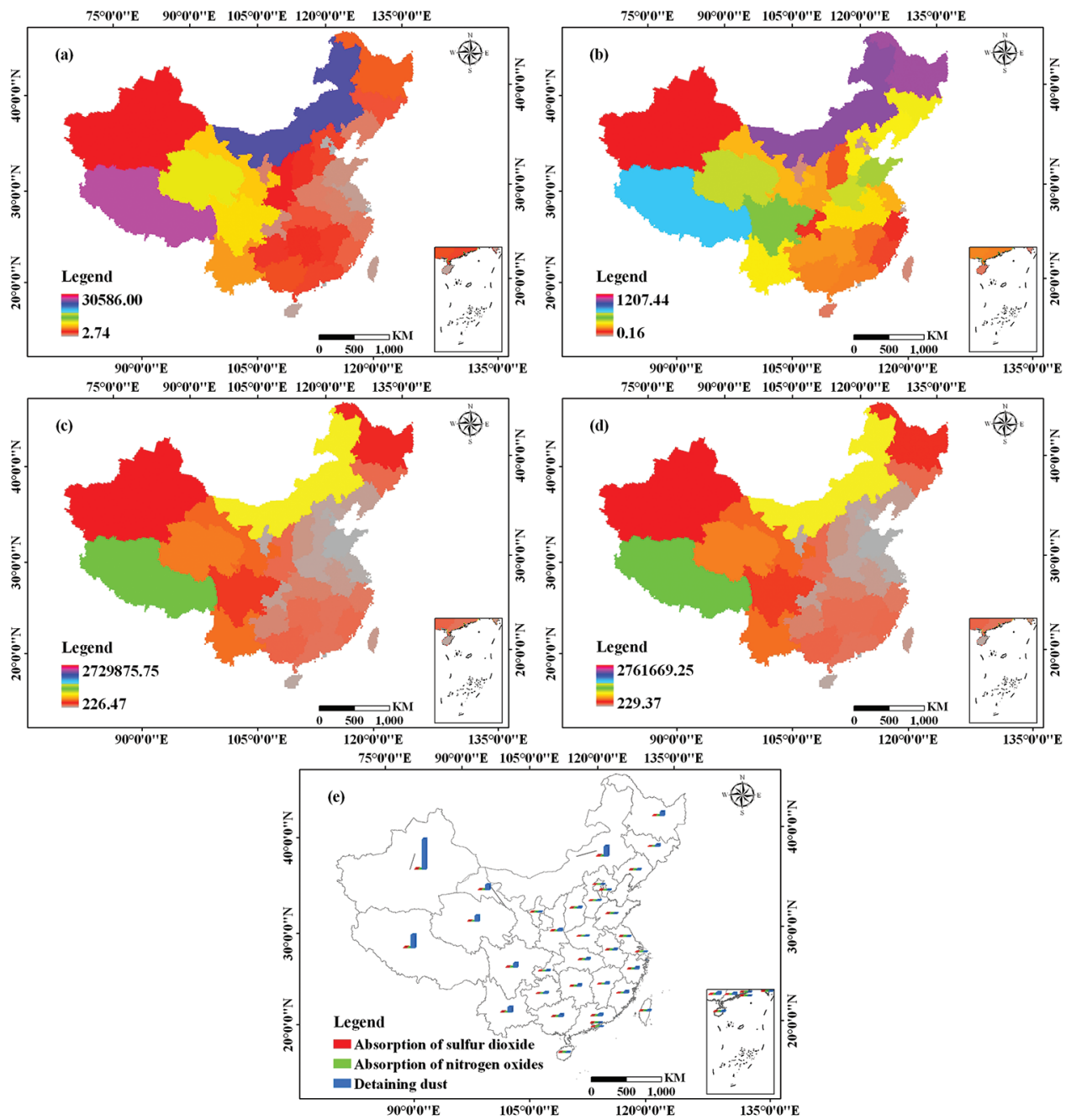

Figure 16. Spatial distributions of the ecosystem service functions of haze absorption by green space in different regions of China in $2001\left(10^{6} \mathrm{Kg}\right)(\mathbf{a}, \mathbf{b}, \mathbf{c}, \mathbf{d}$ and $\mathbf{e}$ are the absorption of sulfur dioxide and nitrogen oxides, dust retention, the total ecosystem service functions and the percent contribution of different ecosystem service functions to haze absorption in different zones, respectively).

$0.14 \%$ of the total regional functions, respectively, The spatial distribution of these functions in 2001 was consistent with the absorption of $\mathrm{SO}_{2}$ and $\mathrm{NO}_{\mathrm{x}}$ in Fig. 17a and $17 \mathrm{~b}$ but different from those shown in Figures 18-22a and 18-22b, which represent values for 2007, 2010, 2013, 2016 and 2018, respectively. Additionally, the functions of dust retention and total ecosystem services (Fig. 16c, d) for green space were 226.47-2729875.75 million $\mathrm{Kg}$ and 229.37-2761669.25 million $\mathrm{Kg}$ in 2001, respectively, and the maximum and minimum values for these services were primarily 

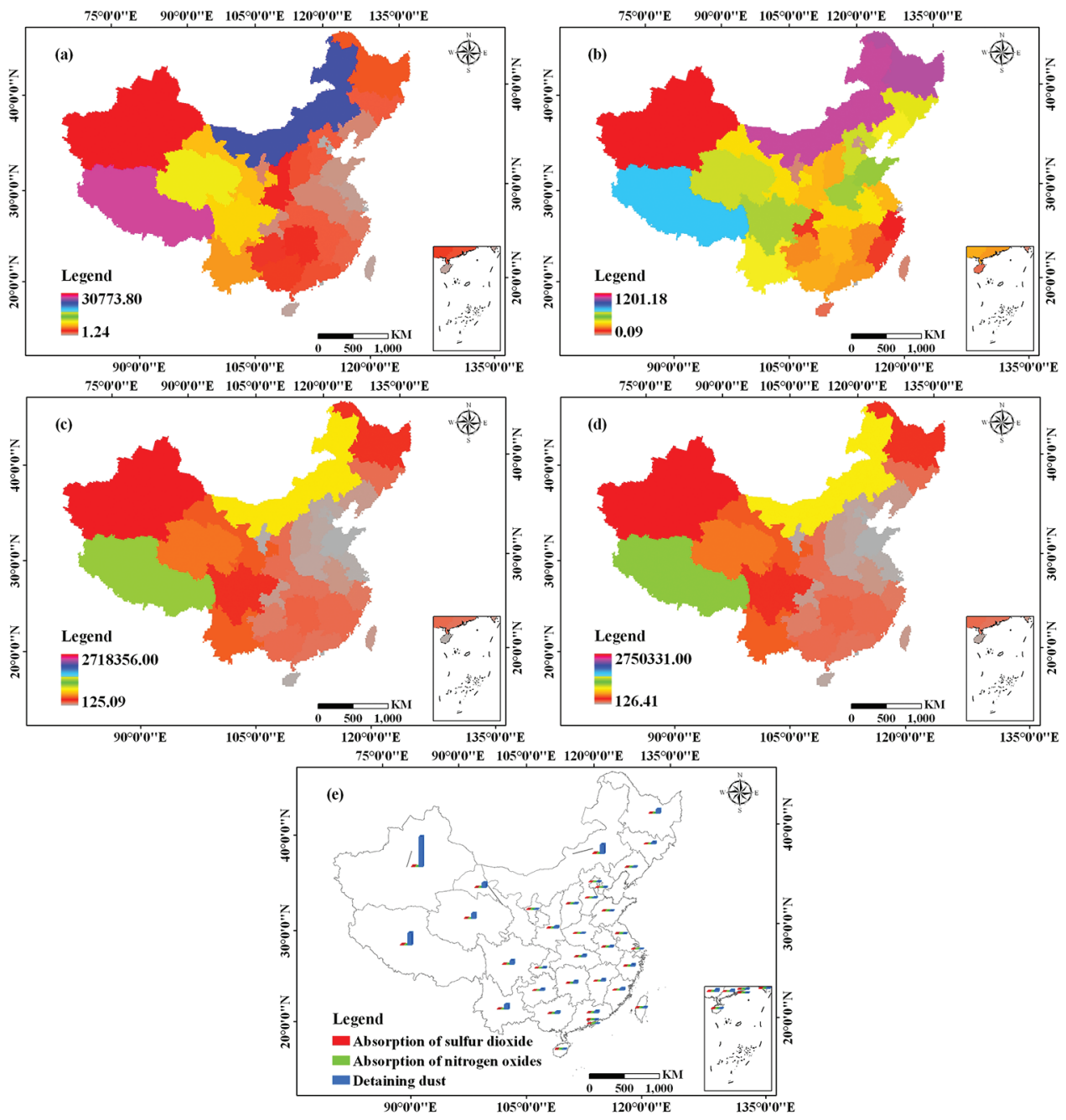

Figure 17. Spatial distribution of the ecosystem service functions of haze absorption by green space in different regions of China in $2004\left(10^{6} \mathrm{Kg}\right)(\mathbf{a}, \mathbf{b}, \mathbf{c}, \mathbf{d}$ and $\mathbf{e}$ are the absorption of sulfur dioxide and nitrogen oxides, dust retention, the total ecosystem service functions and the percent contribution of different ecosystem service functions to haze absorption in different zones, respectively).

in Xinjiang and Shanghai, accounting for 30.97\%, 0.01\%, 30.70\% and $0.01 \%$ of the regional totals, which is consistent with the spatial distribution of dust retention and total ecosystem services in Figures 17-22c and Figures 17-22d in 2004, 2007, 2010, 2013, 2016 and 2018, respectively. Most of the ecosystem service functions of haze absorption by green space were primarily from dust retention, which accounted for approximately $96 \%$ of the total. The functions for $\mathrm{SO}_{2}$ absorption were the next highest, accounting for approximately $3 \%$ of the total, while $\mathrm{NO}_{\mathrm{x}}$ accounted for approximately 

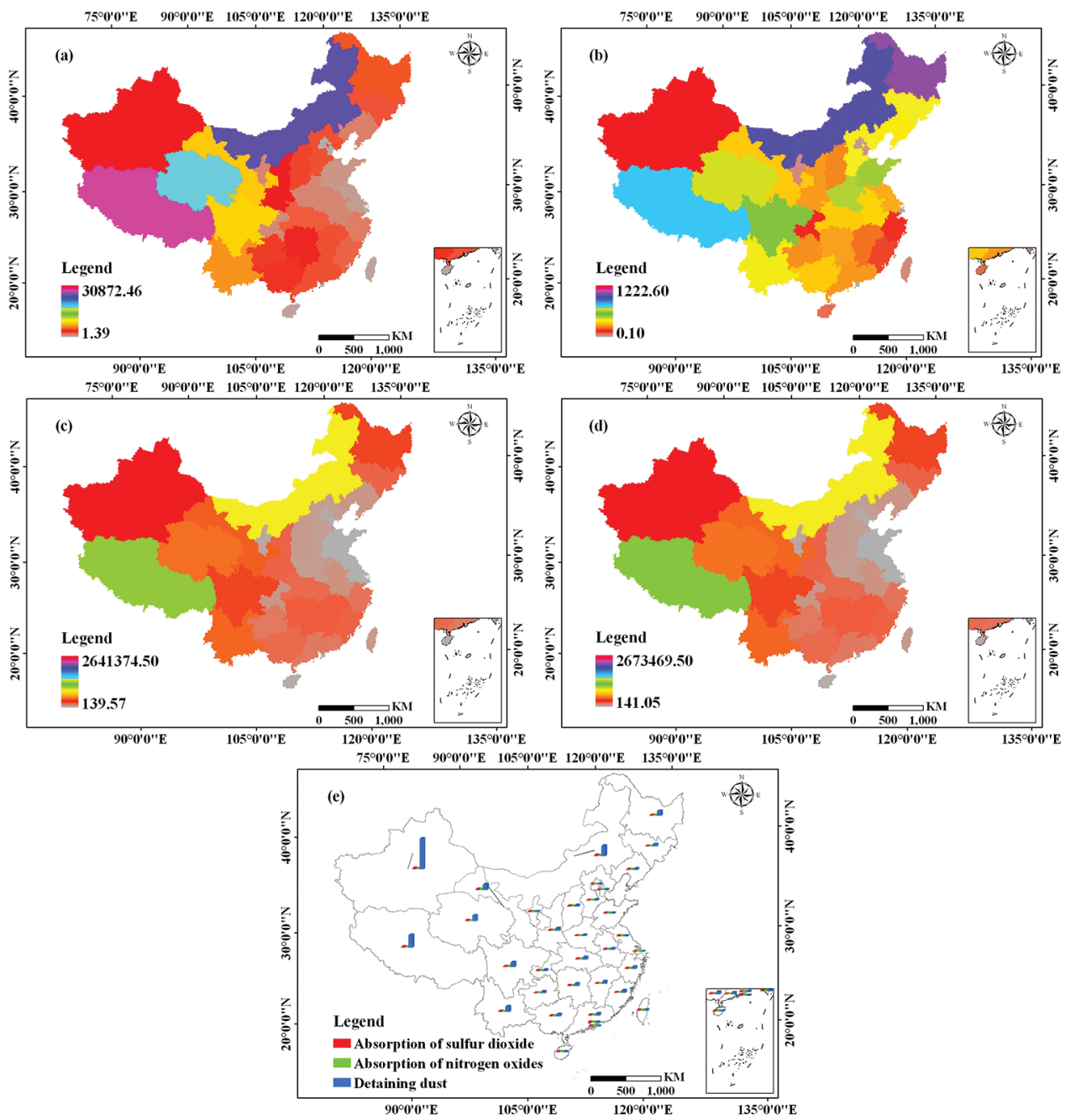

Figure 18. Spatial distribution of the ecosystem service functions of haze absorption by green space in different regions of China in $2007\left(10^{6} \mathrm{Kg}\right)(\mathbf{a}, \mathbf{b}, \mathbf{c}, \mathbf{d}$ and $\mathbf{e}$ are the absorption of sulfur dioxide and nitrogen oxides, dust retention, the total ecosystem service functions and the percent contribution of different ecosystem service functions to haze absorption in different zones, respectively).

$1 \%$ (Fig. 16e) in 2001, which is consistent with the percentages of the ecosystem service functions of haze absorption by green space in Figures 17-22e in 2004, 2007, 2010, 2013, 2016 and 2018, respectively.

The ecosystem service functions of the absorption of $\mathrm{SO}_{2}$ (Fig. 18a) by green space were 1.39-30872.46 million $\mathrm{Kg}$ in 2007, and the maximum and minimum values were mainly distributed in Xinjiang and Shanghai, accounting for $18.25 \%$ and $0.02 \%$ of the regional totals, respectively. This distribution is in accordance with the spatial 

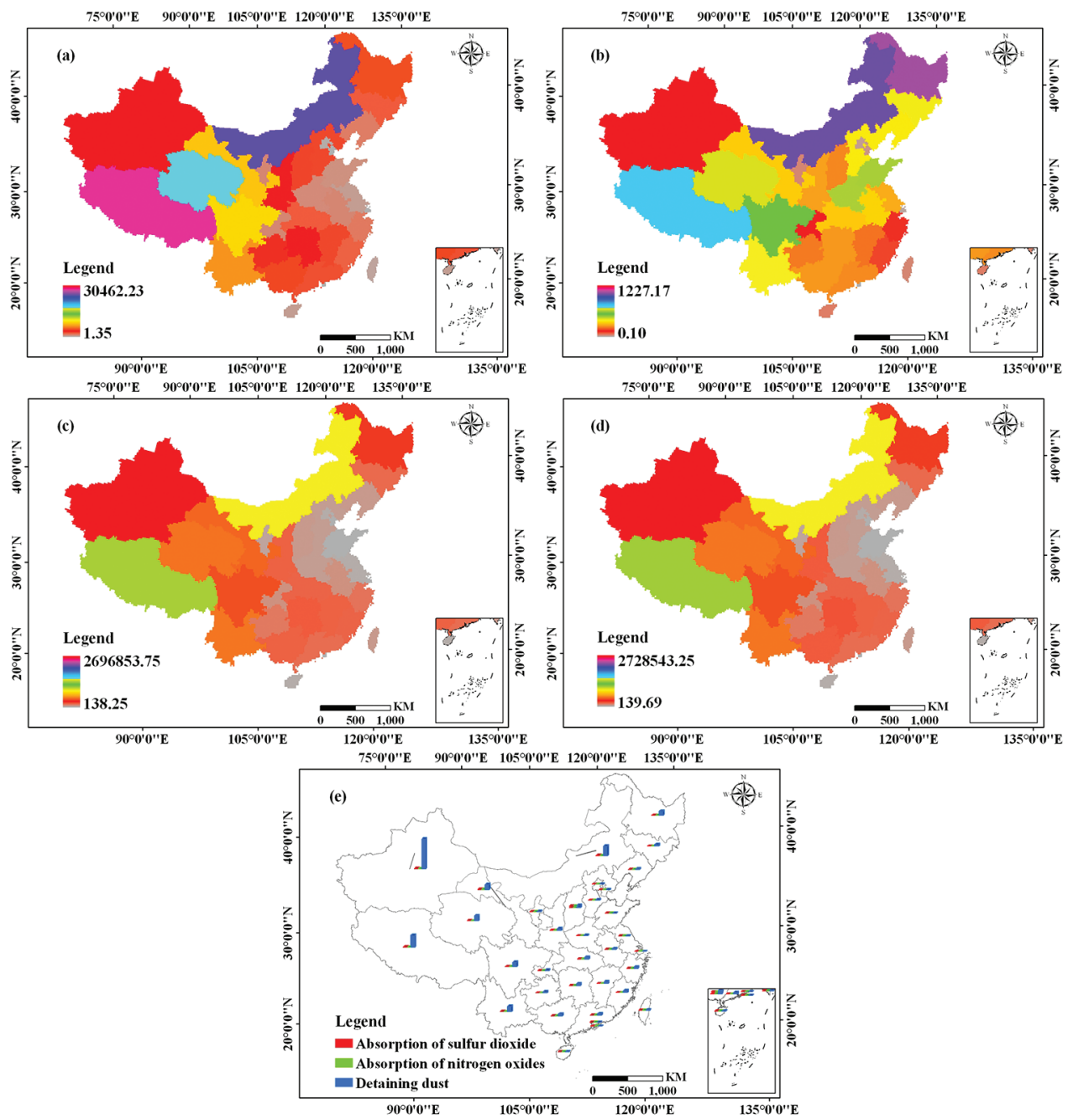

Figure 19. Spatial distribution of the ecosystem service functions of haze absorption by green space in different regions of China in $2010\left(10^{6} \mathrm{Kg}\right)(\mathbf{a}, \mathbf{b}, \mathbf{c}, \mathbf{d}$ and $\mathbf{e}$ are the absorption of sulfur dioxide and nitrogen oxides, dust retention, the total ecosystem service functions and the percent contribution of different ecosystem service functions to haze absorption in different zones, respectively).

distribution of the absorption of $\mathrm{SO}_{2}$ in Figures 19-20a in 2010 and 2013, respectively. The ecosystem service functions of the absorption of $\mathrm{NO}_{\mathrm{x}}$ (Fig. 18b) by green space was $0.10-1222.60$ million $\mathrm{Kg}$ in 2007 , and the maximum and minimum values were mainly in Xinjiang and Shanghai, accounting for $10.87 \%$ and $0.13 \%$ of the regional totals, respectively. This distribution is consistent with the spatial distribution of the absorption of $\mathrm{NO}_{\mathrm{x}}$ in Figures 16b, 19b and Figures 21-22b in 2001, 2010, 2016 and 2018, respectively. 

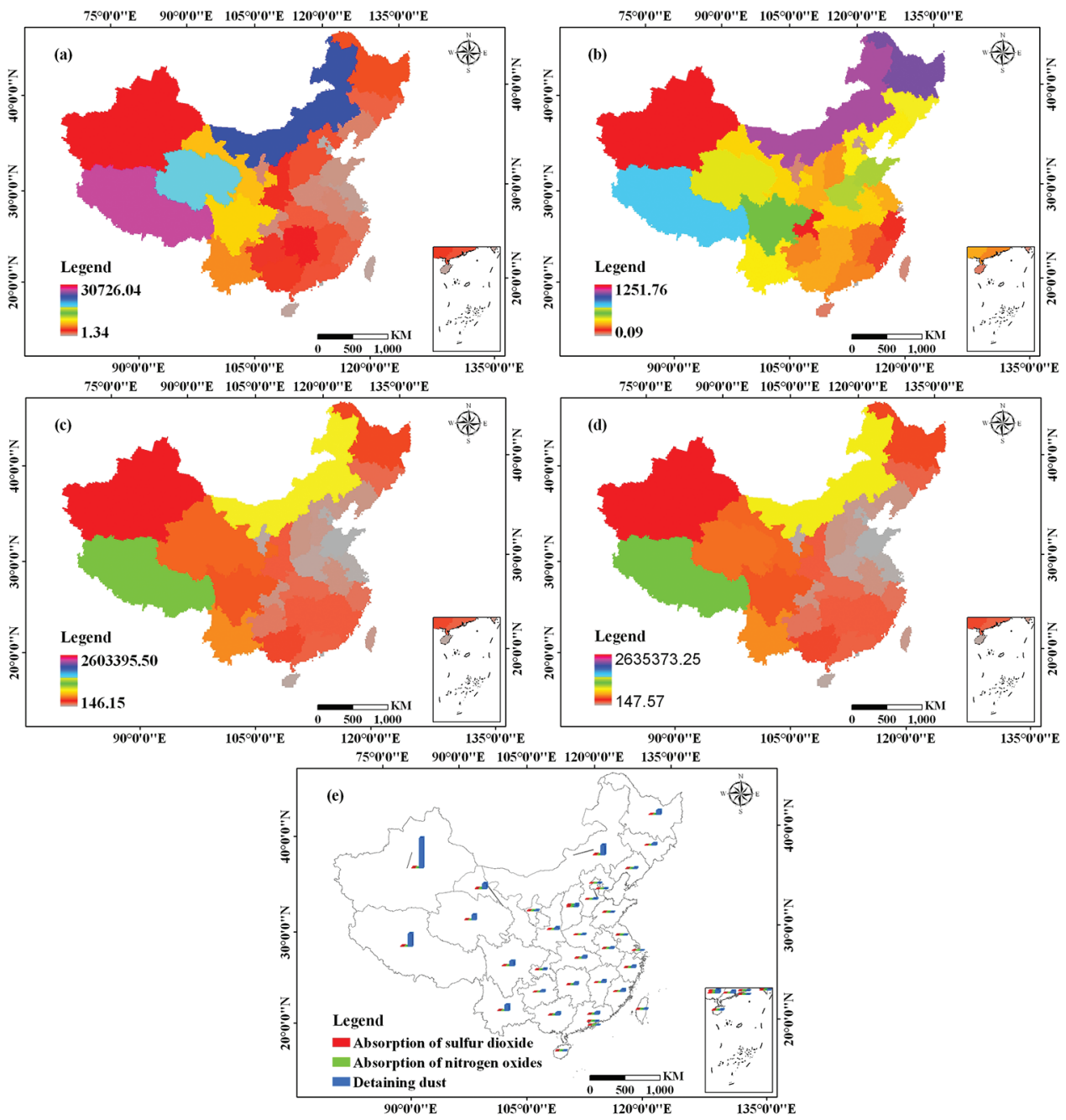

Figure 20. Spatial distribution of the ecosystem service functions of haze absorption by green space in different regions of China in $2013\left(10^{6} \mathrm{Kg}\right)(\mathbf{a}, \mathbf{b}, \mathbf{c}, \mathbf{d}$ and $\mathbf{e}$ are the absorption of sulfur dioxide and nitrogen oxides, dust retention, the total ecosystem service functions and the percent contribution of different ecosystem service functions to haze absorption in different zones, respectively).

As shown in Figures 23-29 (corrected values), the ecosystem service functions of the absorption of $\mathrm{SO}_{2}$ (Fig. 23a) by green space were 0.73-11,739.97 million $\mathrm{Kg}$ in 2001. The maximum and minimum values were primarily distributed in Yunnan and Shanghai, accounting for $8.62 \%$ and $0.03 \%$ of the total regional values, respectively. The spatial distribution of this value in 2001 was inconsistent with the absorption of $\mathrm{SO}_{2}$ in Figures 24-29a, which represent values for 2004, 2007, 2010, 2013, 2016 and 2018, respectively. The ecosystem service functions of the absorption of $\mathrm{NO}_{\mathrm{x}}$ 

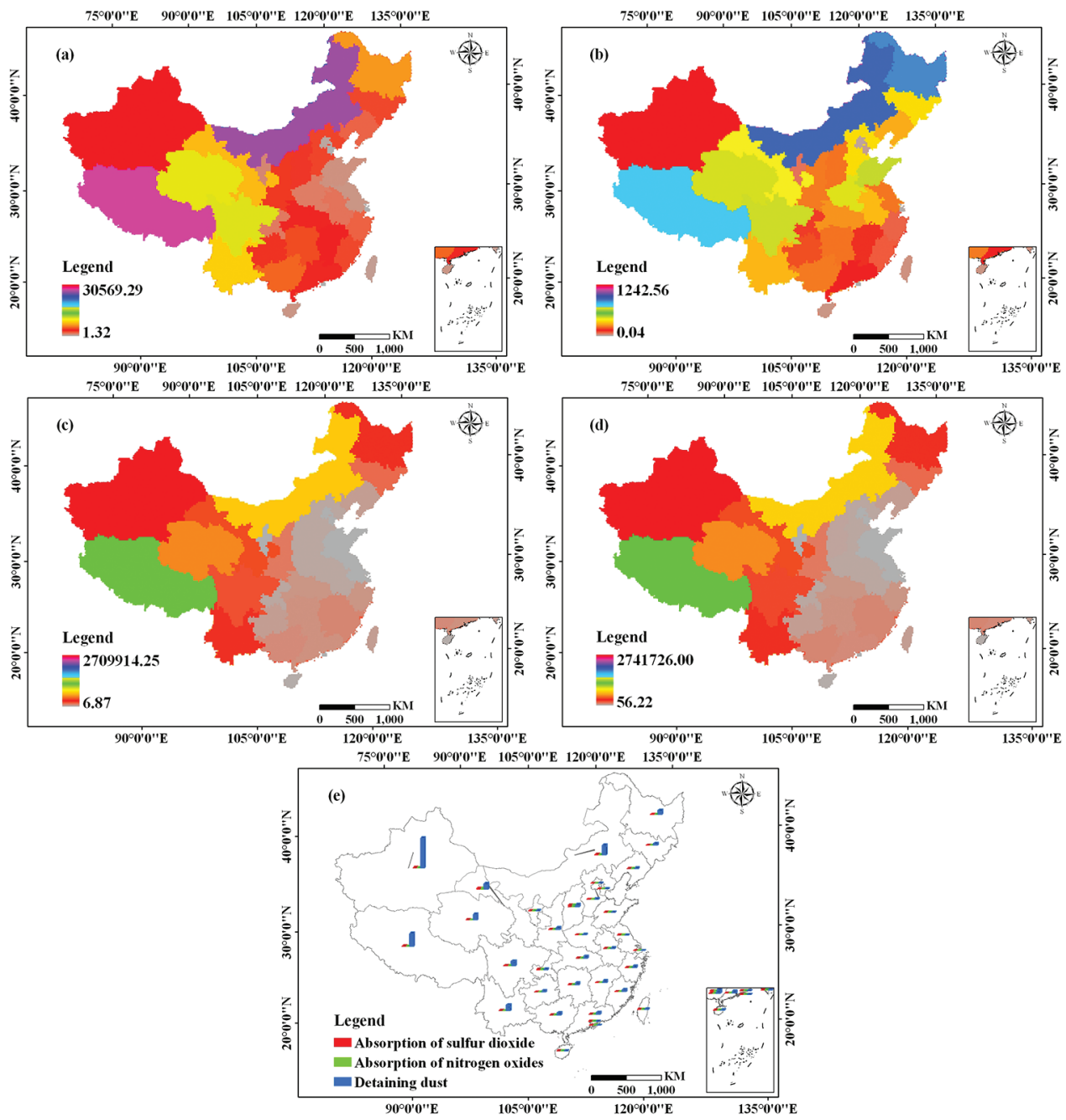

Figure 2 I. Spatial distribution of the ecosystem service functions of haze absorption by green space in different regions of China in $2016\left(10^{6} \mathrm{Kg}\right)(\mathbf{a}, \mathbf{b}, \mathbf{c}, \mathbf{d}$ and $\mathbf{e}$ are the absorption of sulfur dioxide and nitrogen oxides, dust retention, the total ecosystem service functions and the percent contribution of different ecosystem service functions to haze absorption in different zones, respectively).

(Fig. 23b) by green space were 0.04-1206.36 million $\mathrm{Kg}$ in 2001, and the maximum and minimum values were mainly distributed in Heilongjiang and Ningxia, accounting for $10.43 \%$ and $0.11 \%$ of the regional totals, respectively, which is consistent with the spatial distribution of absorption of $\mathrm{NO}_{\mathrm{X}}$ in Figures 24-27b in 2004, 2007, 2010 and 2013, respectively, but inconsistent with Figures 28-29b in 2016 and 2018, respectively. The ecosystem service functions of the absorption of dust retention (Fig. 23c) and total ecosystem services (Fig. 23d) by green space were 58.62-930,837.56 million 

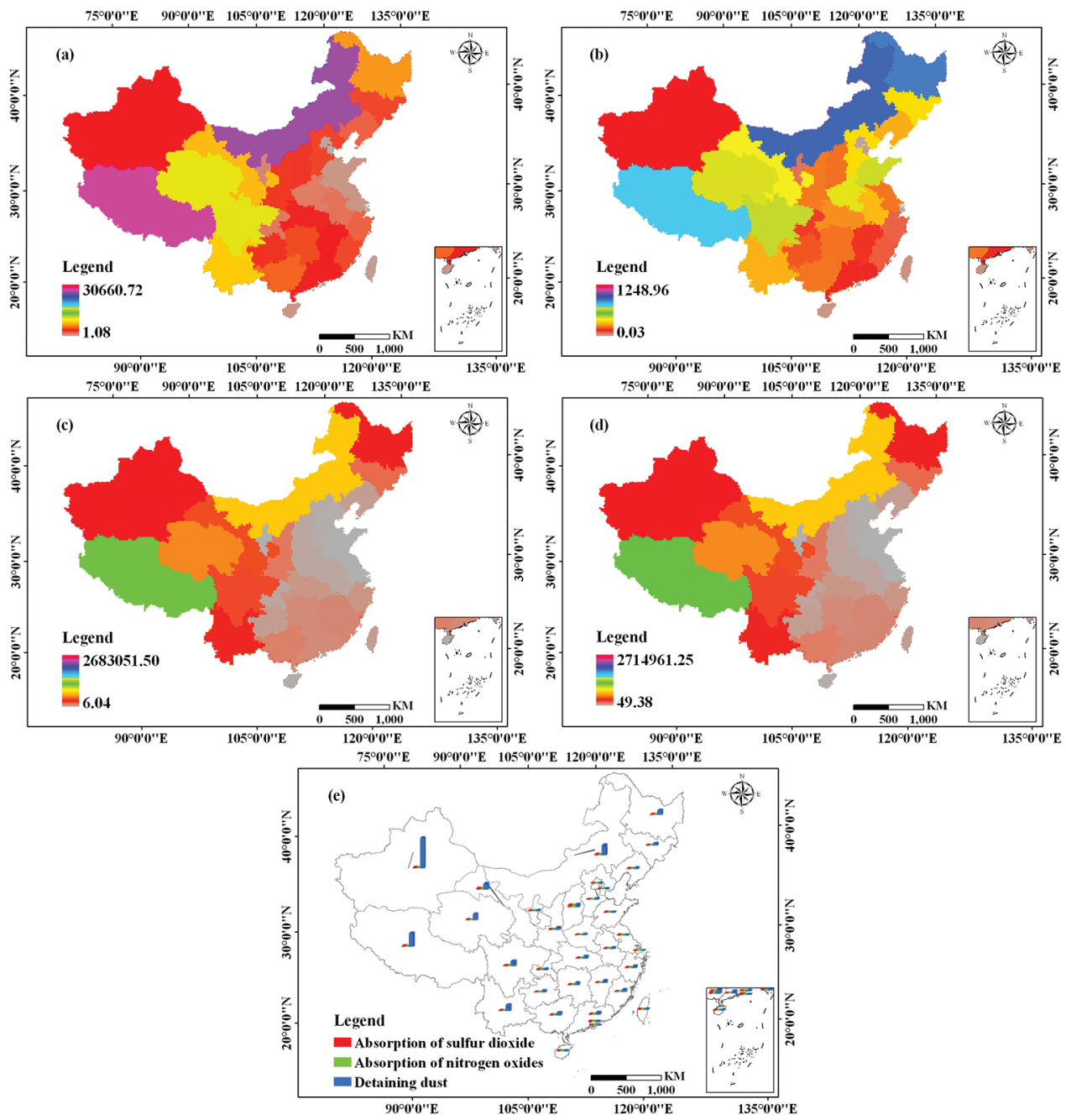

Figure 22. Spatial distribution of the ecosystem service functions of haze absorption by green space in different regions of China in $2018\left(10^{6} \mathrm{Kg}\right)(\mathbf{a}, \mathbf{b}, \mathbf{c}, \mathbf{d}$ and $\mathbf{e}$ are the absorption of sulfur dioxide and nitrogen oxides, dust retention, the total ecosystem service functions and the percent contribution of different ecosystem service functions to haze absorption in different zones, respectively).

$\mathrm{Kg}$ and 59.39-943211.69 million $\mathrm{Kg}$ in 2001. The maximum and minimum values were primarily distributed in Yunnan and Shanghai, accounting for $12.29 \%, 0.01 \%$, $12.21 \%$ and $0.01 \%$ of the total regional functions, respectively. The spatial distribution of this function in 2001 was consistent with the absorption of dust retention and total ecosystem services in Figures 24-27c and 24-27d, which represent functions for 2004, 2007, 2010 and 2013, respectively, but inconsistent with the Figures 28-29c and 28-29d in 2016 and 2018, respectively. 

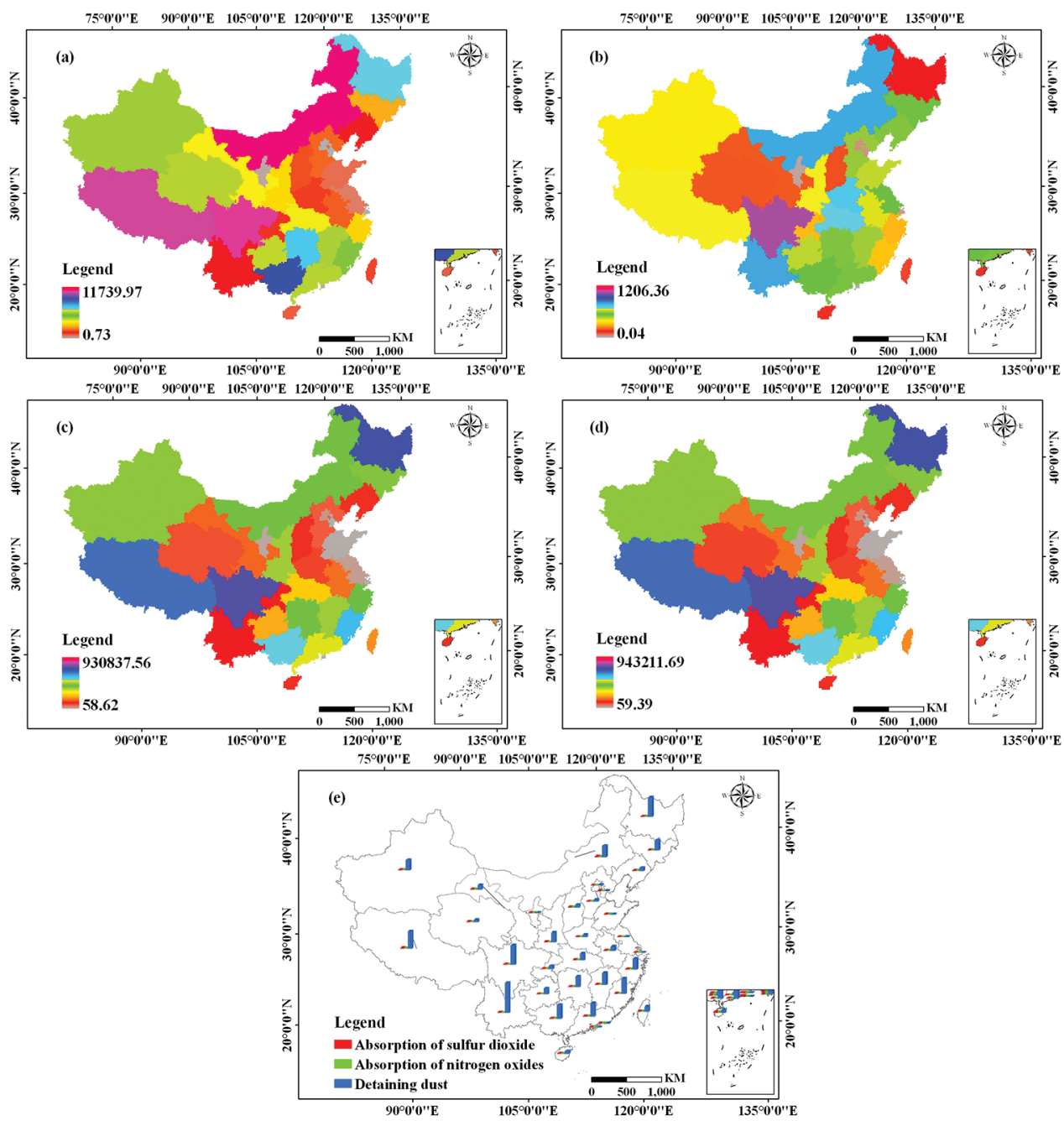

Figure 23. Spatial distributions of the ecosystem service functions of haze absorption by green space in different regions of China in $2001\left(10^{6} \mathrm{Kg}\right)(\mathbf{a}, \mathbf{b}, \mathbf{c}, \mathbf{d}$ and $\mathbf{e}$ are the absorption of sulfur dioxide and nitrogen oxides, dust retention, the total ecosystem service functions and the percent contribution of different ecosystem service functions to haze absorption in different zones, respectively).

The results show that there was a great difference in the spatial distributions of the benchmark and corrected values of haze absorption by green space in different provinces in China, and the maximum and minimum of ecosystem service functions were obviously different. However, the spatial distributions of the benchmark and corrected values also exhibited the same trend. In the same year, the spatial distribution of the ecosystem service functions of haze absorption by green space was very different in different province, but in different years, the difference in the spatial distribution of the 

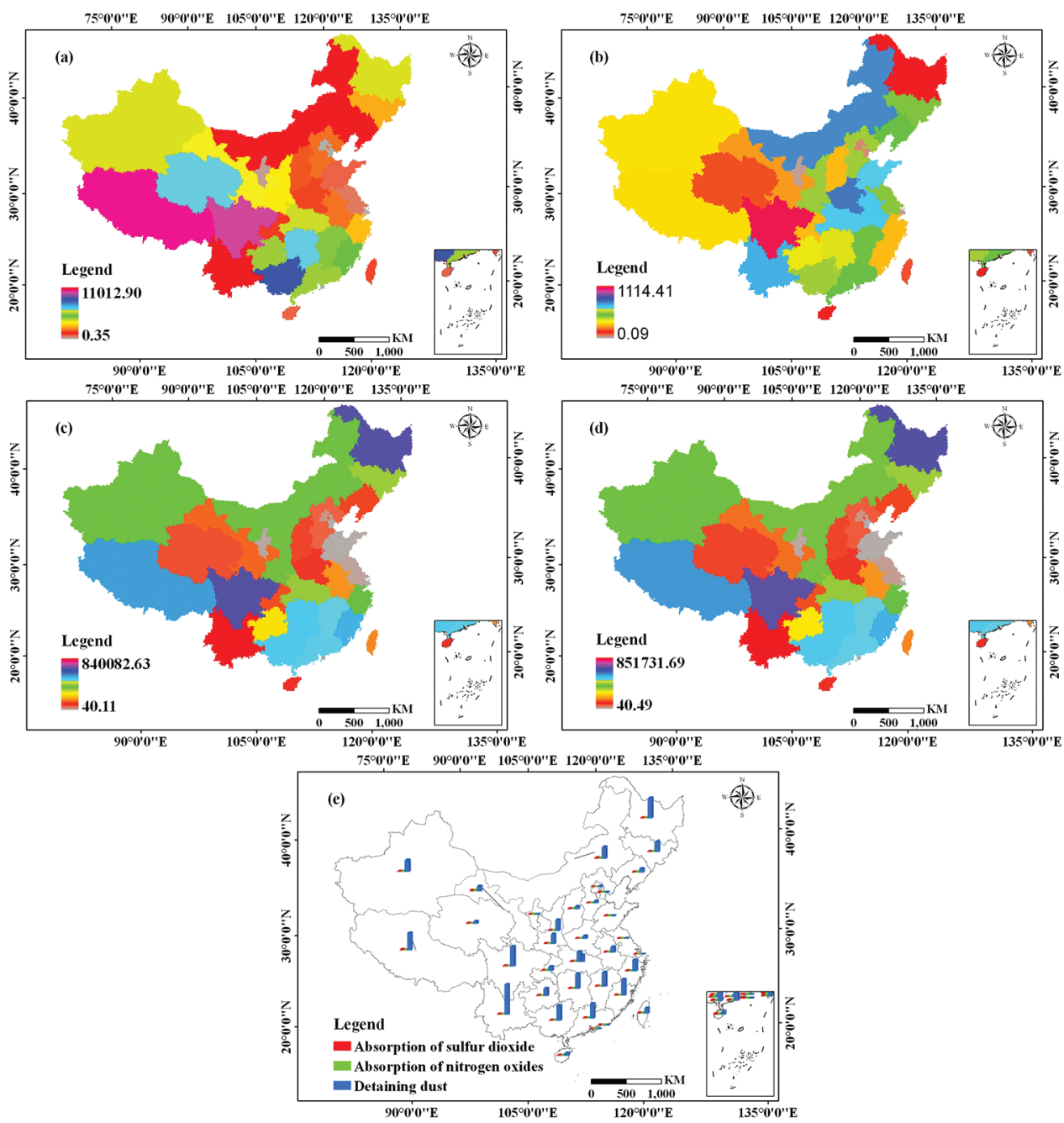

Figure 24. Spatial distributions of the ecosystem service functions of haze absorption by green space in different regions of China in $2004\left(10^{6} \mathrm{Kg}\right)(\mathbf{a}, \mathbf{b}, \mathbf{c}, \mathbf{d}$ and $\mathbf{e}$ are the absorption of sulfur dioxide and nitrogen oxides, dust retention, the total ecosystem service functions and the percent contribution of different ecosystem service functions to haze absorption in different zones, respectively).

ecosystem service functions of haze absorption by green space exhibited little difference in different provinces.

\section{Sensitivity analysis of the ecosystem service function coefficients for haze absorp- tion by green space}

The coefficient of sensitivity of the ecosystem service functions for different green space types was generally quite different from 2001-2018 (Table 4). The sensitivity coef- 

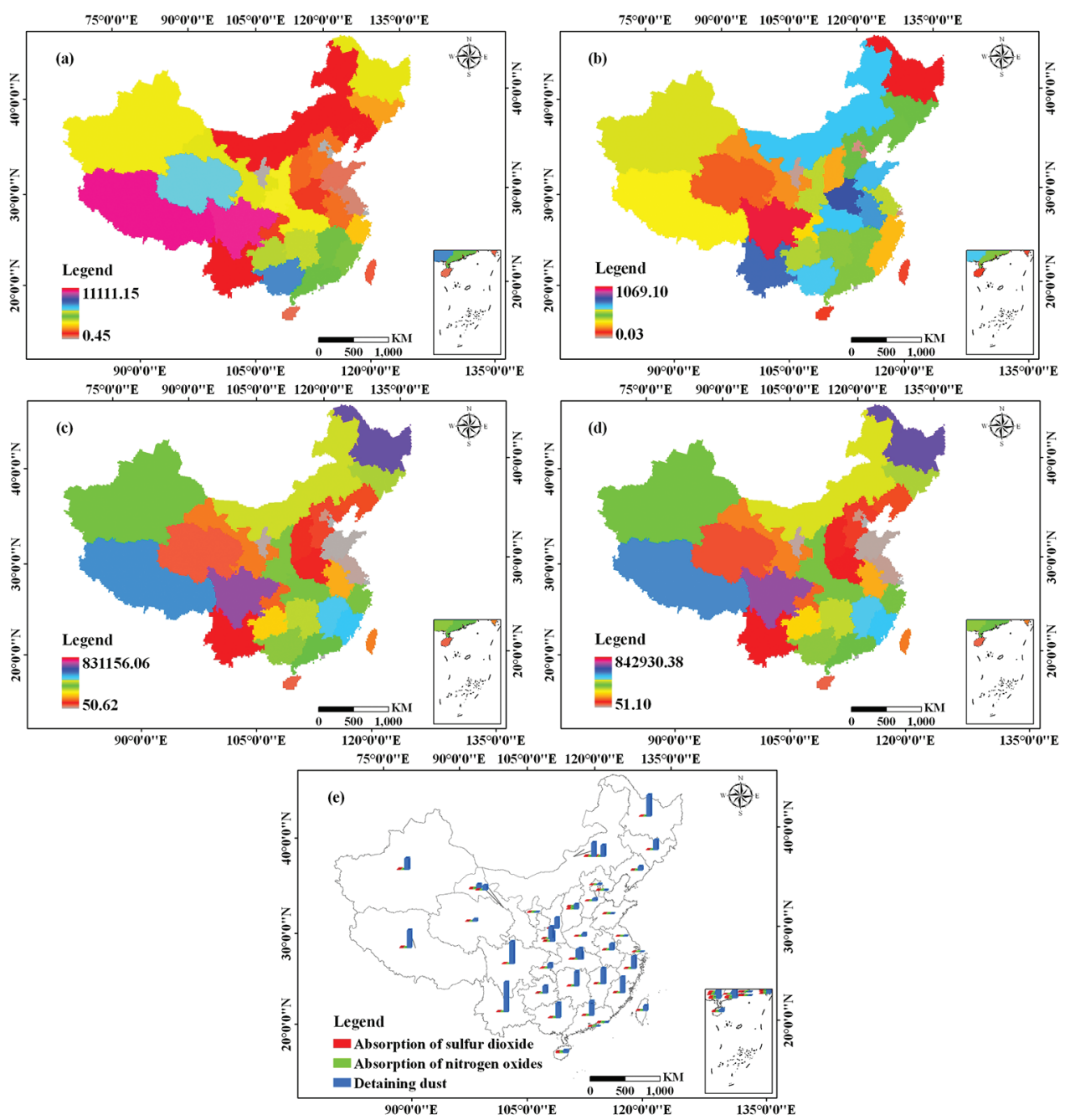

Figure 25. Spatial distributions of the ecosystem service functions of haze absorption by green space in different regions of China in $2007\left(10^{6} \mathrm{Kg}\right)(\mathbf{a}, \mathbf{b}, \mathbf{c}, \mathbf{d}$ and $\mathbf{e}$ are the absorption of sulfur dioxide and nitrogen oxides, dust retention, the total ecosystem service functions and the percent contribution of different ecosystem service functions to haze absorption in different zones, respectively).

ficients for forest cover were elastic, while those of arable land and grass land were inelastic. The coefficients of sensitivity for forest cover were highest due to the large area of this cover type and the high ecosystem service functions coefficient for haze absorption by green space. The coefficients of sensitivity were 0.9868 in 2001, 2004 and 2007, 0.9875 in 2010, 0.9877 in 2013, 0.9817 in 2016 and 2018, respectively, and the change rates were $\pm 49.3424 \%, \pm 49.3398 \%, \pm 49.3405 \%, \pm 49.3767 \%, \pm$ $49.3832 \%, \pm 49.0861 \%$ and $\pm 49.0842 \%$, respectively. The coefficients of sensitivity for grass land were relatively small, with values of 0.0115 in 2001, 0.0113 in 2004, 0.0114 in 2007, 0.0108 in 2010, 0.0105 in 2013, 0.0167 in 2016 and 2018, and the 

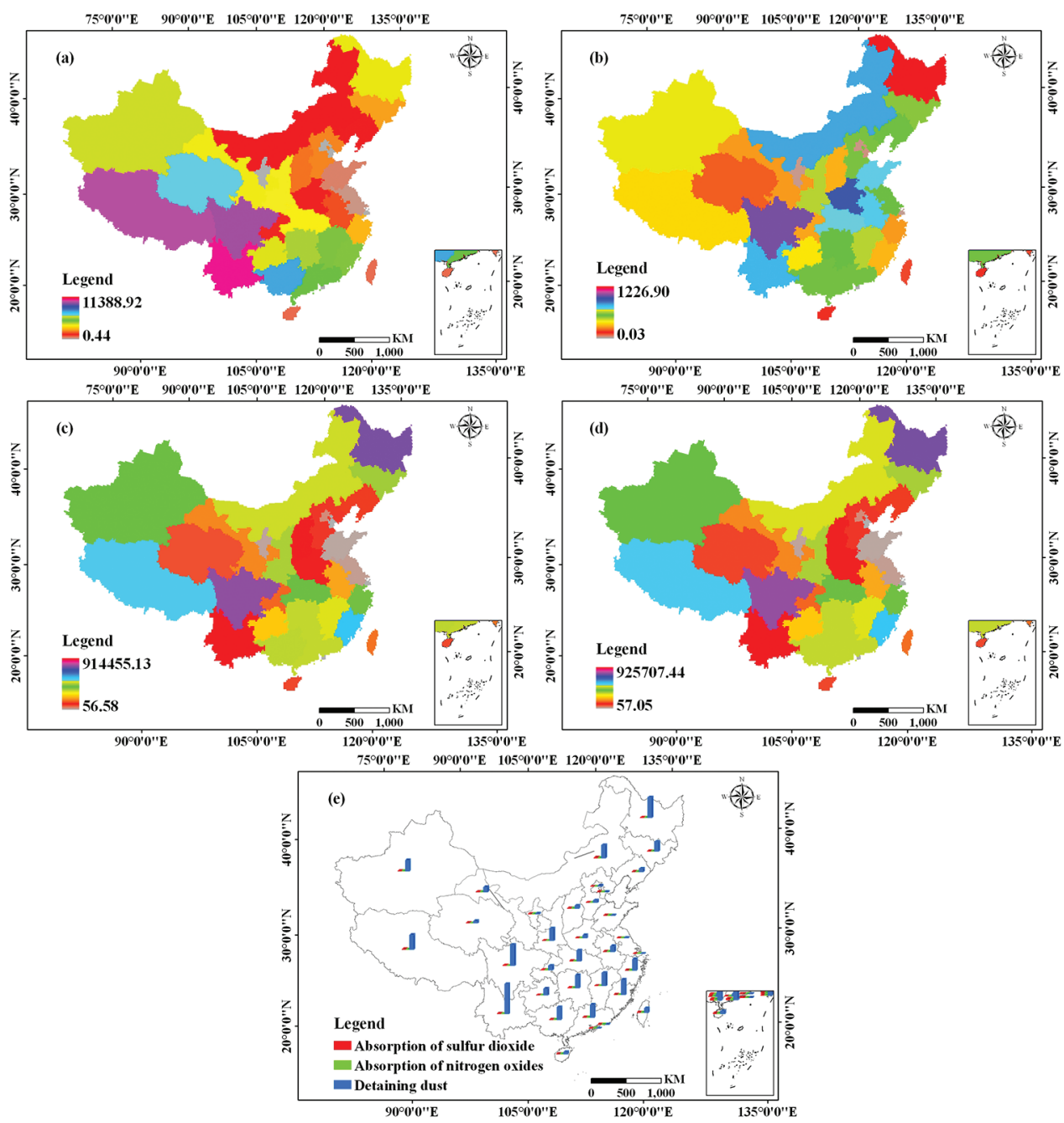

Figure 26. Spatial distributions of the ecosystem service functions of haze absorption by green space in different regions of China in $2010\left(10^{6} \mathrm{Kg}\right)(\mathbf{a}, \mathbf{b}, \mathbf{c}, \mathbf{d}$ and $\mathbf{e}$ are the absorption of sulfur dioxide and nitrogen oxides, dust retention, the total ecosystem service functions and the percent contribution of different ecosystem service functions to haze absorption in different zones, respectively).

change rates for grass land were $\pm 0.5733 \%, \pm 0.5635 \%, \pm 0.5702 \%, \pm 0.5384 \%, \pm$ $0.5268, \pm 0.8365$ and $\pm 0.8374 \%$, respectively. The coefficients of sensitivity for arable land were the smallest due to the low ecosystem service functions coefficient of haze absorption by green space. The values of this coefficient were 0.0017 in 2001 , 0.0019 in 2004, 0.0018 in 2007, 0.0017 in 2010, 0.0018 in 2013, 0.0015 in 2016, and 0.0016 in 2018 , and the change rates were $\pm 0.0843 \%, \pm 0.0967 \%, \pm 0.0893 \%$, $\pm 0.0850 \%, \pm 0.0901 \%, \pm 0.0774 \%$ and $\pm 0.0783 \%$, respectively. 

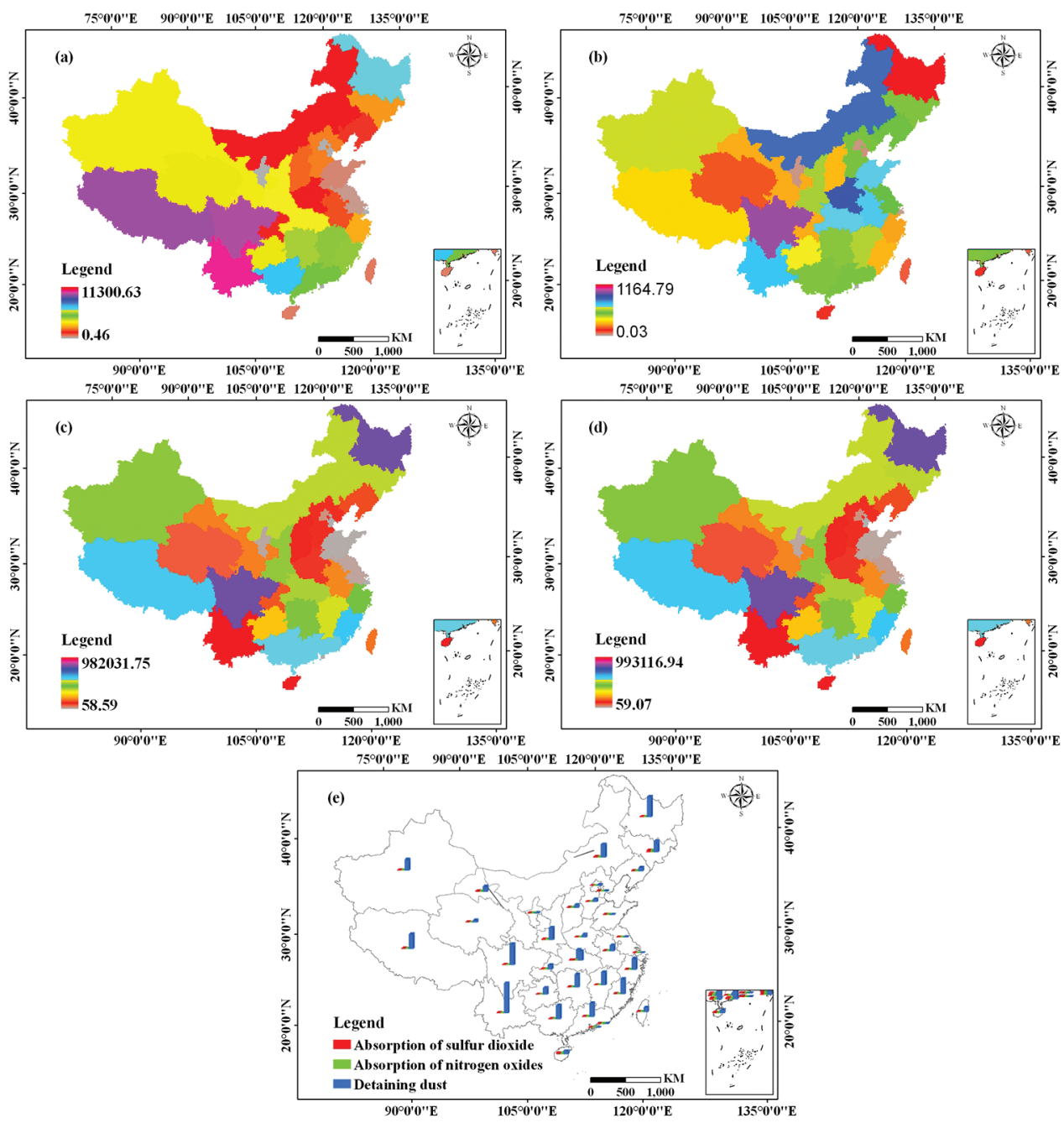

Figure 27. Spatial distributions of the ecosystem service functions of haze absorption by green space in different regions of China in $2013\left(10^{6} \mathrm{Kg}\right)(\mathbf{a}, \mathbf{b}, \mathbf{c}, \mathbf{d}$ and $\mathbf{e}$ are the absorption of sulfur dioxide and nitrogen oxides, dust retention, the total ecosystem service functions and the percent contribution of different ecosystem service functions to haze absorption in different zones, respectively).

\section{Relationship between landscape patterns and the ecosystem service functions of haze absorption by green space}

To quantitatively understand the relationship between land use patterns and ecosystem service functions, a correlation analysis was conducted (Table 5). There were significant correlations between many landscape pattern metrics and ecosystem service functions, which indicated that landscape patterns significantly affected ecosystem service func- 

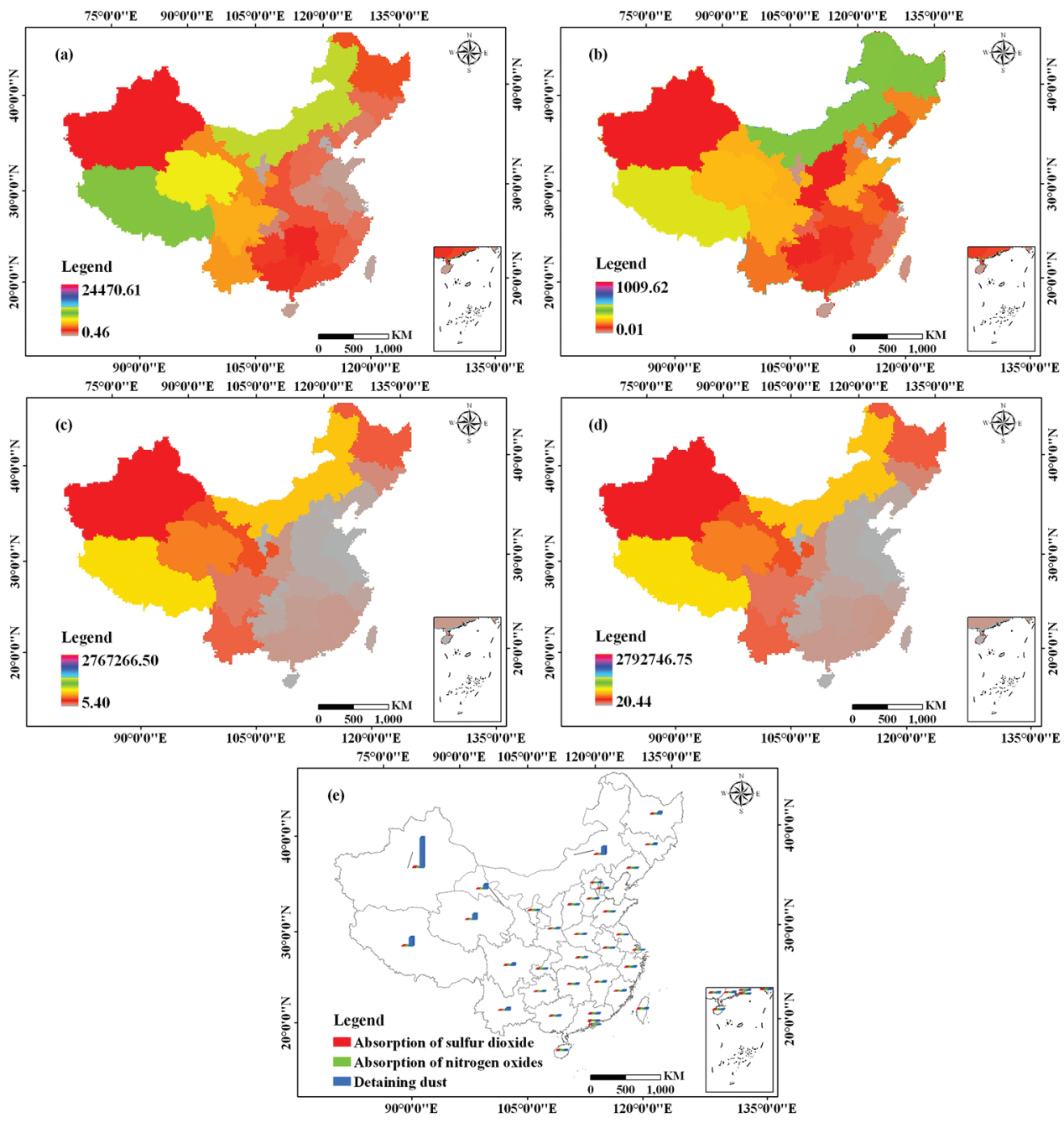

Figure 28. Spatial distributions of the ecosystem service functions of haze absorption by green space in different regions of China in $2016\left(10^{6} \mathrm{Kg}\right)(\mathbf{a}, \mathbf{b}, \mathbf{c}, \mathbf{d}$ and $\mathbf{e}$ are the absorption of sulfur dioxide and nitrogen oxides, dust retention, the total ecosystem service functions and the percent contribution of different ecosystem service functions to haze absorption in different zones, respectively).

tions. The correlation coefficients between $\mathrm{PD}$ and the ecosystem service functions of $\mathrm{SO}_{2}$ absorption, $\mathrm{NO}_{\mathrm{x}}$ absorption, dust retention and total ecosystem services exhibited significant negative relationships with correlation coefficients of $-0.407,-0.511,-0.330$ and -0.332 , respectively. In contrast, the correlation coefficients between SHAPE_AM and the ecosystem service functions of $\mathrm{SO}_{2}$ absorption, $\mathrm{NO}_{x}$ absorption, dust retention and total ecosystem services exhibited significant positive relationships with correlation coefficients of $0.650,0.634,0.568$ and 0.570 , respectively. These results indicate 

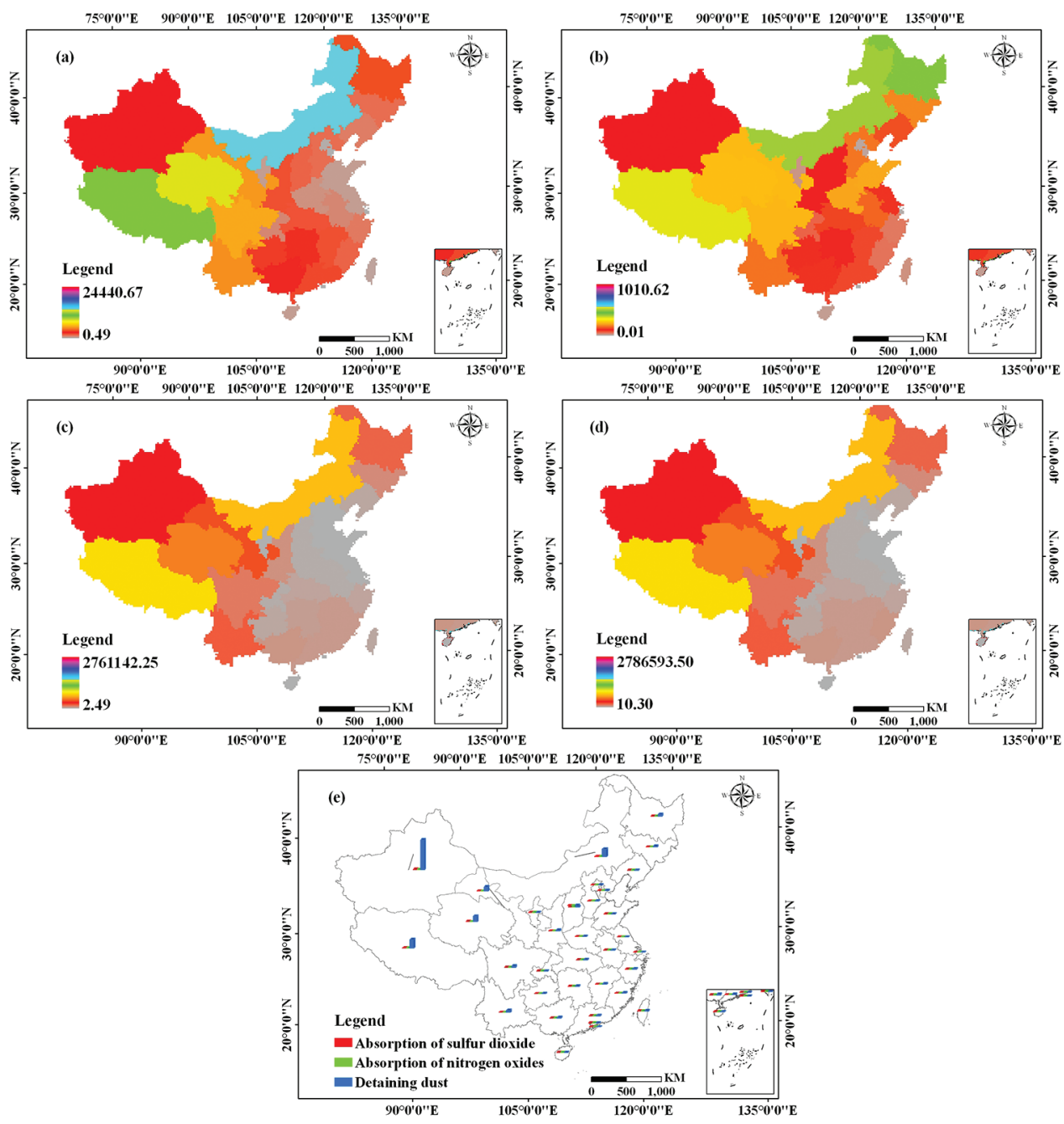

Figure 29. Spatial distributions of the ecosystem service functions of haze absorption by green space in different regions of China in $2018\left(10^{6} \mathrm{Kg}\right)(\mathbf{a}, \mathbf{b}, \mathbf{c}, \mathbf{d}$ and $\mathbf{e}$ are the absorption of sulfur dioxide and nitrogen oxides, dust retention, the total ecosystem service functions and the percent contribution of different ecosystem service functions to haze absorption in different zones, respectively).

that PD and SHAPE_AM have important effects on different ecosystem service functions. In general, the larger the $\mathrm{PD}$, the smaller the ecosystem service functions; the larger the value of SHAPE_AM, the greater the ecosystem service functions.

The correlation coefficients between IJI and the ecosystem service functions of $\mathrm{SO}_{2}$ absorption, $\mathrm{NO}_{\mathrm{x}}$ absorption, dust retention and total ecosystem services exhibited significant negative relationships with correlation coefficients of -0.606, -0.507, -0.449 and -0.452 , respectively. The correlation coefficients between SHDI and the ecosystem 
Table 4. Sensitivity analysis of the ecosystem service functions of haze absorption by green space in China from 2001-2018.

\begin{tabular}{|c|c|c|c|c|c|c|c|}
\hline & \multirow{3}{*}{$\begin{array}{l}\text { Coefficient of } \\
\text { sensitivity }\end{array}$} & \multicolumn{6}{|c|}{ Green space types } \\
\hline & & \multicolumn{2}{|c|}{ Arable land } & \multicolumn{2}{|c|}{ Forest cover } & \multicolumn{2}{|c|}{ Grass land } \\
\hline & & $\mathrm{FC}+50 \%$ & FC-50\% & $\mathrm{FC}+50 \%$ & FC-50\% & $\mathrm{FC}+50 \%$ & FC-50\% \\
\hline \multirow[t]{2}{*}{2001} & $\%$ & 0.0843 & -0.0843 & 49.3424 & -49.3424 & 0.5733 & -0.5733 \\
\hline & CS & 0.0017 & - & 0.9868 & - & 0.0115 & - \\
\hline \multirow[t]{2}{*}{2004} & $\%$ & 0.0967 & -0.0967 & 49.3398 & -49.3398 & 0.5635 & -0.5635 \\
\hline & CS & 0.0019 & - & 0.9868 & - & 0.0113 & - \\
\hline \multirow[t]{2}{*}{2007} & $\%$ & 0.0893 & -0.0893 & 49.3405 & -49.3405 & 0.5702 & -0.5702 \\
\hline & $\mathrm{CS}$ & 0.0018 & - & 0.9868 & - & 0.0114 & - \\
\hline \multirow[t]{2}{*}{2010} & $\%$ & 0.0850 & -0.0850 & 49.3767 & -49.3767 & 0.5384 & -0.5384 \\
\hline & $\mathrm{CS}$ & 0.0017 & - & 0.9875 & - & 0.0108 & - \\
\hline \multirow[t]{2}{*}{2013} & $\%$ & 0.0901 & -0.0901 & 49.3832 & -49.3832 & 0.5268 & -0.5268 \\
\hline & $\mathrm{CS}$ & 0.0018 & - & 0.9877 & - & 0.0105 & - \\
\hline \multirow[t]{2}{*}{2016} & $\%$ & 0.0774 & -0.0774 & 49.0861 & -49.0861 & 0.8365 & -0.8365 \\
\hline & $\mathrm{CS}$ & 0.0015 & - & 0.9817 & - & 0.0167 & - \\
\hline \multirow[t]{2}{*}{2018} & $\%$ & 0.0783 & -0.0783 & 49.0842 & -49.0842 & 0.8374 & -0.8374 \\
\hline & $\mathrm{CS}$ & 0.0016 & - & 0.9817 & - & 0.0167 & - \\
\hline
\end{tabular}

Note: The coefficients of the ecosystem service functions of different land use types were adjusted up and down by $50 \%$ to analyze the coefficients of sensitivity for the three land use types and evaluate the changes in the ecosystem service functions caused by changes in the coefficients [1]. CS refers to the coefficients of sensitivity, and FC refers to functional coefficients.

Table 5. Correlation coefficients between landscape pattern metrics and different ecosystem service functions of haze absorption by green space in China.

\begin{tabular}{l|c|c|c|c|c|c|c|c}
\hline & $\mathbf{S O}_{2}$ & $\mathbf{N O}_{\mathbf{x}}$ & DUST & ALL & PD & SHAPE_AM & IJI & SHDI \\
\hline $\mathrm{SO}_{2}$ & 1.000 & $0.772^{* *}$ & $0.887^{* *}$ & $0.891^{* *}$ & $-0.407^{* *}$ & $0.650^{* *}$ & $-0.606^{* *}$ & $-0.242^{* *}$ \\
\hline $\mathrm{NO}_{\mathrm{x}}$ & $0.772^{* *}$ & 1.000 & $0.750^{* *}$ & $0.752^{* *}$ & $-0.511^{* *}$ & $0.634^{* *}$ & $-0.507^{* *}$ & $-0.316^{* *}$ \\
\hline $\mathrm{DUST}$ & $0.887^{* *}$ & $0.750^{* *}$ & 1.000 & $0.999^{* *}$ & $-0.330^{* *}$ & $0.568^{* *}$ & $-0.449^{* *}$ & $-0.202^{* *}$ \\
\hline $\mathrm{ALL}$ & $0.891^{* *}$ & $0.752^{* *}$ & $1.000^{* *}$ & 1.000 & $-0.332^{* *}$ & $0.570^{* *}$ & $-0.452^{* *}$ & $-0.203^{* *}$ \\
\hline $\mathrm{PD}$ & $-0.407^{* *}$ & $-0.511^{* *}$ & $-0.330^{* *}$ & $-0.332^{* *}$ & 1.000 & $-0.342^{* *}$ & $0.564^{* *}$ & $0.642^{* *}$ \\
\hline $\mathrm{SHAPE} \_$ & $0.650^{* *}$ & $0.634^{* *}$ & $0.568^{* *}$ & $0.570^{* *}$ & $-0.342^{* *}$ & 1.000 & $-0.783^{* *}$ & -0.149 \\
$\mathrm{AM}$ & & & & & & & & \\
\hline IJI & $-0.606^{* *}$ & $-0.507^{* *}$ & $-0.449^{* *}$ & $-0.452^{* *}$ & $0.564^{* *}$ & $-0.783^{* *}$ & 1.000 & $0.227^{* *}$ \\
\hline SHDI & $-0.242^{* *}$ & $-0.316^{* *}$ & $-0.202^{* *}$ & $-0.203^{* *}$ & $0.642^{* *}$ & -0.149 & $0.227^{* *}$ & 1.000 \\
\hline
\end{tabular}

** Significance at the 0.01 probability level. * Significance at the 0.05 probability level

Note: $\mathrm{SO}_{2}, \mathrm{NO}_{\mathrm{x}}$, DUST, and ALL refer to ecosystem service functions of $\mathrm{SO}_{2}$, the absorption of $\mathrm{NO}_{\mathrm{x}}$, dust retention, and total ecosystem service functions, respectively. PD, SHAPE_AM, IJI and SHDI refer to patch density, the area-weighted mean shape index, the interspersion and juxtaposition index, and Shannon's diversity index.

service functions of $\mathrm{SO}_{2}$ absorption, $\mathrm{NO}_{\mathrm{x}}$ absorption, dust retention and total ecosystem services also exhibited significant negative relationships with correlation coefficients of $-0.242,-0.316,-0.202$ and -0.203 , respectively. These results indicate that IJI and SHDI have important effects on different ecosystem service values. In general, the smaller the IJI and SHDI, the larger the ecosystem service functions.

\section{Discussion}

In this paper, the quality of green space is used to modify the ecosystem service functions of haze absorption, making the quantitative assessment results of haze absorption 
by green space more scientific and reasonable. However, the results revealed that the ecosystem service function of haze absorption by green space in China from 2001 to 2018 shows a trend of first increasing and then decreasing, suggesting that the forest area with high haze absorbing capacity should be increased when adjusting the structure of ecological land use, and the occupation of cultivated land due to the rapid expansion of construction land should be regulated to improve the ability of green space to alleviate haze.

Previous literatures explored the responses of ecosystem service functions to land use change, mainly through analyses of water yield (Li et al. 2018), soil conservation (Zhu et al. 2018), habitat quality (Dai et al. 2019), biodiversity protection (Reiss and Chifflard 2018), and climate regulation (Yang and Wang 2019). However, there are few studies on the haze absorption by green space. Moreover, previous studies conducted assessments of ecological quality. Munné et al. (Munné et al. 2003) evaluated riparian habitat quality using an index combining total riparian vegetation cover, cover structure, cover quality and channel alterations that is easy to calculate and can be used with any other index of water quality to assess the ecological status of streams and rivers. The macroalgal species richness and composition of intertidal rocky seashores has been used by researchers in the assessment of ecological quality under the European Water Framework Directive (Wells et al. 2007). Using GIS and remote-sensing and factor-analysis techniques, some scholars analyzed UGS landscape patterns in the compact city of Hong Kong to determine the landscape-ecological quality of different land uses and districts (Tian et al. 2014). Some experts have analyzed the scale, quality and diversity of green infrastructure through remote-sensing techniques and NDVI combined with fieldwork verification at two scales, the local and regional (CalderónContreras and Quiroz-Rosas 2017), and others have conducted research combining ecological quality with ecosystem services. Paetzold et al. (Paetzold et al. 2010) assessed the relationship between ecosystem quality and ecosystem quality, and Yan et al. (Yan et al. 2016) established the assessment framework including V (vigor: NPP), $\mathrm{O}$ (organization: proportion of natural ecosystem area, SHDI, and the contagion index [CONTAG]), and R (resilience: ecological elasticity) to analyze the ecosystem services of soil and water conservation based on ecosystem quality. Finally, Sauvage et al. simulated the role of riverbed compartments in the regulation of water quality as an ecological service (Sauvage et al. 2018). Nevertheless, there have been few studies on the quality of green space, so there has been little research on the ecosystem service functions of haze absorption by green space based on its quality. Therefore, this paper analyzed the ecosystem service functions of haze absorption by green space based on its quality, improving the assessment method of previous studies that only considered the area of green space and providing an improved method for evaluating this ecosystem services, and also providing a reference for the prevention and control of haze and the coordinated development of regional societies, the economy and the environment.

There is a correlation between landscape patterns and ecosystem service functions (Garcia et al. 2014; Gong et al. 2019). This paper considers China as the research area and analyzes the relationship between landscape patterns and the ecosystem service 
functions of haze absorption by green space, landscape diversity (SHDI), fragmentation (PD and SHAPE_AM) and connectivity (IJI) at the national scale, and the correlation coefficients between SHDI, PD, and the ecosystem service functions of the absorption of $\mathrm{SO}_{2}$ and $\mathrm{NO}_{\mathrm{x}}$, dust retention and total ecosystem services exhibited significant negative relationships. These results are essentially identical to those of $\mathrm{Lu}$ et al. (Lu et al. 2018) and Wu et al. (Wu et al. 2015) but differ from those of Zou et al. (Zou et al. 2016).

Uncertainty in ecosystem service assessments has been demonstrated and analyzed by previous studies (Bei et al. 2017; Hou et al. 2013), and haze is affected by industrial pollution sources, meteorological conditions and plant coverage, and these factors affect each other. Therefore, only considering the influencing factor of green space will lead to uncertainty in the study of haze absorption (Snell et al. 2018). Furthermore, the accuracy of input data, model structure, and parameter settings all lead to uncertainty in ecosystem service research (Baustert et al. 2018; Stritih et al. 2019). This study demonstrated uncertainty in the estimation of ecosystem service functions, mainly because ecosystem service functions of haze absorption were estimated by multiplying the area of each land use type by the corresponding functions coefficients.

This paper also has some limitations. First of all, there are many factors affecting haze, including natural factors such as vegetation coverage (Zhang 2019), social and economic factors are comprised of population density, industrial structure and industrial emissions ( $\mathrm{Li}$ et al. 2016), and meteorological factors consisting of wind speed and rainfall (Bei et al. 2016). This paper only considered the haze absorption by green space, which has some shortcomings. In the future, it should be combined with meteorological conditions, pollution sources and socio-economic factors. Secondly, we must combine field observation data to obtain per-unit functions for the absorption of $\mathrm{SO}_{2}$ and $\mathrm{NO}_{\mathrm{X}}$ and dust retention of different green space types, thus making the results more accurate, and future research should also collect more detailed data on green space and select appropriate parameters to improve the accuracy of the calculations. This paper utilizes the functions coefficient method to evaluate the ecosystem service functions of haze absorption by green space and preliminarily explored the ecosystem service functions of $\mathrm{SO}_{2}$ and $\mathrm{NO}_{\mathrm{x}}$ absorption and dust retention by green space for 2001-2018 in China. A mechanistic model that includes haze diffusion, haze absorption by green space, an assessment of ecosystem service function modules, and the ecosystem service functions of haze absorption by green space should be established to produce more accurate and objective results, and to explore more reasonable methods for future studies (Wang et al. 2016). The application of a national-scale analysis of the ecosystem service functions of haze absorption by green space would ameliorate the shortcomings of the small-scale analyses in previous studies and would enrich research into the effect of scale on the ecosystem service functions of haze absorption by green space. The acquisition of large-scale and high-precision remote-sensing data is still an important direction for future research. 


\section{Conclusions}

This paper analyzes the temporal and spatial distributions and sensitivities of the ecosystem service functions of haze absorption by green space based on its quality in 2001, 2004, 2007, 2010, 2013, 2016 and 2018 in China. The main conclusions of this work are as follows:

(1) In general, the ecosystem service functions of haze absorption by green space exhibited first an increasing and then decreasing trend from 2001-2018 in China, increasing by 144652.20 million $\mathrm{Kg}(1.61 \%)$ in 2001-2013 primarily due to the implementation of the Three North Shelterbelt Development Program, the Conversion from Cropland to Forest Program and the Natural Forest Protection Program by the Chinese government. However, the ecosystem service functions decreased by 1410584.00 million $\mathrm{Kg}$ from $2013-2018$, a decrease of $15.42 \%$, primarily because of adjustment of ecological land structure and the reduction of arable land caused by the expansion of construction land. The contributions of forest cover to the ecosystem service values of haze absorption by green space were the largest, with values of $98.68 \%, 98.67 \%, 98.68 \%, 98.75 \%, 98.77 \%, 98.17 \%$ and $98.16 \%$ in 2001, 2004, 2007, 2010, 2013, 2016 and 2018, respectively. The primary ecological function of haze absorption by green space was mainly dust retention, which accounted for $98.09 \%, 98.15 \%, 98.18 \%, 98.26 \%, 98.32 \%, 98.30 \%$ and $98.29 \%$ of the total in 2001, 2004, 2007, 2010, 2013, 2016 and 2018, respectively.

(2) Different ecosystem service functions exhibited great differences in spatial distribution within the same year but small differences between years. In conclusion, the results show that the ecosystem service functions and spatial distribution of haze absorption by green space based on its quality differ greatly from the value considering only the area. Furthermore, the benchmark and corrected values of the contribution rates of haze absorption by different types of green space and ecosystem service functions are different, but the values show a consistent trend. The contribution rates are ranked from largest to smallest as forest cover, grass land and arable land, and the order of ecosystem service function is dust retention, absorption of $\mathrm{SO}_{2}$, and absorption of $\mathrm{NO}_{\mathrm{x}}$. Moreover, the spatial distributions of the benchmark and corrected values also exhibit the same distribution trend. In the same year, the spatial distribution of the ecosystem service values of haze absorption by green space is very different, but there is little difference among the different years.

(3) The coefficients of sensitivity for the ecosystem service functions for forest cover are elastic with values of 0.9868 in 2001, 2004 and 2007, 0.9875 in 2010, 0.9877 in 2013, 0.9817 in 2016 and 2018, respectively, and the change rates were \pm $49.3424 \%, \pm 49.3398 \%, \pm 49.3405 \%, \pm 49.3767 \%, \pm 49.3832 \%, \pm 49.0861 \%$ and $\pm 49.0842 \%$, respectively. The coefficients of sensitivity for arable land and grass land were inelastic. There was a significant negative relationship between 
$\mathrm{PD}$ and the ecosystem service functions of $\mathrm{SO}_{2}$ absorption, $\mathrm{NO}_{\mathrm{x}}$ absorption, dust retention and total ecosystem services, with the correlation coefficients of -0.407 , $-0.511,-0.330$ and -0.332 , respectively. Nevertheless, the correlation coefficients between SHAPE_AM and the ecosystem service functions of $\mathrm{SO}_{2}$ absorption, $\mathrm{NO}_{\mathrm{x}}$ absorption, dust retention and total ecosystem services exhibited significant positive relationships with correlation coefficients of $0.650,0.634,0.568$ and 0.570 , respectively. The green space landscape pattern, which exhibited a uniform patch distribution, has an important effect on the absorption of polluted gases, dust retention and air purification. A higher density of green space patches is accompanied by lower levels of fragmentation and higher levels of air purification.

(4) This paper analyzes and evaluates ecosystem service functions and the spatial distributions thereof, based on the quality of green space, providing a basis for further improving the method for calculating haze absorption by green space and revealing the relationship between ecosystem service functions and landscape patterns. This work is important for the rational planning and improvement of green space ecosystems and for improving the city environment.

(5) This paper analyzes the ecosystem service functions of haze absorption by green space in China, and further research should focus on two approaches. The first is the development of a mechanistic model of the ecosystem service functions of haze absorption by green space that should consist of three modules including a haze diffusion module, a module for haze absorption by green space, and a module that evaluates ecosystem service functions. By including rainfall, wind speed, pollution sources, land use and vegetation types, the function coefficients for haze absorption and other data can be collected in a database. After the model is calibrated and validated, the ecosystem service functions dynamics of haze absorption by green space can be analyzed under different green space and climate change scenarios to predict future changes. The second approach includes a firsttier classification of green space to evaluate the ecosystem service functions of haze absorption in this paper, but second-tier classifications can reflect the differences between different green space types, thus providing more objective and reasonable results. Compared to a first-tier classification of forest cover, second-tier classifications, such as trees and shrubs, have different impacts on the ecosystem service functions of haze absorption. Therefore, further research should provide in-depth explorations of second-tier classifications of green space.

\section{Acknowledgments}

This research was supported by the Scientific Research Program Funded by Shaanxi Provincial Education Department (Program No. 17JK0325), the Fund Project of Shaanxi Key Laboratory of Land Consolidation (2018-JC12), Key Laboratory of Water Cycle and Related Land Surface Processes, Institute of Geographic Sciences and Natural Resources Research, Chinese Academy of Sciences (2016A002), the PhD research start-up foundation of Xi'an Polytechnic University (No. BS1306). 


\section{References}

Alavipanah S, Wegmann M, Qureshi S, Weng Q, Koellner T (2015) The role of vegetation in mitigating urban land surface temperatures: A case study of Munich, Germany during the warm season. Sustainability 7(4): 4689-4706. https://doi.org/10.3390/su7044689

An Z, Huang R-J, Zhang R, Tie X, Li G, Cao J, Zhou W, Shi Z, Han Y, Gu Z, Ji Y (2019) Severe haze in Northern China: A synergy of anthropogenic emissions and atmospheric processes. Proceedings of the National Academy of Sciences of the United States of America 116(18): 8657-8666. https://doi.org/10.1073/pnas.1900125116

Baustert P, Othoniel B, Rugani B, Leopold U (2018) Uncertainty analysis in integrated environmental models for ecosystem service assessments: Frameworks, challenges and gaps. Ecosystem Services 33(2): 110-123. https://doi.org/10.1016/j.ecoser.2018.08.007

Beckett KP, Freer-Smith PH, Taylor G (1998) Urban woodlands: Their role in reducing the effects of particulate pollution. Environmental Pollution 99(3): 347-360. https://doi. org/10.1016/S0269-7491(98)00016-5

Bei N, Xiao B, Meng N, Feng T (2016) Critical role of meteorological conditions in a persistent haze episode in the Guanzhong basin, China. The Science of the Total Environment 550(1): 273-284. https://doi.org/10.1016/j.scitotenv.2015.12.159

Bei N, Wu J, Elser M, Tian F, Cao J, El-Haddad I, Li X, Huang R, Li Z, Long X (2017) Impacts of meteorological uncertainties on the haze formation in Beijing-Tianjin-Hebei (BTH) during wintertime: A case study. Atmospheric Chemistry and Physics 17(23): 14579-14591. https://doi.org/10.5194/acp-17-14579-2017

Calderón-Contreras R, Quiroz-Rosas LE (2017) Analysing scale, quality and diversity of green infrastructure and the provision of Urban Ecosystem Services: A case from Mexico City. Ecosystem Services 23(1): 127-137. https://doi.org/10.1016/j.ecoser.2016.12.004

Chen W, Lu S, Pan N, Wang Y, Wu L (2015) Impact of reclaimed water irrigation on soil health in urban green areas. Chemosphere 119(1): 654-661. https://doi.org/10.1016/j. chemosphere.2014.07.035

Chuai X, Wang J, Zhou H, Fan C, Han Y, Gao J (2019) A review of causes, influencing factors and countermeasures of haze pollution in China. Meteorological and Environmental Research 10(3): 25-28.

Cuffney TF, Brightbill RA, May JT, Waite IR (2010) Responses of benthic macroinvertebrates to environmental changes associated with urbanization in nine metropolitan areas. Ecological Applications 20(5): 1384-1401. https://doi.org/10.1890/08-1311.1

Dai L, Li S, Lewis BJ, Wu J, Yu D, Zhou W, Zhou L, Wu S (2019) The influence of land use change on the spatial-temporal variability of habitat quality between 1990 and 2010 in Northeast China. Journal of Forestry Research 30(6): 2227-2236. https://doi. org/10.1007/s11676-018-0771-x

Davies SJ, Unam L (1999) Smoke-haze from the 1997 Indonesian forest fires: Effects on pollution levels, local climate, atmospheric CO2 concentrations, and tree photosynthesis. Forest Ecology and Management 124(2-3): 137-144. https://doi.org/10.1016/S0378-1127(99)00060-2

De Carvalho RM, Szlafsztein CF (2019) Urban vegetation loss and ecosystem services: The influence on climate regulation and noise and air pollution. Environmental Pollution 245(1): 844-852. https://doi.org/10.1016/j.envpol.2018.10.114 
Devuyst D, Hens L, De Lannoy W (2001) How green is the city? sustainability assessment and the management of urban environments. Columbia University Press: 1-458. https://doi. org/10.7312/devu11802-intro

Fang X, Tang G, Li B, Han R (2014) Spatial and temporal variations of ecosystem service values in relation to land use pattern in the Loess Plateau of China at town scale. PLoS One 9(10): e110745. https://doi.org/10.1371/journal.pone.0110745

Freer-Smith PH, El-Khatib AA, Taylor G (2004) Capture of particulate pollution by trees: A comparison of species typical of semi-arid areas (Ficus nitida and Eucalyptus globulus) with European and North American species. Water, Air, and Soil Pollution 155(1): 173-187. https://doi.org/10.1023/B:WATE.0000026521.99552.fd

Gao L, Zhao Z, Zhang H, Xuebin G, Xiao M (2012) Adjustment of Haikou city ecosystem services value based on habitat quality and ecological location. Beijing Da Xue Xue Bao. Zi Ran Ke Xue Bao 48(5): 833-840.

Gao Y, Zhang M, Liu Z, Wang L, Wang P, Xia X, Tao M, Zhu L (2015) Modeling the feedback between aerosol and meteorological variables in the atmospheric boundary layer during a severe fog-haze event over the North China Plain. Atmospheric Chemistry and Physics 15(8): 4279-4295. https://doi.org/10.5194/acp-15-4279-2015

Garcia X, Llausas A, Ribas A (2014) Landscaping patterns and sociodemographic profiles in suburban areas: Implications for water conservation along the Mediterranean coast. Urban Water Journal 11(1): 31-41. https://doi.org/10.1080/1573062X.2012.758296

Gómez-Moreno FJ, Artínano B, Ramiro ED, Barreiro M, Núñez L, Coz E, Dimitroulopoulou C, Vardoulakis S, Yagüe C, Maqueda G, Sastre M, Román-Cascón C, Santamaría JM, Borge R (2019) Urban vegetation and particle air pollution: Experimental campaigns in a traffic hotspot. Environmental Pollution 247(1): 195-205. https://doi.org/10.1016/j. envpol.2019.01.016

Gong J, Xie Y, Cao E, Huang Q, Li H (2019) Integration of InVEST-habitat quality model with landscape pattern indexes to assess mountain plant biodiversity change: A case study of Bailongjiang watershed in Gansu Province. Journal of Geographical Sciences 29(7): 1193-1210. https://doi.org/10.1007/s11442-019-1653-7

Green M, Xu J (2007) Causes of haze in the Columbia River Gorge. Journal of the Air \& Waste Management Association 57(8): 947-958. https://doi.org/10.3155/1047-3289.57.8.947

Green OO, Garmestani AS, Albro S, Ban NC, Berland A, Burkman CE, Gardiner MM, Gunderson L, Hopton ME, Schoon ML, Shuster WD (2016) Adaptive governance to promote ecosystem services in urban green spaces. Urban Ecosystems 19(1): 77-93. https://doi. org/10.1007/s11252-015-0476-2

Hamada S, Ohta T (2010) Seasonal variations in the cooling effect of urban green areas on surrounding urban areas. Urban Forestry \& Urban Greening 9(1): 15-24. https://doi. org/10.1016/j.ufug.2009.10.002

Han Y, Zhou Z (2015) Evaluation on ecosystem services in haze absorption by urban green land and its spatial pattern analysis in Xi'an. Geographical Research 7(34): 1247-1258.

Hansen AB, Witham CS, Chong WM, Kendall E, Chew BN, Gan C, Hort MC, Lee S-Y (2019) Haze in Singapore-source attribution of biomass burning PM 10 from Southeast 
Asia. Atmospheric Chemistry and Physics 19(8): 5363-5385. https://doi.org/10.5194/ acp-19-5363-2019

Heusinkveld BG, Steeneveld G, van Hove LWA, Jacobs CMJ, Holtslag AAM (2014) Spatial variability of the Rotterdam urban heat island as influenced by urban land use. Journal of Geophysical Research, D, Atmospheres 119(2): 677-692. https://doi. org/10.1002/2012JD019399

Hong H, Chenxing W, Yuesi W, Zifa W, Jianguo L, Yunfa C (2013) Formation mechanism and control strategies of haze in China. Bulletin of Chinese Academy of Sciences 28(3): 344-352.

Hou Y, Burkhard B, Müller F (2013) Uncertainties in landscape analysis and ecosystem service assessment. Journal of Environmental Management 127(1): 117-131. https://doi. org/10.1016/j.jenvman.2012.12.002

Jin F, Zhang Z, Yu X, Rao L, Niu J, Lu S, Xie Y (2005) Value evaluation of forest ecosystem services of Qilian Mountain in Gansu Province. Science of Soil and Water Conservation 3(1): 53-57.

Kopperoinen L, Itkonen P, Niemelä J (2014) Using expert knowledge in combining green infrastructure and ecosystem services in land use planning: An insight into a new place-based methodology. Landscape Ecology 29(8): 1361-1375. https://doi.org/10.1007/s10980014-0014-2

Kreuter UP, Harris HG, Matlock MD, Lacey RE (2001) Change in ecosystem service values in the San Antonio area, Texas. Ecological Economics 39(3): 333-346. https://doi. org/10.1016/S0921-8009(01)00250-6

Kuttler W, Strassburger A (1999) Air quality measurements in urban green areas - a case study. Atmospheric Environment 33(24-25): 4101-4108. https://doi.org/10.1016/S13522310(99)00151-X

Larondelle N, Haase D (2013) Urban ecosystem services assessment along a rural-urban gradient: A cross-analysis of European cities. Ecological Indicators 29(1): 179-190. https://doi. org/10.1016/j.ecolind.2012.12.022

Li Q, Cheng K, Yang X (2016) Economic and social analysis of haze reduction dilemma in China. Environmental and Earth Sciences Research Journal 3(1): 14-22. https://doi. org/10.18280/eesrj.030103

Li S, Yang H, Lacayo M, Liu J, Lei G (2018) Impacts of land-use and land-cover changes on water yield: A case study in Jing-Jin-Ji, China. Sustainability 10(4): 960. https://doi. org/10.3390/su10040960

Li X, Gao Z, Li Y, Gao CY, Ren J, Zhang X (2019) Meteorological conditions for severe foggy haze episodes over north China in 2016-2017 winter. Atmospheric Environment 199(1): 284-298. https://doi.org/10.1016/j.atmosenv.2018.11.042

Liu H-L, Shen Y-S (2014) The impact of green space changes on air pollution and microclimates: A case study of the taipei metropolitan area. Sustainability 6(12): 8827-8855. https://doi.org/10.3390/su6128827

Liu WP, Yu ZR (2016) Simulation on PM2.5 detention service of green space in Haidian District, Beijing, China. Ying Yong Sheng Tai Xue Bao 27(8): 2580-2586. 
Lu DB, Mao WL, Yang DY, Zhao JN, Xu JH (2018) Effects of land use and landscape pattern on PM2.5 in Yangtze River Delta, China. Atmospheric Pollution Research 9(4): 705-713. https://doi.org/10.1016/j.apr.2018.01.012

Mahmoud AHA, El-Sayed MA (2011) Development of sustainable urban green areas in Egyptian new cities: The case of El-Sadat City. Landscape and Urban Planning 101(2): 157170. https://doi.org/10.1016/j.landurbplan.2011.02.008

Maimaitiyiming M, Ghulam A, Tiyip T, Pla F, Latorre-Carmona P, Halik Ü, Sawut M, Caetano M (2014) Effects of green space spatial pattern on land surface temperature: Implications for sustainable urban planning and climate change adaptation. ISPRS Journal of Photogrammetry and Remote Sensing 89(1): 59-66. https://doi.org/10.1016/j.isprsjprs.2013.12.010

Margaritis E, Kang J (2016) Relationship between urban green spaces and other features of urban morphology with traffic noise distribution. Urban Forestry \& Urban Greening 15(1): 174-185. https://doi.org/10.1016/j.ufug.2015.12.009

McDonald AG, Bealey WJ, Fowler D, Dragosits U, Skiba U, Smith RI, Donovan RG, Brett HE, Hewitt CN, Nemitz E (2007) Quantifying the effect of urban tree planting on concentrations and depositions of PM10 in two UK conurbations. Atmospheric Environment 41(38): 8455-8467. https://doi.org/10.1016/j.atmosenv.2007.07.025

Munné A, Prat N, Solà C, Bonada N, Rieradevall M (2003) A simple field method for assessing the ecological quality of riparian habitat in rivers and streams: QBR index. Aquatic Conservation 13(2): 147-163. https://doi.org/10.1002/aqc.529

Ozimec S, Florijancic T, Boskovic I (2016) Biomonitoring urban air pollution by using lichens in the green space of the university campus in osijek (croatia). Journal of Environmental Protection and Ecology 17(4): 1269-1275.

Paetzold A, Warren PH, Maltby LL (2010) A framework for assessing ecological quality based on ecosystem services. Ecological Complexity 7(3): 273-281. https://doi.org/10.1016/j. ecocom.2009.11.003

Pandey B, Agrawal M, Singh S (2014) Coal mining activities change plant community structure due to air pollution and soil degradation. Ecotoxicology (London, England) 23(8): 1474-1483. https://doi.org/10.1007/s10646-014-1289-4

Park J, Kim JH, Lee DK, Park CY, Jeong SG (2017) The influence of small green space type and structure at the street level on urban heat island mitigation. Urban Forestry \& Urban Greening 21(1): 203-212. https://doi.org/10.1016/j.ufug.2016.12.005

Ramakreshnan L, Aghamohammadi N, Fong CS, Bulgiba A, Zaki RA, Wong LP, Sulaiman NM (2018) Haze and health impacts in ASEAN countries: A systematic review. Environmental Science and Pollution Research International 25(3): 2096-2111. https://doi. org/10.1007/s11356-017-0860-y

Reiss M, Chifflard P (2018) Different forest cover and its impact on eco-hydrological traits, invertebrate fauna and biodiversity of spring habitats. Nature Conservation 27: 85-99. https://doi.org/10.3897/natureconservation.27.26024

Rysgaard S, Nielsen TG, Hansen BW (1999) Seasonal variation innutrients, pelagic primary production and grazing in a high-Arctic marine ecosystem, Young Sound, Northeast Greenland. Marine Ecology Progress Series 179(3): 13-25. https://doi.org/10.3354/meps179013 
Saphores J-D, Li W (2012) Estimating the value of urban green areas: A hedonic pricing analysis of the single family housing market in Los Angeles, CA. Landscape and Urban Planning 104(3): 373-387. https://doi.org/10.1016/j.landurbplan.2011.11.012

Sauvage S, Vervier P, Naiman RJ, Alexandre H, Bernard-Jannin L, Boulêtreau S, Delmotte S, Julien F, Peyrard D (2018) Modelling the role of riverbed compartments in the regulation of water quality as an ecological service. Ecological Engineering 118(1): 19-30. https:// doi.org/10.1016/j.ecoleng.2018.02.018

Selmi W, Weber C, Rivière E, Blond N, Mehdi L, Nowak D (2016) Air pollution removal by trees in public green spaces in Strasbourg city, France. Urban Forestry \& Urban Greening 17: 192-201. https://doi.org/10.1016/j.ufug.2016.04.010

Setälä H, Viippola V, Rantalainen A-L, Pennanen A, Yli-Pelkonen V (2013) Does urban vegetation mitigate air pollution in northern conditions? Environmental Pollution 183(1): 104-112. https://doi.org/10.1016/j.envpol.2012.11.010

Snell RS, Elkin C, Kotlarski S, Bugmann H (2018) Importance of climate uncertainty for projections of forest ecosystem services. Regional Environmental Change 18(7): 2145-2159. https://doi.org/10.1007/s10113-018-1337-3

Song S, Gao M, Xu W, Sun Y, Worsnop DR, Jayne JT, Zhang Y, Zhu L, Mei L, Zhen Z (2019) Possible heterogeneous chemistry of hydroxymethanesulfonate (HMS) in northern China winter haze. Atmospheric Chemistry and Physics 19(2): 1357-1371. https://doi. org/10.5194/acp-19-1357-2019

Stritih A, Bebi P, Gret-Regamey A (2019) Quantifying uncertainties in earth observation-based ecosystem service assessments. Environmental Modelling \& Software 111(1): 300-310. https://doi.org/10.1016/j.envsoft.2018.09.005

Sun W, Shao M, Granier C, Liu Y, Ye C, Zheng J (2018) Long-term trends of anthropogenic SO2, NOx, CO, and NMVOCs emissions in China. Earth's Future 6(8): 1112-1133. https://doi.org/10.1029/2018EF000822

Thach T-Q, Wong C-M, Chan K-P, Chau Y-K, Chung Y-N, Ou C-Q, Yang L, Hedley AJ (2010) Daily visibility and mortality: Assessment of health benefits from improved visibility in Hong Kong. Environmental Research 110(6): 617-623. https://doi.org/10.1016/j. envres.2010.05.005

Tian Y, Jim CY, Wang H (2014) Assessing the landscape and ecological quality of urban green spaces in a compact city. Landscape and Urban Planning 121(121): 97-108. https://doi. org/10.1016/j.landurbplan.2013.10.001

Wang G, Innes JL, Lei J, Dai S, Wu SW (2007) China's forestry reforms. Science 318(5856): 1556-1557. https://doi.org/10.1126/science.1147247

Wang Q, Zhuang G, Huang K, Liu T, Deng C, Xu J, Lin Y, Guo Z, Chen Y, Fu Q, Fu JS, Chen J (2015) Probing the severe haze pollution in three typical regions of China: Characteristics, sources and regional impacts. Atmospheric Environment 120(1): 76-88. https://doi. org/10.1016/j.atmosenv.2015.08.076

Wang R, Li R, Sun H (2016) Haze removal based on multiple scattering model with superpixel algorithm. Signal Processing 127(3): 24-36. https://doi.org/10.1016/j.sigpro.2016.02.003 
Waters EJ, Hayasaka Y, Tattersall DB, Adams KS, Williams PJ (1998) Sequence analysis of grape (Vitis vinifera) berry chitinases that cause haze formation in wines. Journal of Agricultural and Food Chemistry 46(12): 4950-4957. https://doi.org/10.1021/jf980421o

Wells E, Wilkinson M, Wood P, Scanlan C (2007) The use of macroalgal species richness and composition on intertidal rocky seashores in the assessment of ecological quality under the European Water Framework Directive. Marine Pollution Bulletin 55(1): 151-161. https:// doi.org/10.1016/j.marpolbul.2006.08.031

Wu J, Xie W, Li W, Li J (2015) Effects of urban landscape pattern on PM2.5 pollution-a Beijing case study. PLoS One 10(11): 0142449. https://doi.org/10.1371/journal.pone.0142449

Wu JN, Zhang P, Yi HT, Qin Z (2016) What causes haze pollution? an empirical study of PM2.5 concentrations in Chinese cities. Sustainability 8(2): 131-144. https://doi. org/10.3390/su8020132

Xue Q, Lan Z, Lian S, Chen Y, Cao K, Zhao Z, Ma X (2018) Analysis of atmospheric visibility degradation in early haze based on the nucleation clustering model. Atmospheric Environment 193(1): 205-213. https://doi.org/10.1016/j.atmosenv.2018.09.019

Yan Y, Zhao C, Wang C, Shan P, Zhang Y, Wu G (2016) Ecosystem health assessment of the Liao River Basin upstream region based on ecosystem services. Acta Ecologica Sinica 36(4): 294-300. https://doi.org/10.1016/j.chnaes.2016.06.005

Yang Y, Wang K (2019) The effects of different land use patterns on the microclimate and ecosystem services in the agro-pastoral ecotone of Northern China. Ecological Indicators 106(1): UNSP 105522. https://doi.org/10.1016/j.ecolind.2019.105522

Yang Y, Liao H, Lou S (2016) Increase in winter haze over eastern China in recent decades: Roles of variations in meteorological parameters and anthropogenic emissions. Journal of Geophysical Research, D, Atmospheres 121(21): 13050-13065. https://doi. org/10.1002/2016JD025136

Ye WH, Wei B, Tong C (1998) Measurement and application of urban ecological compensation. Zhongguo Huanjing Kexue 8(4): 298-301.

Ye LP, Fang LC, Tan WF, Wang YQ, Huang Y (2016) Exploring the effects of landscape structure on aerosol optical depth (AOD) patterns using GIS and HJ-1B images. Environmental Science. Processes \& Impacts 18(2): 265-276. https://doi.org/10.1039/C5EM00538H

Yu S, Li P, Wang L, Wu Y, Wang S, Liu K, Zhu T, Zhang Y, Hu M, Zeng L, Zhang X, Cao J, Alapaty K, Wong DC, Pleim J, Mathur R, Rosenfeld D, Seinfeld JH (2018) Mitigation of severe urban haze pollution by a precision air pollution control approach. Scientific Reports 8(1): 8151. https://doi.org/10.1038/s41598-018-26344-1

Zhang D (2019) Study on the correlation between the temporal and spatial variation of atmospheric PM2.5 and PM10 and vegetation coverage in Xi'an City. Master Thesis. Northwest University (Xi'an).

Zhang L, Wang T, Lv M, Zhang Q (2015a) On the severe haze in Beijing during January 2013: Unraveling the effects of meteorological anomalies with WRF-Chem. Atmospheric Environment 104(1): 11-21. https://doi.org/10.1016/j.atmosenv.2015.01.001

Zhang P, He L, Fan X, Huo P, Liu Y, Zhang T, Pan Y, Yu Z (2015b) Ecosystem service value assessment and contribution factor analysis of land use change in Miyun County, China. Sustainability 7(6): 7333-7356. https://doi.org/10.3390/su7067333 
Zhang Z, Zhang X, Gong D, Kim S-J, Mao R, Zhao X (2016) Possible influence of atmospheric circulations on winter haze pollution in the Beijing-Tianjin-Hebei region, northern China. Atmospheric Chemistry and Physics 16(2): 561-571. https://doi.org/10.5194/ acp-16-561-2016

Zhu X, Liu W, Jiang XJ, Wang P, Li W (2018) Effects of land-use changes on runoff and sediment yield: Implications for soil conservation and forest management in Xishuangbanna, Southwest China. Land Degradation \& Development 29(9): 2962-2974. https://doi. org/10.1002/ldr.3068

Zou B, Xu S, Sternberg T, Fang X (2016) Effect of land use and cover change on air quality in urban sprawl. Sustainability 8(7): 677. https://doi.org/10.3390/su8070677

Zoulia I, Santamouris M, Dimoudi A (2009) Monitoring the effect of urban green areas on the heat island in Athens. Environmental Monitoring and Assessment 156(1-4): 275-292. https://doi.org/10.1007/s10661-008-0483-3 